Prepared for the U.S. Department of Energy under Contract DE-AC05-76RL01830

\title{
Evaluation of Shear Strength Threshold of Concern for Retrieval of Interim-Stored K-Basin Sludge in the Hanford Site
}

Y Onishi

ST Yokuda

AJ Schmidt

October 2010

\section{Pacific Northwest}

NATIONAL LABORATORY

Proudly Operated by Battelle Since 1965 


\title{
DISCLAIMER
}

This report was prepared as an account of work sponsored by an agency of the United States Government. Neither the United States Government nor any agency thereof, nor Battelle Memorial Institute, nor any of their employees, makes any warranty, express or implied, or assumes any legal liability or responsibility for the accuracy, completeness, or usefulness of any information, apparatus, product, or process disclosed, or represents that its use would not infringe privately owned rights. Reference herein to any specific commercial product, process, or service by trade name, trademark, manufacturer, or otherwise does not necessarily constitute or imply its endorsement, recommendation, or favoring by the United States Government or any agency thereof, or Battelle Memorial Institute. The views and opinions of authors expressed herein do not necessarily state or reflect those of the United States Government or any agency thereof.

\author{
PACIFIC NORTHWEST NATIONAL LABORATORY \\ operated by \\ BATTELLE \\ for the \\ UNITED STATES DEPARTMENT OF ENERGY \\ under Contract DE-ACO5-76RL01830
}

Printed in the United States of America

\author{
Available to DOE and DOE contractors from the \\ Office of Scientific and Technical Information, \\ P.O. Box 62, Oak Ridge, TN 37831-0062; \\ ph: (865) 576-8401 \\ fax: (865) 5765728 \\ email: reports@adonis.osti.gov
}

\author{
Available to the public from the National Technical Information Service, \\ U.S. Department of Commerce, 5285 Port Royal Rd., Springfield, VA 22161 \\ ph: (800) $553-6847$ \\ fax: (703) 605-6900 \\ email: orders@nits.fedworld.gov \\ online ordering: http://www.ntis.gov/ordering.htm
}




\section{Evaluation of Shear Strength} Threshold of Concern for Retrieval of Interim-Stored K-Basin Sludge in the Hanford Site

Y Onishi

ST Yokuda

AJ Schmidt

October 2010

Prepared for

the U.S. Department of Energy

under Contract DE-AC05-76RL01830

Pacific Northwest National Laboratory

Richland, Washington 99352 



\section{Executive Summary}

K-Basin sludge will be recovered into the Sludge Transport and Storage Containers (STSCs) and will be stored in the T Plant for interim storage (at least ten years). Long-term sludge storage tests conducted by Pacific Northwest National Laboratory show that high uranium content K Basin sludge can selfcement and form a strong sludge with a bulk shear strength of up to $65 \mathrm{kPa}$. Some of this sludge has "paste" and "chunks" with shear strengths of approximately 3- $5 \mathrm{kPa}$ and $380-770 \mathrm{kPa}$, respectively. High uranium content sludge samples subjected to hydrothermal testing (e.g., $185^{\circ} \mathrm{C}, 10 \mathrm{~h}$ ) have been observed to form agglomerates with a shear strength up to $170 \mathrm{kPa}$. After interim storage at $\mathrm{T}$ Plant, the sludge in the STSCs will be mobilized by water jets impinging the sludge.

The objective of the evaluation was to determine the range of sludge shear strength for which there is high confidence that a water-jet retrieval system can mobilize stored K-Basin sludge from STSCs. The shear strength at which the sludge can be retrieved is defined as the "shear strength threshold of concern." If the sludge shear strength is greater than the value of the shear strength threshold of concern, a water-jet retrieval system will be unlikely to mobilize the sludge up to the container's walls. The shear strength threshold of concern can be compared with the range of possible shear strengths of K-Basin stored sludge to determine if the current post interim-storage, water-jet retrieval method is adequate.

Fourteen effective cleaning radius (ECR) models were reviewed, and their validity was examined by applying them to Hanford 241-SY-101 and 241-AZ-101 Tanks to reproduce the measured ECR produced by the mixer pumps. The validation test identified that the Powell-3 and Crowe-2 ECR models are more accurate than other ECR models reviewed. These ECR models were used to address a question as to whether the effective cleaning radius of a water jet is sufficient or if it can be readily expanded to cover the range of possible shear strengths. These results will assist CH2M HILL Plateau Remediation Company (CHPRC) to establish the technical basis of the feasibility of the sludge retrieval and storage plan and to develop an adequate water jet system to retrieve the stored K-Basin sludge in the STSCs. The STSCs are 2:1 elliptical-head vessels, 58 inches in diameter and 105 inches tall. Each STSC will contain 0.5 to $2.1 \mathrm{~m}^{3}$ of settled sludge with the specific loading dependent upon sludge type.

As a starting point for this evaluation, a XAGO's HydroLance ${ }^{\mathrm{TM}}$ water jet system, which has two 1-mm, two 3-mm, and three 3.5-mm nozzles, was considered. This XAGO system was previously operated at $42 \mathrm{gpm}$ at $377 \mathrm{psi}$ pressure to mobilize simulant sludge in engineered containers. The Powell3 and Crowe-2 ECR models were applied to the stored K-Basin sludge with various shear strength values, assuming that water jet nozzles with 1-, 2-, 3-, and 3.5-mm diameters were located at 1, 5, 10, 17, and 25 inches from the STSC wall. The ECR model results with 200-kPa shear strength are summarized in Table S.1 and in the following bullets: 
Table S.1. Jet Characteristics to Erode $200 \mathrm{kPa}$ Sludge: Nozzle Diameter and Effective Cleaning Radius, Based on Powell-3 Correlation

\begin{tabular}{cccccc}
\hline Effective & & \multicolumn{4}{c}{ Single Jet Nozzle Diameter } \\
\cline { 3 - 6 } $\begin{array}{c}\text { Cleaning } \\
\text { Radius }\end{array}$ & & & & & \\
\hline \multirow{2}{*}{25 inches } & Jet Characteristics & $1-\mathrm{mm}$ & $2-\mathrm{mm}$ & $3.0-\mathrm{mm}$ & 3.5 -mm \\
& Discharge pressure, psi & $>100,000$ & 30,000 & 13,000 & 9400 \\
& Nozzle flow rate, gpm & 16 & 32 & 48 & 55 \\
& Nozzle jet velocity, m/s & 1,300 & 640 & 430 & 360 \\
\hline \multirow{2}{*}{17 inches } & Discharge pressure, psi & 57,000 & 14,000 & 5,900 & 4,500 \\
& Nozzle flow rate, gpm & 11 & 22 & 32 & 38 \\
& Nozzle jet velocity, m/s & 880 & 440 & 290 & 250 \\
\hline \multirow{2}{*}{ 10 inches } & Discharge pressure, psi & 19,000 & 4,900 & 2,100 & 1,500 \\
& Nozzle flow rate, gpm & 6.4 & 13 & 19 & 22 \\
& Nozzle jet velocity, m/s & 510 & 260 & 170 & 140 \\
\hline \multirow{2}{*}{ inches } & Discharge pressure, psi & 4,800 & 1,200 & 510 & 380 \\
& Nozzle flow rate, gpm & 3.2 & 6.4 & 9.4 & 11 \\
& Nozzle jet velocity, m/s & 260 & 130 & 84 & 72 \\
\hline \multirow{2}{*}{1 inch } & Discharge pressure, psi & 200 & 49 & 21 & 15 \\
& Nozzle flow rate, gpm & 0.65 & 1.3 & 1.9 & 2.2 \\
& Nozzle jet velocity, m/s & 52 & 26 & 17 & 14 \\
\hline
\end{tabular}

(a) $\mathrm{ECR}=$ distance between jet nozzle and container wall.

- When a single nozzle located 25 inches from the STSC wall is used, a jet injected from a 1-mm or probably a 2-mm nozzle is sufficiently strong to mobilize the stored K-Basin sludge up to 25 inches away at 42-gpm jet discharge. For effective erosion of high-strength sludge, the nozzles with the small diameters require very high jet velocities and pressure. As an example, a single 2-mm nozzle would require a discharge rate and minimum pressure of approximately $32 \mathrm{gpm}$ and 30,000 psi to erode the sludge with $200-\mathrm{kPa}$ shear strength up to the STSC wall. The required pressure for a single $1-\mathrm{mm}$ nozzle is too high for a realistic application. Note that the water jet industry has high-pressure pumps that generate 40,000 to 94,000 psi to produce a very high velocity. When a single $3-\mathrm{mm}$ or $3.5-\mathrm{mm}$ nozzle located at 25 inches from the wall is used, the required jet discharge and pressure for 3-mm nozzles are approximately 48 gpm and 13,000 psi, respectively, to mobilize all sludge up to 25 inches away. Those for a 3.5-mm nozzle are $55 \mathrm{gpm}$ and 9,400 psi.

- As shown in Table S.1, for a given nozzle diameter, the required flowrate is a linear function of the ECR while the discharge pressure follows a power law dependency. If a single nozzle of $2 \mathrm{~mm}$ diameter (or larger) is located at 10 inches (or less) from the STSC wall, these single nozzles could erode the stored K-Basin sludge to the tank wall with a discharge pressure under 5000 psi.

- For the nozzles located 5 inches from the STSC wall, 1-, 2-, 3-, and 3.5-mm nozzles would need 3.2-, 6.4-, 9.4-, and 11-gpm jet discharges, respectively, to mobilize the stored K-Basin sludge with 200$\mathrm{kPa}$ shear strength. The corresponding minimum required pressures are 4,800, 1,200, 510, and 380 psi, respectively.

- For the nozzles located 1 inch from the STSC wall, single 1-, 2-, 3-, and 3.5-mm nozzles would need 0.7-, 1.3-, 1.9-, and 2.2-gpm jet discharges, respectively, to mobilize the stored K-Basin sludge with 
200-kPa shear strength. The corresponding minimum required pressures are 200, 49, 21 and $15 \mathrm{psi}$, respectively.

- None of these cases shown in Table S.1 is expected to erode $10 \%$ of the 0.5 -in. STSC wall thickness in 96 hours. Some of these jet discharges may be too small to be practical for the stored K-Basin sludge retrieval operation. For example, the jet discharges for the nozzles located at 1 inch from the wall are 0.65 to $2.2 \mathrm{gpm}$. If a nozzle discharge is increased by twice for each case, then $10 \%$ of the wall thickness would be eroded in 24 hours for all the cases.

- When all seven nozzles of the XAGO system are placed between 5 and 25 inches away from the wall and are used at $42 \mathrm{gpm}$, it is unlikely that these jets would mobilize all of the sludge in the STSCs at 377-psi pressure. However, when these seven nozzles are located at 1 inch from the STSC wall, they will erode the sludge up to the wall at $42 \mathrm{gpm}$. Wall erosion may become an issue if jets continue to impinge the same STSC location for 2 hours or more.

- It is important to note that a moving nozzle is known to be more effective to mobilize the sludge because an impulsive water jet may need about $1 / 3$ or less of the energy required to break the material than a steady jet.

With the Powell-3 ECR model, parametric studies were also conducted by varying the shear strength of the stored K-Basin sludge, jet nozzle diameters, jet discharge, and the required ECR to erode the sludge up to the STSC tank wall.

The water jets to mobilize the stored K-Basin sludge should not erode more than $10 \%$ of the STSC tank wall. The tank wall erosion amount was estimated with the Papp wall erosion model for 1-, 3-, and 3.5-mm nozzles located at 1, 5, 17, and 25 inches from the STSC wall for 10-, 20-, 30- and 40-\% entrained solid concentrations of the jets. The wall erosion must be evaluated for a water jet retrieval system, which is capable of eroding the sludge.

These parametric study results with the Powell-3 ECR and the Papp wall erosion models would assist in developing the suitable water jet retrieval system to mobilize the stored K-Basin sludge. An important uncertainty of the use of these models for the stored K-Basin sludge analysis is that these models were developed from experiments with much weaker sludge (all below 10-kPa shear strength), slower jet velocity, and larger nozzle diameter than those expected for the stored K-Basin sludge.

We recommend the following exploratory evaluations as the follow-up of the current study:

- Conduct small- and large-scale water jet testing with high-strength, homogeneous, and heterogeneous simulants developed at Pacific Northwest National Laboratory with the shear strength ranging from $3 \mathrm{kPa}$ to up to $200 \mathrm{kPa}$. By using these realistically high-strength simulants and a high-pressure pump to generate the high jet velocity, this jet testing can assist in developing an optimal design for a waterjet retrieval system and its operational mode. They could provide a sound basis to successfully retrieve the stored K-Basin sludge from the STSCs. The small-scale testing would be conducted at very high pressure, and the large-scale testing would be conducted at the required pressure of 5,000 psi or less. Some of this jet testing may also be conducted to evaluate stainless steel wall erosion.

- Evaluate the feasibility of developing simple and unified methodologies to estimate the solids erosion rate and settling. 
- Conduct computer simulations of the water jet erosion and mixing of the stored K-Basin sludge in the STSCs with a suitable fluid dynamics code applicable to sludge mobilization to determine

- the extent of the sludge erosion

- the degree of uniformity of suspended solid concentrations

to assist in the development of the design and operational mode of a water jet retrieval system. 


\section{Acronyms}

CFD computational fluid dynamics

CHPRC CH2M HILL Plateau Remediation Company

DOE U.S. Department of Energy

DST double-shell tank

ECR effective cleaning radius

ORNL Oak Ridge National Laboratory

PNNL Pacific Northwest National Laboratory

SRS Savannah River Site

STP Sludge Treatment Project

STSC sludge transport and storage container

WTP Hanford Tank Waste Treatment and Immobilization Plant

\section{List of Symbols}
A constant
b coefficient
C solid or slurry concentration
$\mathrm{C}_{1}, \mathrm{C}_{2} \quad$ constants
$\mathrm{C}_{\mathrm{D}} \quad$ drag coefficient
$\mathrm{C}_{\text {ref }} \quad$ reference slurry concentration
$\mathrm{C}_{\mathrm{V}} \quad$ solid volume fraction
$\mathrm{C}_{\mathrm{Vmax}} \quad$ maximum solid volume fraction (the packing factor)
$\mathrm{d}_{\mathrm{j}} \quad$ nozzle jet diameter
$\mathrm{D}_{\mathrm{F}} \quad$ fractal dimension (between 0 and 3)
$\mathrm{D}_{\text {tank }} \quad$ tank diameter
E Erosion depth
$\mathrm{E}_{\text {ref }} \quad$ Reference erosion depth rate
ECR effective cleaning radius
$F_{D}$ densimetric Froude Number
g gravitational acceleration constant
h jet nozzle height above the solid surface
$\mathrm{K}, \mathrm{k} \quad$ erodibility coefficient
$\mathrm{P} \quad$ particle mean diameter 


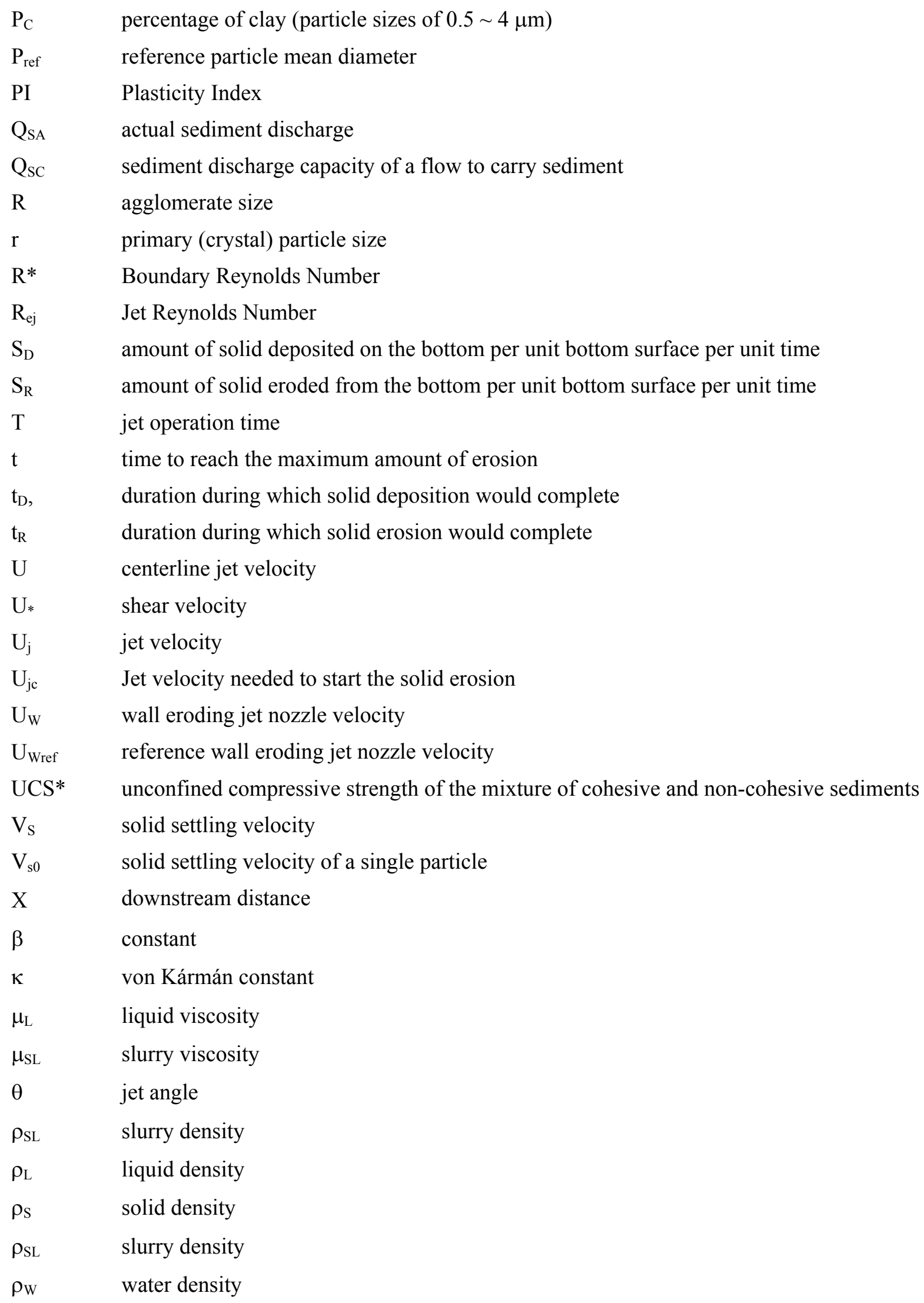


$\tau$

$\tau_{\mathrm{CD}}$

$\tau_{\mathrm{C}}$

$\tau_{\mathrm{CC}}$

$\tau_{\mathrm{CM}}$

$\tau_{\max }$

$\tau_{\mathrm{S}}$

$\tau_{\mathrm{S}}{ }^{*}$

$\tau_{\mathrm{y}}$

shear stress of the flow/jet acting on the surface of the solid layer

critical shear stress for solid deposition

critical shear stress for solid erosion

critical shear stress of a mixture of cohesive and non-cohesive sediments

critical shear stress for solid mass erosion

maximum shear stress a impinging jet is imposing on the soil

shear strength

Solid Erosion Number by jet impingement

yield stress of the Bingham fluid 



\section{Contents}

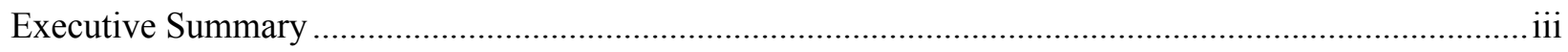

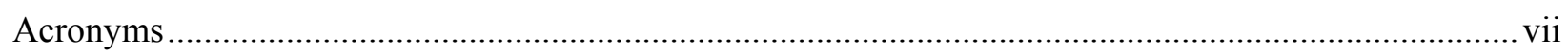

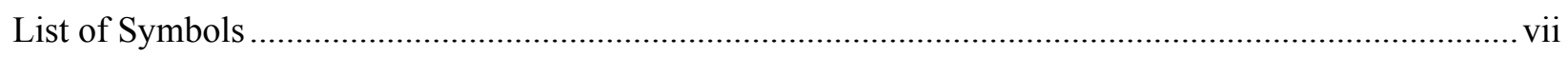

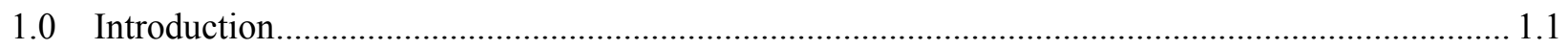

2.0 Effective Cleaning Radius Equations for Solid Erosion ........................................................ 2.1

2.1 Effective Cleaning Radius Description....................................................................... 2.1

2.2 Effective Cleaning Radius Calculation Models ................................................................ 2.1

2.3 Applicability and Validation of the ECR Models to Hanford Waste .................................. 2.10

3.0 Shear Strength Threshold of Concern Evaluation ................................................................. 3.1

3.1 Basis for Parameter in Strength Threshold Evaluation........................................................ 3.1

3.2 Parametric Evaluation of Strength Threshold of Concern Using Powell-3 and the

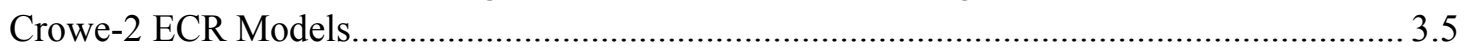

3.3 Further Assessment of Jet Erosion Using Powell-3 ECR Model ...................................... 3.12

3.4 Parametric Evaluation of Strength Threshold of Concern using SRS-1, -2, -3 and

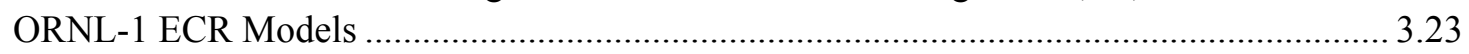

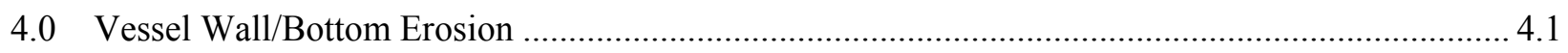

4.1 Vessel Wall/Bottom Erosion Theory ................................................................................ 4.1

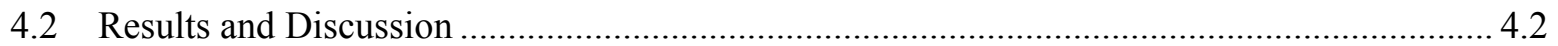

5.0 Brief Discussions on Solid Erosion and Settling, and Possible Exploratory Evaluation.................. 5.1

5.1 Water Jet Testing with High-Strength Simulants for Measurements of Effective Cleaning

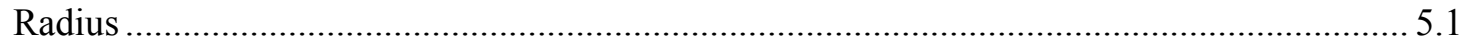

5.2 Critical Shear Stresses for Erosion and Deposition .......................................................... 5.5

5.3 Solid Erosion and Deposition Rates ............................................................................ 5.11

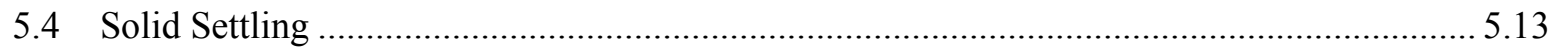

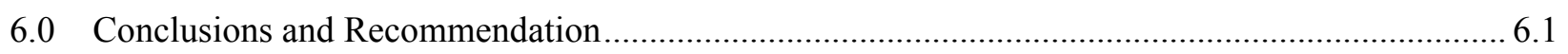

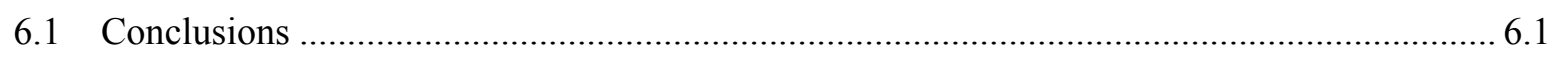

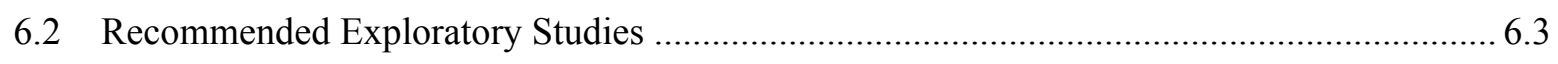

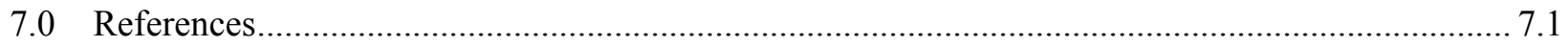




\section{Figures}

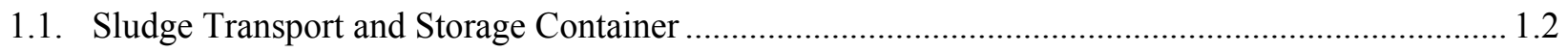

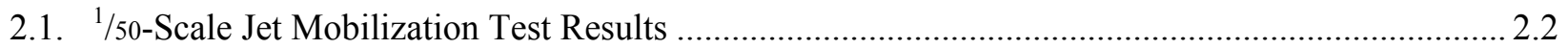

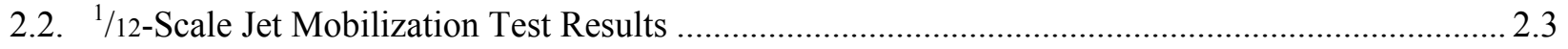

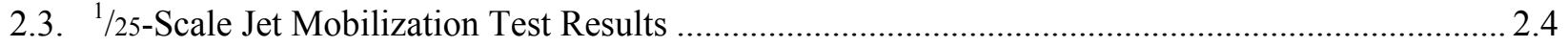

2.4. Flow Profile of a Homogeneous Free Jet................................................................................. 2.7

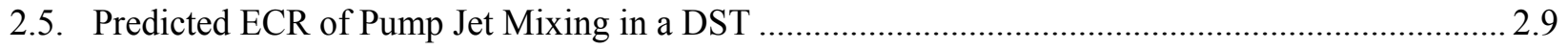

2.6. Predicted Pump Jet Mixing and Waste Chemical Reactions .................................................... 2.10

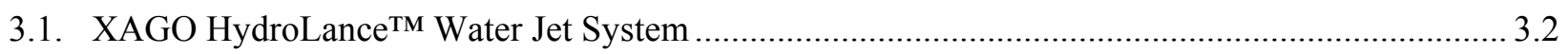

3.2. XAGO HydroLance ${ }^{\mathrm{TM}}$ High Pressure Nozzles in Air ................................................................. 3.2

3.3. XAGO HydroLance ${ }^{\mathrm{TM}}$ Coandra Head in Air................................................................................... 3.3

3.4. Critical Shear Stress for Erosion vs. Shear strength of Soil..................................................... 3.12

3.5. Shear Strength Threshold of Concern vs. Discharge of a Single Jet Located 25 Inches Away

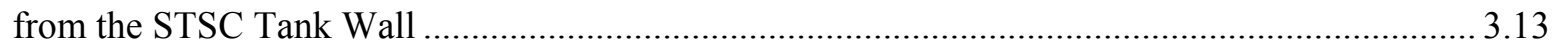

3.6. Shear Strength Threshold of Concern vs. Discharge of a Single Jet Located 17 Inches Away from the STSC Tank Wall

3.7. Estimated Shear Strength Threshold of Concern vs. Discharge of a Single Jet Located 10 Inches Away from the STSC Tank Wall .............................................................................. 3.15

3.8. Estimated Shear Strength Threshold of Concern vs. Discharge of a Single Jet Located 5 Inches Away from the STSC Tank Wall ............................................................................. 3.16

3.9. Estimated Shear Strength Threshold of Concern vs. Discharge of a Single Jet Located 1 Inch Away from the STSC Tank Wall............................................................................... 3.17

3.10. Estimated ECR vs. Jet Discharge of a Single Jet of 1-, 2-, 3-, or 3.5-mm Diameter Nozzle

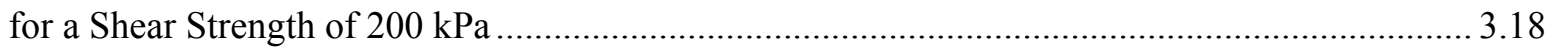

3.11. Estimated ECR vs. Jet Discharge of a Single Jet of 1-, 2-, 3-, or 3.5-mm Diameter Nozzle

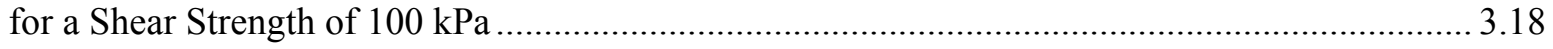

3.12. Estimated ECR vs. Jet Discharge of a Single Jet of 1-, 2-, 3-, or 3.5-mm Diameter Nozzle for a Shear Strength of $30 \mathrm{kPa}$

3.13. Estimated Variation of ECR with Shear Strength at Discharge of 55 gpm of a Single Jet ............ 3.20

3.14. Estimated Variation of ECR with Shear Strength at Jet Discharge of 30 gpm of a Single Jet ....... 3.20

3.15. Estimated Variation of ECR with Shear Strength at Jet Discharge of 15 gpm of a Single Jet....... 3.21

3.16. Estimated Variation of ECR with Shear Strength at Jet Discharge of $7 \mathrm{gpm}$ of a Single Jet ......... 3.21

3.17. Estimated Variation of ECR with Shear Strength at Jet Discharge of 2 gpm of a Single Jet......... 3.22

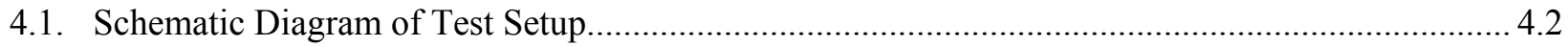


4.2. Nozzle Jet Velocity vs. Operation Time for $10 \%$ Container Wall Erosion with 10 -vol\% Concentration and Various Nozzle Diameters: Top Is of 25-in. Jet Distance from Nozzle, Middle Is 17-in. Jet Distance from Nozzle, and Bottom Is a Combination of 25-in. and 17-in. Jet Distances from Nozzle.

4.3. Nozzle Jet Velocity vs. Operation Time for $10 \%$ Container Wall Erosion with 10 -vol\% Concentration and Various Nozzle Diameters: Top Is of 5-in. Jet Distance from Nozzle, Middle Is 1-in. Jet Distance from Nozzle, and Bottom Is a Combination of 5-in. and 1-in. Jet Distances from Nozzle

4.4. Nozzle Jet Velocity vs. Operation Time for $10 \%$ Container Wall Erosion with 20 -vol\% Concentration and Various Nozzle Diameters: Top Is of 25-in. Jet Distance from Nozzle, Middle Is of 17-in. Jet Distance from Nozzle, and Bottom Is of Combination of 25-in. and 17-in. Jet Distances from Nozzle

4.5. Nozzle Jet Velocity vs. Operation Time for $10 \%$ Container Wall Erosion with 20 -vol\% Concentration and Various Nozzle Diameters: Top Is of 5-in. Jet Distance from Nozzle, Middle Is of 1-in. Jet Distance from Nozzle, and Bottom Is of Combination of 5-in. and 1-in. Jet Distances from Nozzle...

4.6. Nozzle Jet Velocity vs. Operation Time for $10 \%$ Container Wall Erosion with 30 -vol\% Concentration and Various Nozzle Diameters: Top Is of 25-in. Jet Distance from Nozzle, Middle Is of 17-in. Jet Distance from Nozzle, and Bottom Is of Combination of 25-in. and 17-in. Jet Distances from Nozzle.

4.7. Nozzle Jet Velocity vs. Operation Time for $10 \%$ Container Wall Erosion with 30 -vol\% Concentration and Various Nozzle Diameters: Top Is of 5-in. Jet Distance from Nozzle, Middle Is of 1-in. Jet Distance from Nozzle, and Bottom Is of Combination of 5-in. and 1-in. Jet Distances from Nozzle

4.8. Nozzle Jet Velocity vs. Operation Time for $10 \%$ Container Wall Erosion with 40 -vol\% Concentration and Various Nozzle Diameters: Top Is of 25-in. Jet Distance from Nozzle, Middle Is of 17-in. Jet Distance from Nozzle, and Bottom Is of Combination of 25-in. and 17-in. Jet Distances from Nozzle.

4.9. Nozzle Jet Velocity vs. Operation Time for $10 \%$ Container Wall Erosion with 40 -vol\% Concentration and Various Nozzle Diameters: Top Is of 5-in. Jet Distance from Nozzle, Middle Is of 1-in. Jet Distance from Nozzle, and Bottom Is of Combination of 5-in. and 1-in. Jet Distances from Nozzle.....

5.1. Conceptual Small-Scale Water Jet Test Set-up ....................................................................... 5.3

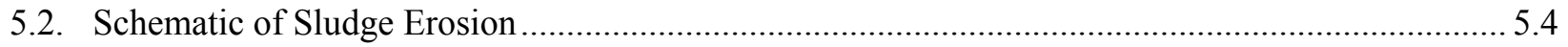

5.3. Solid Erosion and Deposition Processes........................................................................................ 5.6

5.4. Shield Diagram for Critical Shear Stress for Erosion .............................................................. 5.7

5.5. One-Dimensional Solid Concentration Distribution.............................................................. 5.13

5.6. Measured Solid Settling of Hanford Waste in a 30-ft Column .................................................... 5.15

5.7. Variation of Drag Coefficient with Particle Reynolds Number.................................................... 5.16

5.8. Measured Variation of Agglomerate Settling Velocity with Solid Concentrations........................ 5.18

5.9. Variation of Solid Settling with Solid Concentrations ............................................................. 5.20 


\section{Tables}

2.1. Hanford 241-SY-101 and 241-AZ-101 Test Conditions Used for the ECR Model Validation...... 2.11

2.2. Comparison of Predicted ECRs with Measured ECRs of Hanford Tanks 241-SY-101 and 241-AZ-101 2.11

3.1. Parameters for Stored K-Basin Sludge and Water Jet System Conditions 3.4

3.2. Estimated Shear Strength Threshold of Concern for the Stored K-Basin Sludge by Using a Single Nozzle (42 gpm) at Distance of 25 inches Away from the STSC Tank Wall

3.3. Estimated Shear Strength Threshold of Concern for the Stored K-Basin Sludge by Using a Single Nozzle (42 gpm) at Distance of 17 Inches Away from the STSC Tank Wall.......

3.4. Estimated Shear Strength Threshold of Concern for the Stored K-Basin Sludge by Using a Single Nozzle (42 gpm) at Distance of 10 Inches Away from the STSC Tank Wall...

3.5. Estimated Shear Strength Threshold of Concern for the Stored K-Basin Sludge by Using a Single Nozzle (42 gpm) at Distance of 5 Inches Away from the STSC Tank Wall

3.6. Estimated Shear Strength Threshold of Concern for the Stored K-Basin Sludge by Using a Single Nozzle (42 gpm) at Distance of 1 Inch Away from the STSC Tank Wall .....

3.7. Estimated Shear Strength Threshold of Concern for the Stored K-Basin Sludge by Using All Seven Nozzles (42 gpm) of the XAGO system at Distance of 25 Inches Away from the STSC Tank Wall.

3.8. Estimated Shear Strength Threshold of Concern for the Stored K-Basin Sludge by Using All Seven Nozzles (42 gpm) of the XAGO system at Distance of 17 Inches Away from the STSC Tank Wall.

3.9. Estimated Shear Strength Threshold of Concern for the Stored K-Basin Sludge by Using All Seven Nozzles (42 gpm) of the XAGO system at Distance of 10 Inches Away from the STSC Tank Wall.

3.10. Estimated Shear Strength Threshold of Concern for the Stored K-Basin Sludge by Using All Seven Nozzles (42 gpm) at Distance of 5 Inches Away from the STSC Tank Wall.

3.11. Estimated Shear Strength Threshold of Concern for the Stored K-Basin Sludge by Using All Seven Nozzles (42 gpm) at Distance of 1 Inch Away from the STSC Tank Wall.....

3.12. Shear Strength Threshold of Concern for Stored K-Bain Sludge at 42-gpm Jet Discharge Predicted by the Powell-3 and Crowe-2 ECR Models.

3.13. Calculated Jet Velocity and Width at $0,1,5,10,17$, and 25 Inches Downstream at a Discharge Rate of $42 \mathrm{gpm}$

3.14. Required Jet Velocity to Erode 25 Inches of Stored K-Bain Sludge Predicted by SRS-1,-2, -3, and ORNL-1 ECR Models when a Single Nozzle is Used.

3.15. Required Jet Velocity to Erode 17 Inches of Stored K-Bain Sludge Predicted by SRS-1,-2, -3, and ORNL-1 ECR Models when a Single Nozzle Is Used

3.16. Required Jet Velocity to Erode 10 inches of Stored K-Bain Sludge Predicted by SRS-1,-2, -3, and ORNL-1 ECR Models when a Single Nozzle Is Used .... 
3.17. Required Jet Velocity to Erode 5 inches of Stored K-Bain Sludge Predicted by SRS-1,-2, -3, and ORNL-1 ECR Models when a Single Nozzle Is Used

3.18. Required Jet Velocity to Erode 1 inch of Stored K-Bain Sludge Predicted by SRS-1,-2,-3, and ORNL-1 ECR Models when a Single Nozzle Is Used

3.19. Required Jet Velocity to Erode 25 Inches of Stored K-Bain Sludge Predicted by SRS-1,-2, -3, and ORNL-1 ECR Models when All Seven Nozzles of the XAGO System Are Used.

3.20. Required Jet Velocity to Erode 17 Inches of Stored K-Bain Sludge Predicted by SRS-1,-2,-3, and ORNL-1 ECR Models when All Seven Nozzles of the XAGO System Are Used

3.21. Required Jet Velocity to Erode 10 Inches of Stored K-Bain Sludge Predicted by SRS-1,-2,-3, and ORNL-1 ERC Models when All Seven Nozzles of the XAGO System Are Used

3.22. Required Jet Velocity to Erode 5 Inches of Stored K-Bain Sludge Predicted by SRS-1,-2,-3, and ORNL-1 ERC Models when All Seven Nozzles of the XAGO System Are Used

3.23. Required Jet Velocity to Erode 1 Inches of Stored K-Bain Sludge Predicted by SRS-1,-2,-3, and ORNL-1 ERC Models when All Seven Nozzles of the XAGO System Are Used

4.1. Nozzle Jet Velocities for 10\% Container Wall Erosion with 10-vol\% Concentration, 25-in. Jet Distance from Nozzle, and Various Nozzle Diameters

4.2. Nozzle Jet Velocities for 10\% Container Wall Erosion with 10 -vol\% Concentration, 17 -in. Jet Distance from Nozzle, and Various Nozzle Diameters

4.3. Nozzle Jet Velocities for 10\% Container Wall Erosion with 10-vol\% Concentration, 5-in. Jet Distance from Nozzle, and Various Nozzle Diameters

4.4. Nozzle Jet Velocities for 10\% Container Wall Erosion with 10-vol\% Concentration, 1-in. Jet Distance from Nozzle, and Various Nozzle Diameters

4.5. Nozzle Jet Velocities for $10 \%$ Container Wall Erosion with 20 -vol\% Concentration, 25-in. Jet Distance from Nozzle, and Various Nozzle Diameters

4.6. Nozzle Jet Velocities for 10\% Container Wall Erosion with 20-vol\% Concentration, 17-in. Jet Distance from Nozzle, and Various Nozzle Diameters

4.7. Nozzle Jet Velocities for 10\% Container Wall Erosion with 20 -vol\% Concentration, 5-in. Jet Distance from Nozzle, and Various Nozzle Diameters .

4.8. Nozzle Jet Velocities for 10\% Container Wall Erosion with 20-vol\% Concentration, 1-in. Jet Distance from Nozzle, and Various Nozzle Diameters.

4.9. Nozzle Jet Velocities for 10\% Container Wall Erosion with 30-vol\% Concentration, 25-in. Jet Distance from Nozzle, and Various Nozzle Diameters

4.10. Nozzle Jet Velocities for 10\% Container Wall Erosion with 30-vol\% Concentration, 17-in. Jet Distance from Nozzle, and Various Nozzle Diameters

4.11. Nozzle Jet Velocities for 10\% Container Wall Erosion with 30-vol\% Concentration, 5-in. Jet Distance from Nozzle, and Various Nozzle Diameters

4.12. Nozzle Jet Velocities for 10\% Container Wall Erosion with 30-vol\% Concentration, 1-in. Jet Distance from Nozzle, and Various Nozzle Diameters

4.13. Nozzle Jet Velocities for 10\% Container Wall Erosion with 40 -vol\% Concentration, 25-in. Jet Distance from Nozzle, and Various Nozzle Diameters 
4.14. Nozzle Jet Velocities for 10\% Container Wall Erosion with 40-vol\% Concentration, 17-in. Jet Distance from Nozzle, and Various Nozzle Diameters

4.15. Nozzle Jet Velocities for 10\% Container Wall Erosion with 40-vol\% Concentration, 5-in. Jet Distance from Nozzle, and Various Nozzle Diameters

4.16. Nozzle Jet Velocities for 10\% Container Wall Erosion with 40-vol\% Concentration, 1-in. Jet Distance from Nozzle, and Various Nozzle Diameters 


\subsection{Introduction}

Irradiated uranium metal fuel elements of the N-Reactor along the Columbia River in eastern Washington State have been stored in the K-East and the K-West Basin fuel storage pools at the Hanford Site of the U.S. Department of Energy (DOE). The spent fuel storage and packaging operations resulted in the generation of radioactive sludge in these two basins. The fuel has been removed from the $\mathrm{K}$ Basins, and the sludge currently resides in the K-West Basin in large underwater engineered containers. The first phase of the Sludge Treatment Project (STP) is to retrieve and load the sludge into Sludge Transport and Storage Containers (STSCs) and transport the STSCs to T-Plant for interim storage (Honeyman and Rourk 2009). The projected sludge loadings in the STSCs will vary depending upon the sludge type: $2.1 \mathrm{~m}^{3}$ for KE Engineered Container sludge, $1.6 \mathrm{~m}^{3}$ for KW KE Engineered Container sludge, and $0.5 \mathrm{~m}^{3}$ for the KW Settler Tank sludge (Johnson and Dhaliwal 2009). The sludge consists of a variety of particulate materials, including a fraction of reactive uranium metal particles and water (Schmidt 2010, Johnson 2010). The second phase of this project will be to retrieve the sludge in the STSCs from interim storage. The retrieved sludge will then be treated and packaged for eventual shipment to the Waste Isolation Pilot Plant in New Mexico.

Some of the sludge samples stored and tested at Pacific Northwest National Laboratory (PNNL) have been observed to self-cement and form strong sludge (Delegard et al. 2005, Delegard et al 2007, and Wells et al. 2009). CH2M HILL Plateau Remediation Company (CHPRC) plans to use water jets, e.g., the HydroLance ${ }^{\mathrm{TM}}$ XAGO retrieval system (CHPRC 2009), to retrieve K-Basin sludge after interim storage. It is important to determine whether water jets can mobilize and erode the stored K-Basin sludge from the STSCs, especially the high uranium content KW settler sludge.

The objective of the evaluation was to determine the range of sludge shear strength for which there is high confidence that a water-jet retrieval system can mobilize stored K-Basin sludge from STSCs. The shear strength at which the sludge can be retrieved is defined as the "shear strength threshold of concern." If the sludge shear strength is greater than the value of the shear strength threshold of concern, a water-jet retrieval system will be unlikely to mobilize the sludge up the container's walls. The shear strength threshold of concern can be compared with the range of possible shear strength of K-Basin stored sludge to determine if the current post interim-storage, water-jet retrieval method is adequate. The evaluation results will assist in the development and improvement of a water jet sludge retrieval system.

Effective cleaning radius (ECR) models were used here to address a question as to whether the effective cleaning radius of water jets is sufficient or readily expanded to cover the range of possible shear strength. These results will assist CH2M HILL Plateau Remediation Company (CHPRC) to establish the technical basis of the feasibility of the sludge retrieval and storage plan and to develop an adequate water jet system to retrieve the stored K-Basin sludge in the STSCs. Figure 1.1 shows an example of the STSC with a centrally located inner cylinder (24 in. diameter) for sludge cooling (CHPRC 2010). The STSCs are 2:1 elliptical- head vessels, 58 in. diameter and 105 in. tall. Each STSC will contain 0.5 to $2.1 \mathrm{~m}^{3}$ of settled sludge with the specific loading dependent upon sludge type. The center penetration (24 in. diameter) on the top of the STSCs would available for access to facilitate sludge retrieval. 

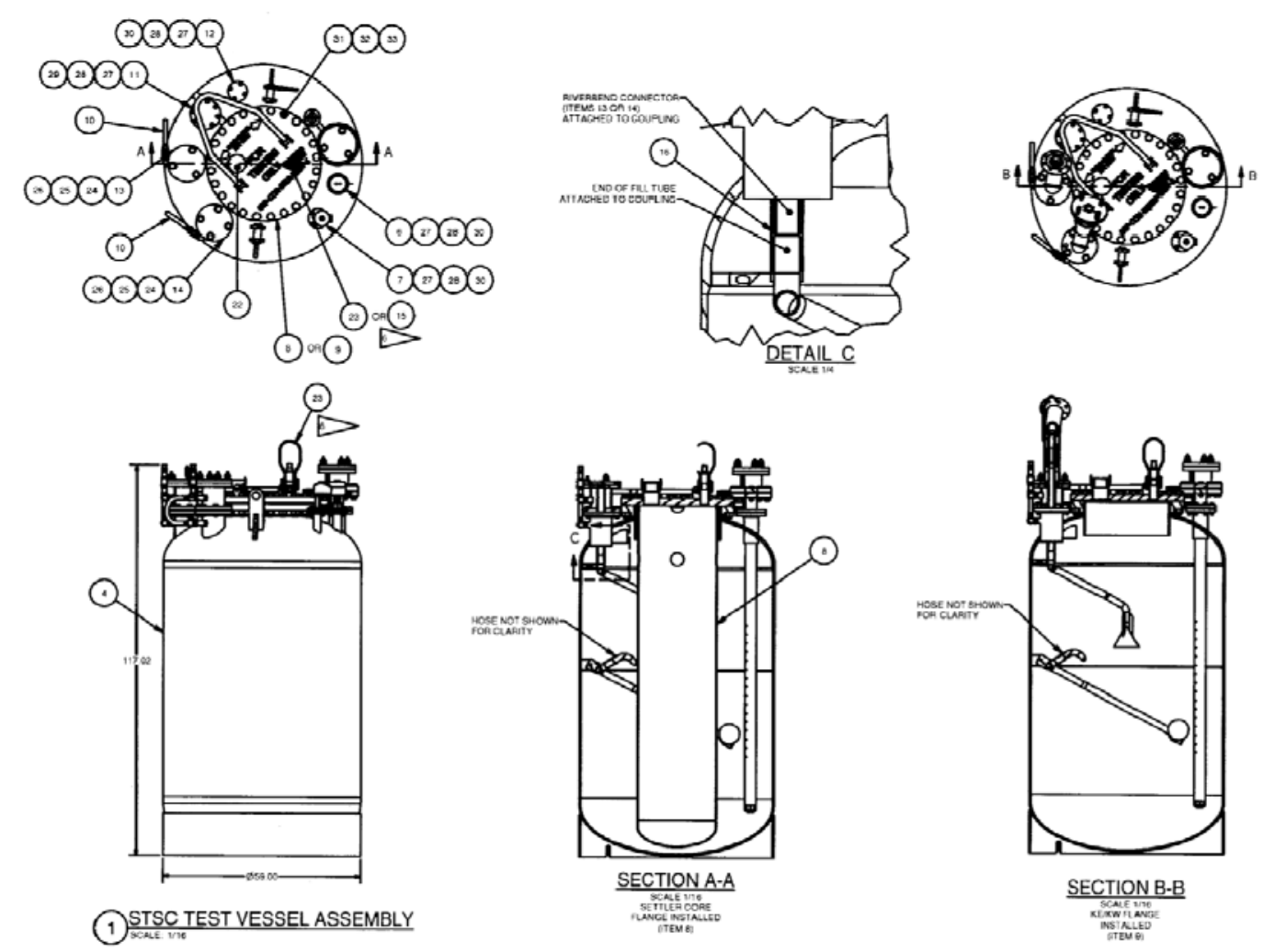

Figure 1.1. Sludge Transport and Storage Container (CHPRC 2010)

K-Basin sludge has been characterized and evaluated to support sludge management since 1993. Existing documents and data sources for sludge waste characterization are tabulated in Westcott et al. (2009). The shear strength of the K Basin sludge is an important factor for predicting mobilization behavior during retrieval. The shear strength is defined as the maximum stress force that can be applied to a material before it deforms. Materials that exhibit shear strength are typically solid/liquid multiphase systems and display solid-like behavior at low stresses and fluid-like behavior at high stresses. During the solid-like behavior, the material behaves elastically where it will strain to a point at a given stress. When the stress is removed, the material will return to its initial state. The shear strength is regarded as the transition between elastic behavior and viscous flow.

Results from shear strength measurements conducted on K Basin sludge samples (predominantly collected from the KE floor, KE pits, and KE canisters) from 1995-2002 are summarized in Poloski et al. (2002) and Plys and Schmidt (2009). These measurements were used to establish the shear strength range of 1 to 8200 Pa provided in the Sludge Technical Databook (Schmidt 2010). The shear strength is affected by sample history, and most of the measurements given in Poloski et al. (2002) were obtained from sludge samples that been settled/gelled for several days to several weeks. Typically, in this time range, the samples exhibited shear strengths from less than 100 to about $3000 \mathrm{~Pa}$. A series of strength measurements was performed on samples that had settled/gelled for 20 to 30 days, and for these samples, the strengths ranged up to $8000 \mathrm{~Pa}$.

Shear strength measurements were performed on samples collected from the KW Engineered Containers in 2009 (Fiskum et al. 2009), and all samples were found to exhibit strengths of less than 
$1000 \mathrm{~Pa}$. These samples had been passed through 500-micron sieves and had settled/gelled for several days to several weeks.

To characterize the behavior of sludge samples during long-term storage, a 28-month study was conducted with six K East (KE) Basin sludge samples from May 2002 to September 2004 (Delegard et al. 2005). For this study, sludge slurries were loaded into glass graduated cylinders and allowed to settle with a cover of water. The mass and volumes of the sludge samples were monitored over the test duration. The study was performed under hot cell storage conditions $\left(\sim 32\right.$ to $38^{\circ} \mathrm{C}, \sim 30$ to $41 \%$ relative humidity, slightly below atmospheric pressure, and $\sim 5 \mathrm{Rad} /$ hour radiation field). One of the KE sludge samples, 96-13 (82 wt\% uranium) used in the study had previously dried out during storage, but was reconstituted (i.e., it was rewetted/mixed and prepared as a settled slurry, approximately 6 months before initiation of the long-term storage tests). At the conclusion of the 28-month study, the 96-13 sample was found to be in an agglomerated state. The agglomeration and self-cementation were so severe that the glass graduated cylinder had to be broken to recover the sample. The sample recovery operation was videotaped. The other five sludge samples did not agglomerate, and at the end of the 28 -month test period were readily re-suspended. The higher total uranium concentration in sample 96-13 may have contributed to its self-agglomeration. In FY 2009, at the request of STP, PNNL prepared and issued a topical report, "Assessment of Jet Erosion for Potential Post-Retrieval K-Basin Settled Sludge (Wells et al. 2009). This work includes an assessment of the agglomerated sample 96-13, based on written and video records. The sample was described to be a heterogeneous cohesive sediment with "paste" material of estimated shear strength 3 to $5 \mathrm{kPa}$ joining "chunks" of estimated shear strength ranging from 380 to $770 \mathrm{kPa}$. The bulk material shear strength was estimated to at 15 to $65 \mathrm{kPa}$.

In another study (Delegard et al. 2007), various sludge samples were subjected to hydrothermal conditions (e.g., $185^{\circ} \mathrm{C}, 10$ to $72 \mathrm{~h}$ ), and the sludge agglomerated to form relatively high-strength material (shear strengths ranged from $9 \mathrm{kPA}$ to $170 \mathrm{kPa}$, based on unconfined compressive strength

measurements). In this study, samples with the higher uranium contents exhibited greater strength. Based on sludge characterization and testing results, after interim storage of sludge in T Plant, sludge may exhibit shear strengths of up to about $200 \mathrm{kPA}$ when it is retrieved from the STSCs.

To achieve the evaluation objective stated above, various available calculation methods of the effective cleaning radius (ECR) of a water jet are described and discussed in Section 2. The ECR is the distance between the jet nozzle exit and the base of the non-mobilized sludge bank. These ECR models were used to determine the shear strength threshold of concern, and these results are presented in Section 3. Possible erosion of the wall and bottom of the STSC by an impinging jet is evaluated in Section 4 . Section 5 provides a list and high-level discussion of some recommended future exploratory evaluations. Conclusions and recommendations are provided in Section 6, and cited references are listed in Section 7. 



\subsection{Effective Cleaning Radius Equations for Solid Erosion}

This section describes the ECR models and discusses their applicability to Hanford waste.

\subsection{Effective Cleaning Radius Description}

Hanford radioactive waste is expected to be mobilized in STSC sludge storage tanks, double-shell tanks (DSTs), and the Hanford Tank Waste Treatment and Immobilization Plant's (WTP)'s waste process vessels by water and slurry jets. Thus, it is important to determine if these jets are capable of eroding the required amounts of settled sludge and saltcake in these tanks and vessels. The ECR is often used in DOE's Hanford, Savannah River, and Oak Ridge Sites to express the jet eroding capacity. Beside the ECR formulas presented in this section, various other methods have also been used at the Hanford Site to determine the capability of pump jet mixers and pulse jet mixers to mobilize settled solids, and these examples are also briefly discussed in this section (Onishi et. al. 2002, Meyer et al., 2009). Wells et al. (2009) reviewed jet erosion phenomena, the shear strength, and critical shear stress for erosion relevant to potential, post-retrieval, K-Basin settled sludge.

\subsection{Effective Cleaning Radius Calculation Models}

Many experimental and field studies of solid erosion by a water jet have been conducted to obtain the critical shear stress for erosion to quantify the amount and rate of solid erosion (Clark and Wynn 2007, Mazurek and Hossain 2009) as will be discussed in Section 5. Various ECR models have also been developed at the DOE sites (Powell et al. 1997, Tedeschi 2000, Poirier 2004). However, these DOE studies have not addressed the solids erosion in terms of the critical shear stress for erosion, but rather with the shear strength or yield stress to express the sludge strength to resist the erosion. ECR models were developed at the DOE sites through small-scale to full-scale experiments. Thus, this section focuses on the DOE models because they do not use critical shear stress for erosion values, which have not been reported in DOE studies.

Powell conducted $1 / 50-, 1 / 25$-, and $1 / 12$-scaled physical models to develop four ECR formulas to predict the performance of a mixer pump to mobilize the settled waste in the Hanford DSTs (Powell 1995a,b, Powell et al. 1997). The Hanford DSTs are 75-ft-diameter tanks and can contain a mixture of sludge, saltcake, and supernatant liquid to the maximum depth of approximately $33 \mathrm{ft}$. The mixer pump in most cases has a 6-inch-diameter nozzle, and the jet exit velocity from a 300-hp mixer pump is $60 \mathrm{ft} / \mathrm{s}$ in the DSTs. For the $1 / 50$ - (bench-) scale model, Powell conducted 17 test runs with a stationary water jet to erode the kaolin, bentonite, and kaolin/Ludox as solid simulants. Ludox is colloidal silica. The ECR model, called here as the Powell-1 model, developed with the $1 / 50$-scale model, is

$$
E C R=6.1 U_{j} d_{j} \tau_{S}^{-0.49} \quad \text { Based on }{ }^{1} / 50 \text {-scale model }
$$

where $d_{j}$ is the nozzle jet diameter $(\mathrm{cm}), U_{j}$ is the jet velocity $(\mathrm{cm} / \mathrm{s})$, and $\tau_{\mathrm{S}}$ is the shear strength (dynes/ $\mathrm{cm}^{2}$ ). 
Figure 2.1 shows these data and calculated results from Equation 2.1. This figure also has calculated results from Equation 2.2 derived with the $1 / 12$-scale testing, as will be discussed below. The symbol $\mathrm{U}_{0}$ in this figure is the same as $U_{j}$, and $D$ is the same as $d_{j}$.

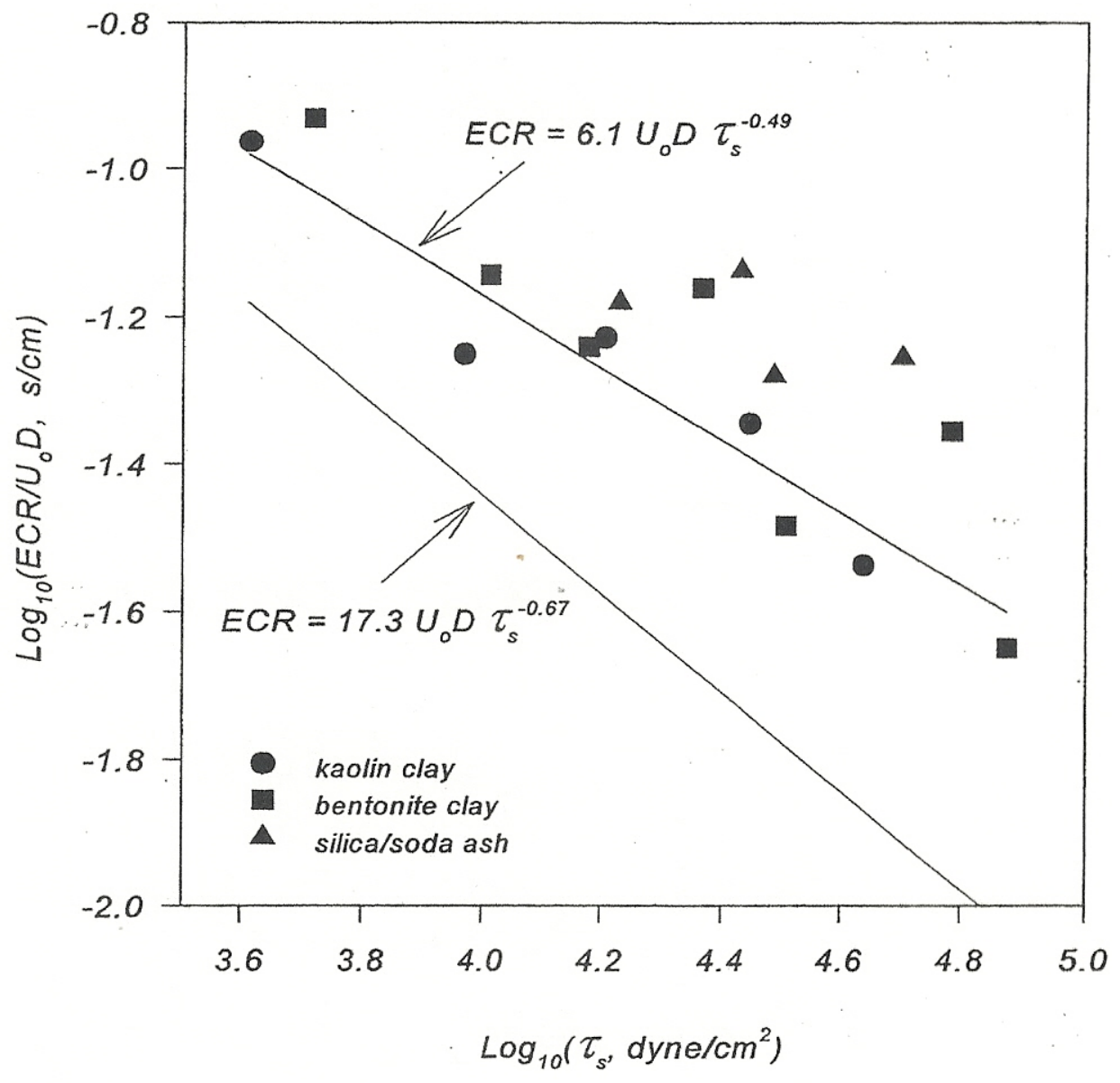

Figure 2.1. ${ }^{1} / 50-$ Scale Jet Mobilization Test Results (Powell et al. 1997)

Powell's $1 / 12$-scale model used silica power and sodium carbonate solution and was run for over 24 hours. The shear strength was approximately $1,000 \mathrm{~Pa}$ (Powell et al. 1997). The Powell-2 ECR model derived from these experiments is

$$
E C R=17.3 U_{j} d_{j} \tau_{S}^{-0.67} \text { Based on }{ }^{1 / 12} \text {-scale model }
$$




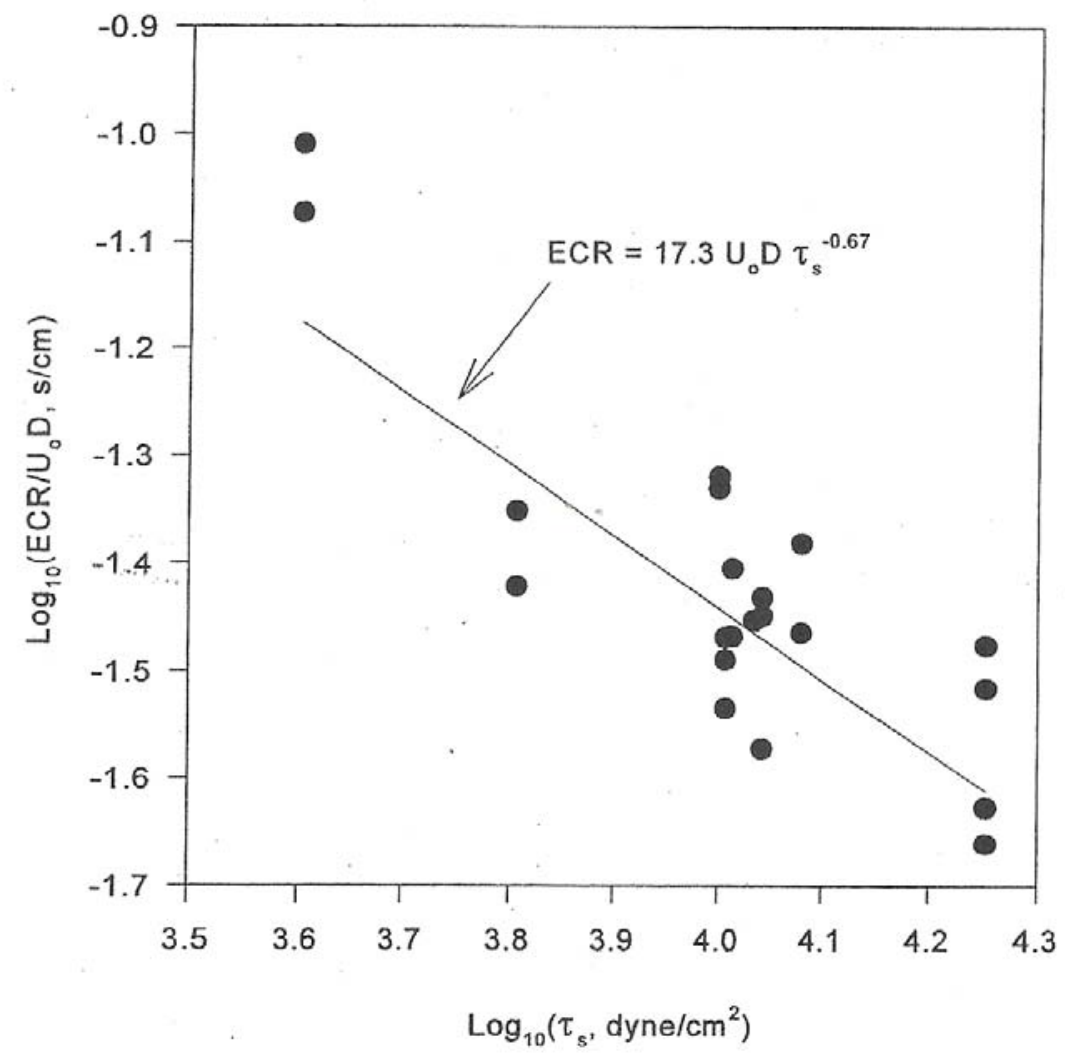

Figure 2.2. $1 / 12$-Scale Jet Mobilization Test Results (Powell et al. 1997)

The fit of Equation 2.2 with the measured ECR is shown in Figure 2.2.

Powell also conducted $1 / 12$-scale model experiments with kaolin, salt, and Ludox after 24-hour curing. Their shear strength varied from 1,500 $\mathrm{Pa}$ to 6,000 $\mathrm{Pa}$. Most of these runs lasted for 4 hours, but some lasted more than 24 hours. The ECR was not a function of the shear strength in these runs, and he judged that these experiments were not good tests.

Powell conducted his most comprehensive ECR testing with a $1 / 25$-scale model having a rotating pump (Powell et al. 1997). Simulants are bentonite, bentonite/kaolin, kaolin/Ludox, Kaolin/ $\mathrm{NaCl}$, and kaolin/Plaster of Paris, having a shear strength of up to about 10,000 Pa. Forty-five runs were made to obtain the following Powell-3 ECR model:

$$
E C R=4.0 U_{j} d_{j} \tau_{S}^{-0.46} \quad \text { Based on }{ }^{1} / 25 \text {-scale model }
$$

Because bentonite is a moisture-absorbing clay, the longer he ran the test, the larger the ECR. To be somewhat conservative, he selected the following Powell-4 ECR model:

$$
E C R=3.0 U_{j} d_{j} \tau_{S}^{-0.46} \quad \text { Based on }{ }^{1} / 25 \text {-scale model }
$$




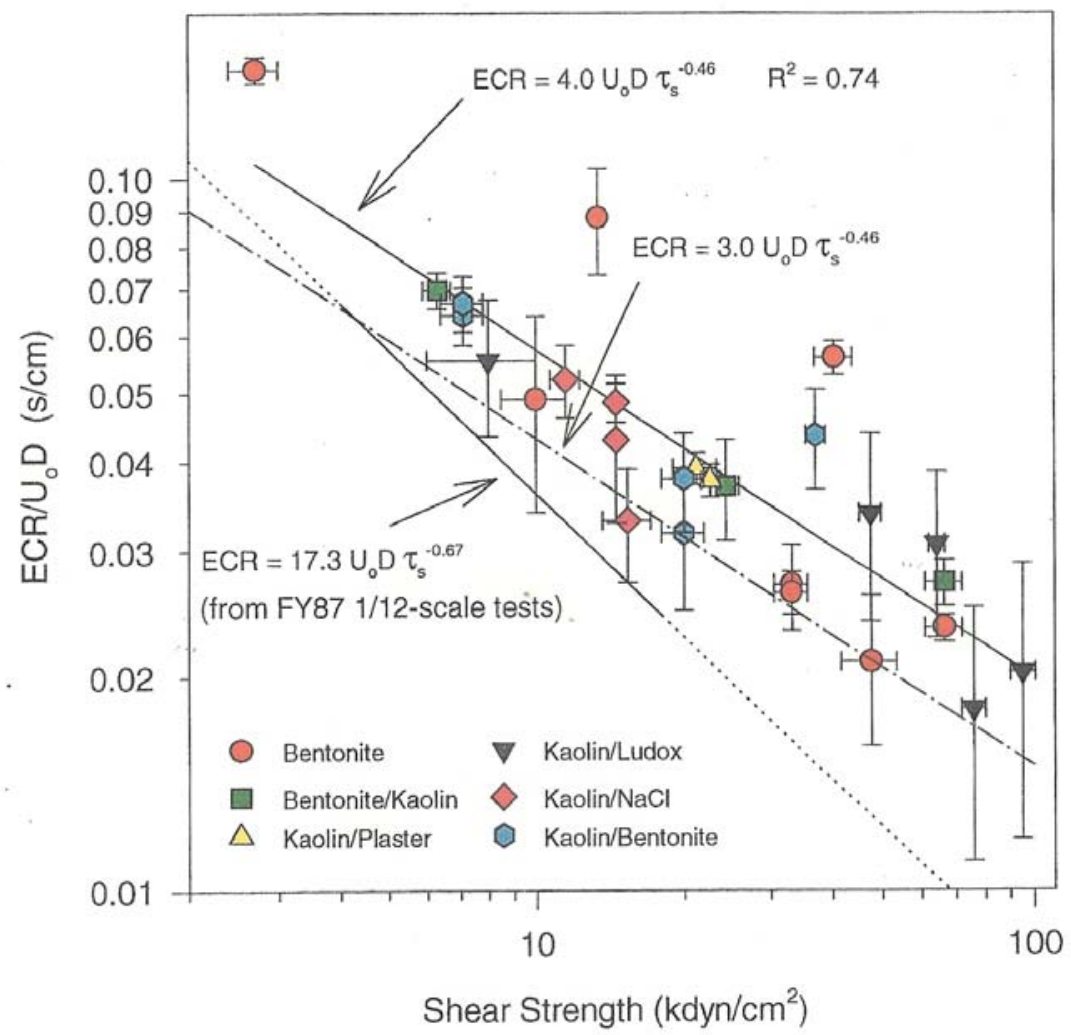

Figure 2.3. ${ }^{1} / 25$-Scale Jet Mobilization Test Results (Powell et al. 1997)

A comparison of Equations 2.3 and 2.4 with measured $1 / 25$-scale model data is shown in Figure 2.3, and the accuracy of Powell-3 and 4 models is reported to be about $\pm 20 \%$.

The $1 / 25$-scale experiments had a nozzle diameter of $6.1 \mathrm{~mm}$, and a nozzle jet velocity of $18 \mathrm{~m} / \mathrm{s}$ $(60 \mathrm{ft} / \mathrm{s})$. The current XAGO sludge retrieval system has jet nozzle diameters of 1,3 , and $3.5 \mathrm{~mm}$ (CHPRC 2009). Thus, the nozzle size of the $1 / 25$-scale tests was somewhat comparable to those of the XAGO system, although the jet velocity used in Powell's $1 / 25$ scale physical model may be smaller than those of the XAGO system.

All four of Powell's ECR models (Equations 2.1 through 2.4) use the unit of $\mathrm{cm}$ for ECR and $\mathrm{d}_{\mathrm{j}}, \mathrm{U}_{\mathrm{j}}$ is in $\mathrm{cm} / \mathrm{s}$, and $\tau_{\mathrm{S}}$ is in dynes $/ \mathrm{cm}^{2}$.

Because non-dimensional formulas have generally a wider application range than dimensional formulas like Equations 2.1 through 2.4, Crowe at Washington State University developed a nondimensional ECR formula for the Crowe- 1 model by using Powell's $1 / 12$ and $1 / 25$-scale experimental data (Tedeschi 2000).

$$
\frac{E C R}{d_{j}}=0 . .913 R_{e j L}{ }^{0.2} \tau_{S L}{ }^{*-0.173} F_{D L}{ }^{0.194}
$$




$$
\begin{gathered}
F_{D L}=\frac{U_{j}}{\sqrt{\left(\frac{\rho_{S L}-\rho_{W}}{\rho_{L}}\right) g d_{j}}} \equiv \text { Densimetric Froude Number } \\
R_{e j L}=\frac{U_{j} d_{j} \rho_{S L}}{\mu_{S L}} \equiv \text { Jet Reynolds Number } \\
\tau_{S L}^{*}=\frac{\tau_{S}}{\rho_{S L} U_{j}^{2}} \equiv \text { Solid Erosion Number by Jet Impingement }
\end{gathered}
$$

where $\mathrm{g}=$ gravitational acceleration constant

$$
\begin{aligned}
\mu_{\mathrm{SL}} & =\text { slurry viscosity }\left(\mathrm{N}-\mathrm{s} / \mathrm{m}^{2}\right) \\
\rho_{\mathrm{SL}} & =\text { slurry density }\left(\mathrm{kg} / \mathrm{m}^{3}\right) \\
\rho_{\mathrm{L}} & =\text { liquid density }\left(\mathrm{kg} / \mathrm{m}^{3}\right) \\
\rho_{\mathrm{W}} & =\text { water density }\left(\mathrm{kg} / \mathrm{m}^{3}\right) \\
\tau_{\mathrm{S}} & =\text { shear strength of sludge and saltcake }\left(\mathrm{N} / \mathrm{m}^{2}\right) .
\end{aligned}
$$

However, as shown in Table 2.1 and Table 2.2, the ECR model validation performed with actual pump jet mixing data in DSTs 241-SY-101 and 241-AZ-101 indicates that Equation 2.5 with the standard definitions of the densimetric Froude number $\left(F_{D}\right)$ shown as Equation 2.9, the Reynolds number $\left(R_{e j}\right)$ shown as Equation 2.10, and the solid erosion number by jet impingement $\left(\tau_{\mathrm{S}}{ }^{*}\right)$ shown as Equation 2.11 has a better match to the measured ECR values than unconventional definitions of these three nondimensional parameters of Equations 2.6 through 2.8.

$$
\begin{gathered}
F_{D}=\frac{U_{j}}{\sqrt{\left(\frac{\rho_{S}-\rho_{L}}{\rho_{L}}\right) g d_{j}}} \equiv \text { Densimetric Froude Number } \\
R_{e j}=\frac{U_{j} d_{j} \rho_{L}}{\mu_{L}} \equiv \text { Jet Reynolds Number } \\
\tau_{S}^{*}=\frac{\tau_{S}}{\rho_{L} U_{j}^{2}} \equiv \text { Solid Erosion by Jet Impingement }
\end{gathered}
$$

where $\mu_{\mathrm{L}}$ is the liquid viscosity, $\rho_{\mathrm{L}}$ is the liquid density, and $\rho_{\mathrm{S}}$ is the solid density.

Thus, Equation 2.5 with Equations 2.9 through 2.11 was also included in this analysis as the Crowe 2 ECR model. 
Gauglitz et al. (2009) converted Equation 2.3 to a non-dimensional ECR formula by changing the power of $\tau_{\mathrm{S}}$ from -0.46 to -0.5 and re-wrote the correlation by matching the ECR value of Equation 2.3 at a shear strength of $1,000 \mathrm{~Pa}$. His model is

$$
\frac{E C R}{d_{j}}=5.78 \tau_{S} *^{-0.5}
$$

Equation 2.12 deviates from the Powell-3 ECR model by $10 \%$ at 100 and 10,000 Pa shear strength. Because Equations 2.5 through 2.12 are non-dimensional, any consistent units can be used for these equations.

Historically, the Hanford Site has used shear strength as a measure of the solid layer strength, while the Savannah River and the Oak Ridge Sites use the yield stress of a Bingham fluid to represent the solid layer strength. For use at the Savannah River Site, the Savannah River and Oak Ridge National Laboratories developed the following ECR formulas, mostly using kaolin as a simulant (Powell et al. 1997, Poirier 2004).

For use at the Savannah River Site, the Savannah River and Oak Ridge Sites developed the following ECR formula by Churnetski (Reshman et al. 2007) and Poirier (2004), respectively

$$
\begin{aligned}
& E C R=0.97 d_{j} U_{j}\left(\frac{\tau_{y}}{\rho_{L}}\right)^{-0.5} \\
& E C R=4.4 d_{j} U_{j}\left(\frac{\tau_{y}}{\rho_{L}}\right)^{-0.5}
\end{aligned}
$$

where $\tau_{\mathrm{y}}$ is the yield stress of the Bingham fluid.

Poirier (2004) developed Equation 2.14 by using the jet centerline velocity of a three-dimensional round jet injected into an infinite space of the same fluid (a free homogeneous jet). As shown in Figure 2.4, the centerline jet velocity of a free homogeneous jet is expressed by (Weigel 1964, Onishi et al. 2003) by

$$
\frac{U}{U_{j}}=6.2 \frac{d_{j}}{X}
$$

where $U=$ centerline jet velocity at distance $X$ (see Figure 2.4)

$\mathrm{U}_{\mathrm{j}}=$ nozzle Jet velocity of a homogeneous free jet

$\mathrm{d}_{\mathrm{j}}=$ nozzle diameter

$X=$ downstream distance (the distance between the nozzle and a point of interest). 


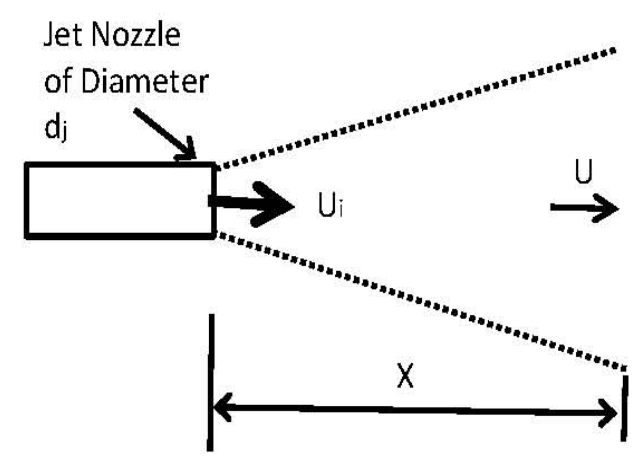

Figure 2.4. Flow Profile of a Homogeneous Free Jet

He assumed that the force acting on the solid surface, $\tau_{x}$, is equal to $\rho U^{2} / 2$. Assigning $X=E C R$ and the force, $\tau_{\mathrm{x}}$, equal to the yield stress, Poirier derived the ECR formula, Equation 2.14. He explained that the coefficient of 0.97 of Churnetski's ECR model (Equation 2.13) is smaller than his coefficient of 4.4 (Equation 2.14) possibly because of the friction caused by the tank wall in Churnetski's experiment.

Reshman et al. (2007) reported the following ECR model for the Savannah River Site application:

$$
\frac{E C R}{d_{j}}=C_{1} U_{j}\left(\frac{\rho_{L}}{2 g \tau_{y}}\right)^{0.5} \exp \left[-C_{2} \tan \left(\frac{1}{2 \theta}\right)\right]
$$

where $\mathrm{C}_{1}, \mathrm{C}_{2}=$ constants

$\mathrm{g}=$ gravitational acceleration

$\theta=$ jet angle

$\rho_{\mathrm{L}}=$ eroding solution density

$\tau_{\mathrm{y}}=$ yield stress.

The Savannah River Site researchers also developed several other ECR models, as discussed here. Through a half tank test with a simulant of $30 \mathrm{wt} \%$ of kaolin and $70 \mathrm{wt} \%$ water, the following ECR model, the Savannah River Site (SRS)-1 Model, was derived (Powell et al. 1997):

$$
E C R=0.045 d_{j} U_{j}
$$

For the full tank experiment with a simulant of $20 \mathrm{wt} \%$ kaolin and $80 \mathrm{wt} \%$ water, the following ECR model, the SRS-2 Model, was obtained:

$$
E C R=0.064 d_{j} U_{j}
$$

For the $1 / 12$-scale model experiment with $44 \mathrm{wt} \%, 49 \mathrm{wt} \%$, and $56 \mathrm{wt} \%$ kaolin, the third model, the SRS-3 Model, was developed as

$$
E C R=0.043 d_{j} U_{j}
$$


Oak Ridge National Laboratory derived the following ECR model, the ORNL-1 Model (Hylton et al. 1995):

$$
E C R=0.142 d_{j} U_{j}
$$

This equation is derived through a study of Melton Valley Storage Tanks at the Oak Ridge Site by using a kaolin simulant having the yield stress of $10 \mathrm{~Pa}$. Their solid layer strength, however, was too low to be applicable to the stored K-Basin sludge.

All these ECR models (Equations 2.17 through 2.20) use the length scale of $\mathrm{cm}$, and the jet velocity is in $\mathrm{cm} / \mathrm{s}$. These models are not a function of the solid layer strength (either yield strength or shear strength). It may be because their solid layer strength is relatively small (probably up to several thousands Pascal of shear strength) and that their variations among these tests to derive these equations are too narrow to examine the effects of the solid layer strength on the ECR. However, comparing these four equations indicates that the ECR becomes smaller as the kaolin concentrations increase; thus, the solid layer strength (e.g., shears strength or yield stress) increases.

The West Valley Site in New York also conducted a $1 / 6$-scale model testing with kaolin simulant to examine the performance of an impinging jet to mobilize solids for Tank 8D-2 (Powell et al. 1997). The in situ shear strength was reported to be $0.4 \sim 34.2 \mathrm{kPa}$. However, the shear strength value reported may not be accurate because kaolin with water may not be capable of producing a shear strength of tens of thousands of Pascal (Powell et al. 1997). Moreover, they did not report the values of the nozzle diameter, jet velocity, and ECR, so their study results cannot be used to evaluate the stored K-Basin sludge mobilization.

There are various other formulas (equivalent of the ECR formulas) in soil mechanics, hydraulics, and chemicals engineering disciplines (Bathija 1982, Mazurek et al. 2001). However, no required data (e.g., critical shear stress for erosion) were reported to be collected at the Hanford Site to be able to apply these models to the Hanford waste, as will be discussed in Section 5.

Besides the use of ECR models, many computer simulations were conducted to determine the pump jet mixing performance for the DSTs at the Hanford Site (Onishi and Recknagle 1997, Onishi et al. 2000, 2003). An example of the predicted ECR of two mixer pumps mobilizing sludge in a DST is shown in Figure 2.5, depicting a half of the tank (Onishi et al. 2003). 


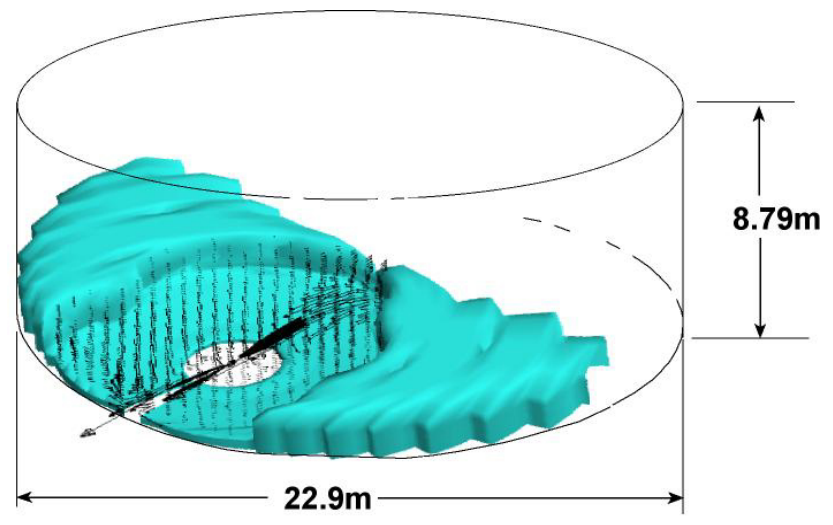

Figure 2.5. Predicted ECR of Pump Jet Mixing in a DST

Because some solids are dissolved (or precipitated) when they are mixed with other waste, water, or another liquid, the waste rheology of the supernatant, the slurry, and the solids layer as well as the solids concentrations would change. These changes affect the jet mixing performance. The effects of solid dissolution/precipitation and waste rheology changes on the pump jet mixing performance were evaluated by using the three-dimensional, time-dependent, ARIEL code. This code couples the waste chemical changes, rheology change, and slurry mixing to simulate these phenomena simultaneously (Onishi et al. 1999).

Low activity waste mixed with water by two pump jet mixers in a DST was examined by simulating waste chemistry and waste mixing simultaneously by the ARIEL code. The chemical reactions simulated by the ARIEL code in this case were

$$
\begin{aligned}
& \mathrm{Na}^{+}+\mathrm{NO}_{3}{ }^{-}=\mathrm{NaNO}_{3}(a q) \\
& \mathrm{Na}^{+}+\mathrm{NO}_{2}{ }^{-}=\mathrm{NaNO}_{2}(a q) \\
& \mathrm{Na}^{+}+\mathrm{NO}_{3}{ }^{-}=\mathrm{NaNO}_{3}(\mathrm{~s}) \\
& \mathrm{Na}^{+}+\mathrm{OH}^{-}=\mathrm{Na}^{+}+\mathrm{OH}^{-} \\
& 2 \mathrm{Na}^{+}+\mathrm{CO}_{3}{ }^{2-}+\mathrm{H}_{2} \mathrm{O}=\mathrm{Na}_{2} \mathrm{CO}_{3} \cdot \mathrm{H}_{2} \mathrm{O}(\mathrm{s}) \\
& 2 \mathrm{Na}^{+}+\mathrm{SO}_{4}{ }^{2-}=\mathrm{Na}_{2} \mathrm{SO}_{4}(\mathrm{~s}) \\
& \mathrm{Al}(\mathrm{OH})_{4}^{-}=\mathrm{Al}(\mathrm{OH})_{3}(\mathrm{~s})+\mathrm{OH}^{-}
\end{aligned}
$$

The model set-up and the predicted distribution of one of the solids, thermonatrite $\left[\mathrm{Na}_{2} \mathrm{CO}_{3} \cdot \mathrm{H}_{2} \mathrm{O}(\mathrm{s})\right]$, are shown in Figure 2.6. 

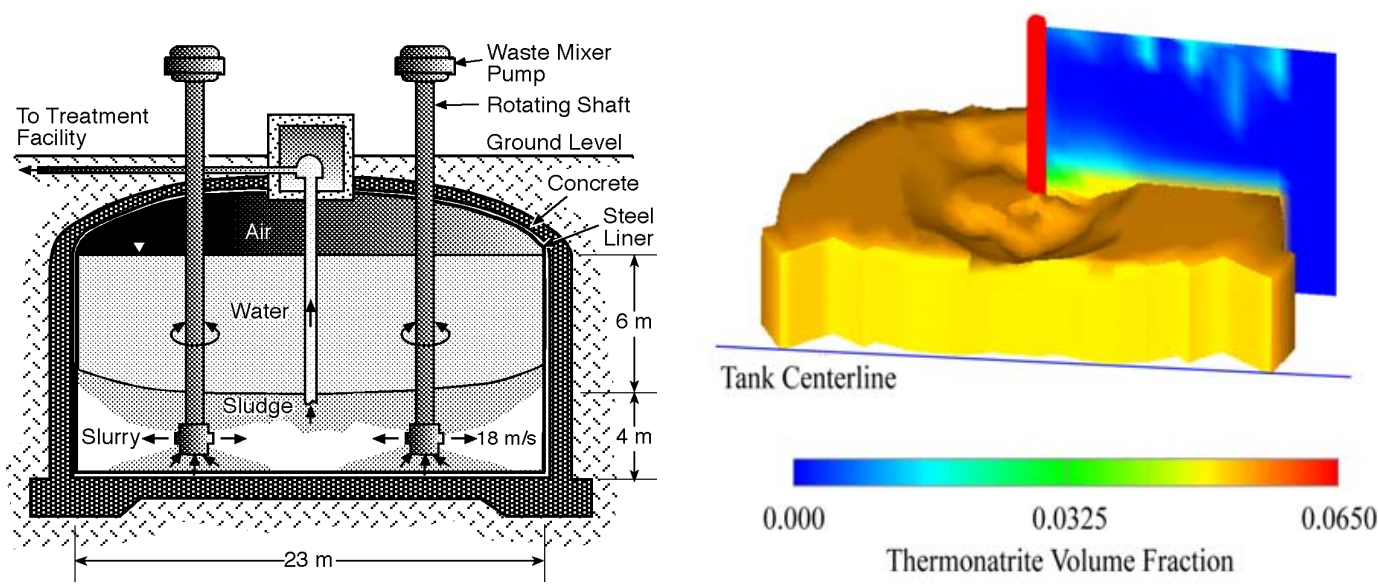

Figure 2.6. Predicted Pump Jet Mixing and Waste Chemical Reactions

\subsection{Applicability and Validation of the ECR Models to Hanford Waste}

As stated above, the Hanford Site uses the shear strength as a measure of the solid layer strength, while the Savannah River and the Oak ridge Sites use the yield stress of a Bingham fluid to represent the solid layer strength. Examine Poirier's ECR formula (Equation 2.14) here as an example.

Comparing Equation 2.14 with Powell-3 ECR model (Equation 2.3) indicates that

$$
\tau_{X}=\tau_{y}=2.15 \rho \tau_{S}^{0.92} \approx \tau_{S}
$$

However, the shear strength, $\tau_{\mathrm{S}}$, of the Hanford waste is usually a few orders of magnitude greater than the yield stress, $\tau_{\mathrm{y}}$ (Peloski et al. 2007). Thus, there is a potential applicability problem when these ECR models containing $\tau_{\mathrm{y}}$ developed with the Savannah River sludge are applied to the Hanford waste. However, if one considers the force acting on the solid layer, $\tau_{\mathrm{X}}$, to be the shear strength, $\tau_{\mathrm{S}}$, then Poirier's ECR model, Equation 2.14, is close to Powell's' ECR formula, Equation 2.4. Thus, the ECR models with yield stress (Equations 2.13 through 2.15) developed for the Savannah River waste were judged to not adequately represent the Hanford waste.

The actual performance of pump jet mixing in Hanford 241-SY-101 and 241-AZ-101 Tanks was determined by measuring the ECR in these tanks (Carlson et al. 2000, 2001). Thus, all of the ECR models listed above except Equations 2.13 through 2.16 were applied to these two tanks to compare predicted ECR values with measured ECR. This validation test was conducted to examine their applicability to the Hanford waste and select appropriate ECR models to determine values of the shear strength threshold of concern. Table 2.1 presents tank conditions used for the ECR model validation testing (Gauglitz et al. 2010, Carlson et al. 2000, 2001). 
Table 2.1. Hanford 241-SY-101 and 241-AZ-101 Test Conditions Used for the ECR Model Validation

\begin{tabular}{ccc}
\hline Tank Conditions & Hanford Tanks & \\
& 241-SY-101 & 241-AZ-101 \\
\hline Tank Diameter, $\mathrm{m}$ & 23 & 23 \\
Liquid Density, $\mathrm{kg} / \mathrm{m}^{3}$ & 1,500 & 1,220 \\
Liquid Viscosity, Pa-s & 0.006 & 0.002 \\
Solid Density, $\mathrm{kg} / \mathrm{m}^{3}$ & 2,300 & 1,840 \\
Solid Volume Fraction & 0.16 & 0.020 \\
Shear Strength, Pa & 730 & 1,770 \\
Slurry Density, $\mathrm{kg} / \mathrm{m}^{3}$ & 1,628 & 1,232 \\
Slurry Viscosity, Pa-s & 0.1 & 0.004 \\
Nozzle Diameter, cm & 6.6 & 15.2 \\
Nozzle Jet Velocity, $\mathrm{m} / \mathrm{s}$ & 21 & 18.3 \\
Measured ECR, $\mathrm{ft}$ & 30 & 37 \\
\hline
\end{tabular}

As shown in Table 2.1, the measured ECR values are 30 and 37 feet for the SY-101 and AZ-101 Tanks, respectively. Predicted ECR values and their comparisons are shown in Table 2.2 for the ECR models-Equations 2.1 through 2.12 and 2.17 through 2.20.

Table 2.2. Comparison of Predicted ECRs with Measured ECRs of Hanford Tanks 241-SY-101 and 241-AZ-101

\begin{tabular}{|c|c|c|c|c|}
\hline \multirow[b]{2}{*}{ ECR Models } & \multicolumn{2}{|c|}{$241 \mathrm{SY}-101$} & \multicolumn{2}{|c|}{ 241-AZ-101 } \\
\hline & $\begin{array}{c}\text { Predicted } \\
\text { ECR, } \\
\mathrm{ft}\end{array}$ & $\begin{array}{c}\text { Ratio of } \\
\text { Predicted to } \\
\text { Measured ECR } \\
\text { of } 30 \mathrm{ft}\end{array}$ & $\begin{array}{c}\text { Predicted } \\
\text { ECR, } \\
\mathrm{ft}\end{array}$ & $\begin{array}{l}\text { Ratio of } \\
\text { Predicted to } \\
\text { Measured } \\
\text { ECR of } 37 \mathrm{ft}\end{array}$ \\
\hline Crowe-1; Eqs. $2.5 \sim 2.8$ & 9.9 & 0.33 & 35.7 & 0.96 \\
\hline Crowe -2; Eqs. 2.5, $2.9 \sim 2.11$ & 16.5 & 0.55 & 37.1 & 1.00 \\
\hline Powell-1; Eq. 2.1 & 35.5 & 1.18 & 46.1 & 1.25 \\
\hline Powell-2; Eq. 2.2 & 20.3 & 0.68 & 22.5 & 0.61 \\
\hline Powell-3; Eq. 2.3 & 30.4 & 1.01 & 40.6 & 1.10 \\
\hline Powell-4; Eq. 2.4 & 22.8 & 0.76 & 30.4 & 0.82 \\
\hline Gauglitz; Eq. 2.12 & 37.7 & 1.26 & 43.8 & 1.18 \\
\hline SRS-1; Eq. 2.17 & 20.5 & 0.68 & 41.0 & 1.11 \\
\hline SRS-1; Eq. 2.18 & 29.1 & 0.97 & 58.4 & 1.58 \\
\hline SRS-1; Eq. 2.19 & 19.6 & 0.65 & 39.2 & 1.06 \\
\hline ORNL-1; Eq. 2.20 & 64.6 & 2.15 & 130 & 3.50 \\
\hline
\end{tabular}

The validation test with measured ECR values of these two Hanford tanks shows that The Powell-3 Model (Equation 2.3) best matches to the measured ECRs overall. The Crowe-2 Model (Equation 2.5 with Equations 2.9 through 2.11) predicted the AZ-101's ECR very well, but significantly underpredicted SY-101's ECR value. As expected, the Gauglitz Model (Equation 2.12) predictions reasonably match with these two tanks' measured ECR values because it was converted from of a dimensional form of the Powell-3 model to a non-dimensional form. 
The SRS-1, SRS-2, and SRS-3 Models (Equations 2.17 through 2.19) do not match with measured ECRs consistently. Moreover, these models do not have terms to present the strength of the settled solid layer, either with shear strength or yield stress. As stated previously, their ECR testing was with kaolin, and the test variation of the solid layer strength was relatively narrow to show its effects on the ECR. Current homogeneous simulant strength measurements being conducted by PNNL under another K-Basin evaluation task indicates that the shear strength of a kaolin-water mixture is up to several thousand Pascal. Because the stored K-Basin sludge is expected to have a shear strength of possibly up to $200 \mathrm{kPa}$, these three SRS models are not applicable to predict ECR values for the stored K-Basin sludge. This is also true for the Oak Ridge National Laboratory (ORNL)-1 Model (Equation 2.20), which does not have a term to represent the strength of the settled solid layer.

Thus, this validation test led to the conclusion that the Powell-3 Model is a reasonable choice among these ECR models to evaluate the shear strength threshold of concern for the stored K-Basin sludge. Its predictions should also be checked against those of the Crowe-2 Model because the latter was independently derived with Powell's scaled model ECR experiments, and it is in a non-dimensional form. For completeness, all ECR models presented here, except Equations 2.13 through 2.16, were applied to the assumed stored K-Basin sludge condition, as will be discussed in Section 3. 



\subsection{Shear Strength Threshold of Concern Evaluation}

Some of the stored heterogeneous cohesive sludge with high uranium content has "paste" and "chunks," and they self-cemented during the 28-month settling testing, as stated previously. The chunks have the estimated shear strength of $380 \sim 770 \mathrm{kPa}$ sludge (Delegard et al. 2005, Wells et al. 2009). High uranium content sludge samples subjected to hydrothermal treatment (e.g., $185^{\circ} \mathrm{C}, 10 \mathrm{~h}$ ) were observed to form agglomerates with a shear strength of up to $170 \mathrm{kPa}$ (Delegard et al. 2007).

In this section, the Powell-3 and Crowe-2 ECR models are applied to the stored K-Basin sludge with various shear strength values, assuming that water jet nozzles with 1-, 2-, 3-, and 3.5-mm diameters were located at 1, 5, 10, 17, and 25 inches from the STSC wall.

\subsection{Basis for Parameter in Strength Threshold Evaluation}

Water jets are expected to mobilize stored sludge for retrieval from the STSCs. The water jet system previously tested was the XAGO's HydroLance ${ }^{\mathrm{TM}}$ retrieval system. The XAGO system successfully mobilized a sludge simulant from an engineered container mock up with the shear strength of $8 \mathrm{kPa}$ at MASF with a remote operation with a 42-gpm jet discharge (CHPRC 2009).

The shear strength at which the sludge up to the container's wall can be retrieved is identified here as the shear strength threshold of concern, as stated previously. If the sludge shear strength is greater than the value of the threshold shear strength, a water-jet retrieval system will be unlikely to mobilize the sludge up to the container's wall. In this section, the values of the shear strength threshold of concern are determined and are compared with the range of possible shear strengths of the stored K-Basin sludge to assist in the development of an adequate water-jet retrieval method. To estimate the threshold shear strength, the ECR models of Powell, Crowe, and Gauglitz presented in Section 2 were used.

XAGO's HydroLance ${ }^{\mathrm{TM}}$ water jet system previously tested has two 1-mm, two 3-mm, and three 3.5-mm nozzles to inject water at 42 gpm from a high pressure pump to erode sludge (CHPRC 2009). It also produces a coandra flow induced by an 8 -gpm jet discharge for slurry suction. The XAGO system is shown in Figure 3.1 through Figure 3.3 (CHPRC 2009). 


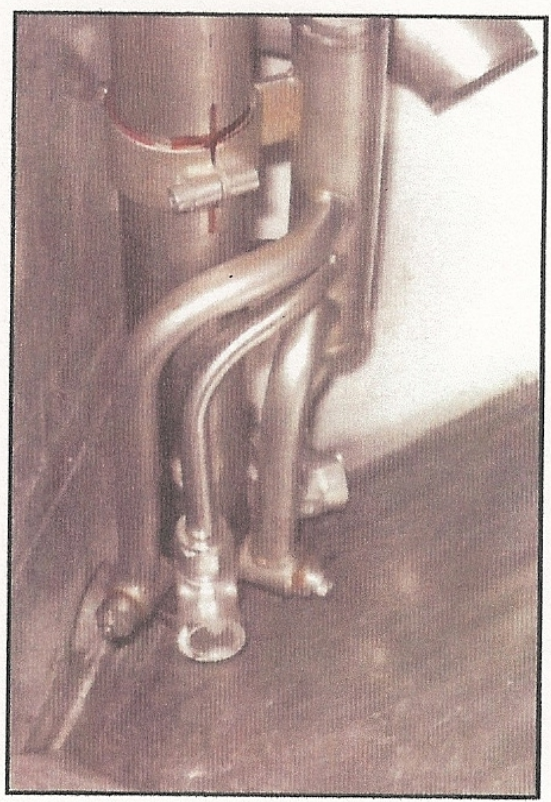

Figure 3.1. XAGO HydroLance ${ }^{\mathrm{TM}}$ Water Jet System (CHPRC 2009)

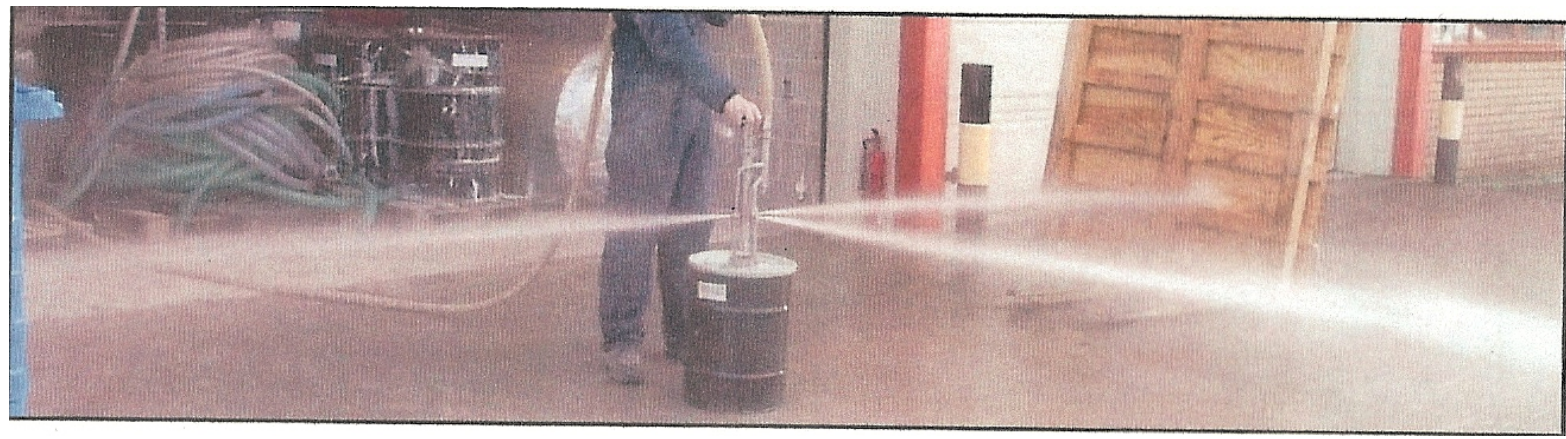

Figure 3.2. XAGO HydroLance ${ }^{\mathrm{TM}}$ High Pressure Nozzles in Air (CHPRC 2009) 


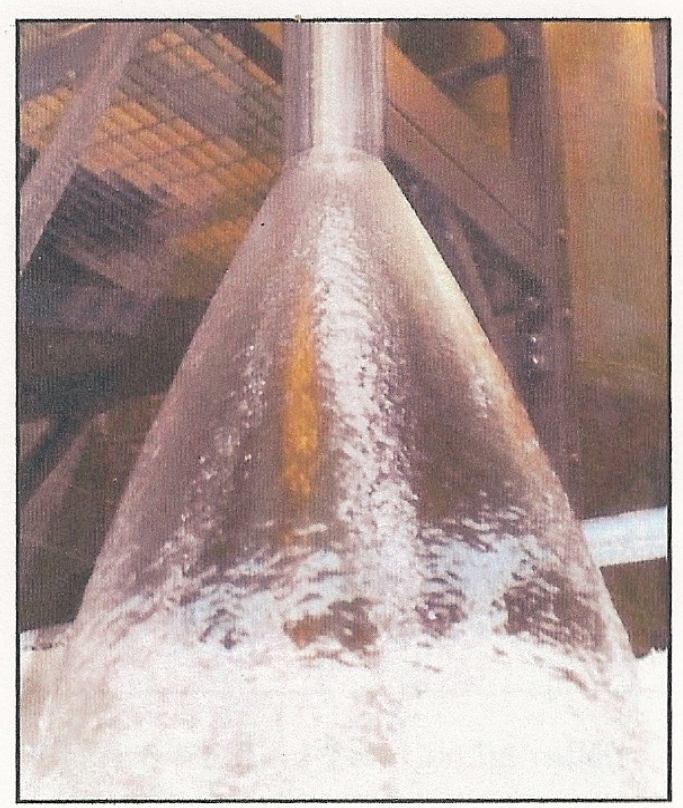

Figure 3.3. XAGO HydroLance ${ }^{\mathrm{TM}}$ Coandra Head in Air (CHPRC 2009)

Table 3.1 identifies the conditions used to represent the stored K-Basin sludge conditions and the water jet system input values used in the parametric evaluation of the strength threshold. 
Table 3.1. Parameters for Stored K-Basin Sludge and Water Jet System Conditions

\begin{tabular}{|c|c|c|}
\hline Items & Values & Basis \\
\hline Solid Density & $7,000 \mathrm{~kg} / \mathrm{m}^{3}$ & $\begin{array}{l}\text { Average of Design \& Safety Basis } \\
\text { KW Settler Sludge (Schmidt 2010) }\end{array}$ \\
\hline Water Jet Flow Rate & $42 \mathrm{gpm}$ & $\begin{array}{l}\text { XAGO Retrieval System } \\
\text { Operating Conditions CHPRC } \\
(2009)\end{array}$ \\
\hline High-Pressure Jet Nozzles & $\begin{array}{l}\text { Two nozzles of } 1-\mathrm{mm} \text { diameter } \\
\text { Two nozzles of } 3-\mathrm{mm} \text { diameter } \\
\text { Three nozzles of } 3.5-\mathrm{mm} \text { diameter }\end{array}$ & $\begin{array}{l}\text { XAGO System Preliminary } \\
\text { Design Configuration, CHPRC } \\
\text { (2009) }\end{array}$ \\
\hline High-Pressure Jet Nozzles & 2-mm diameter single nozzle & $\begin{array}{l}\text { Additional Mid-size Nozzle } \\
\text { Selected for Evaluation by } \\
\text { CHPRC and PNNL }\end{array}$ \\
\hline $\begin{array}{l}\text { Jet Nozzle Velocity } \\
\text { at } 42 \text { gpm }\end{array}$ & $\begin{array}{l}\text { A single } 1-\mathrm{mm} \text { nozzle }=3,370 \mathrm{~m} / \mathrm{s} \\
\text { A single } 2-\mathrm{mm} \text { nozzle }=843 \mathrm{~m} / \mathrm{s} \\
\text { A single } 3-\mathrm{mm} \text { nozzle }=375 \mathrm{~m} / \mathrm{s} \\
\text { A single } 3.5-\mathrm{mm} \text { nozzle }=275 \mathrm{~m} / \mathrm{s} \\
\text { All seven nozzles }=59 \mathrm{~m} / \mathrm{s} \text { (as used } \\
\text { in the XAGO system) }\end{array}$ & Calculated \\
\hline $\begin{array}{l}\text { Slurry Jet to Hit the Sludge } \\
\text { Layer } \\
\text { Solid volume fraction } \\
\text { Slurry density } \\
\text { Slurry viscosity }\end{array}$ & $\begin{array}{l}\text { (Used only for Crowe-1 Model) } \\
\qquad \begin{array}{c}0.2 \\
2,200 \mathrm{~kg} / \mathrm{m}^{3} \\
0.03 \mathrm{~Pa}-\mathrm{s}\end{array}\end{array}$ & $\begin{array}{l}\text { Assumed } \\
\text { Between KW Con \& KW Settler } \\
\text { Assumed }\end{array}$ \\
\hline $\begin{array}{c}\text { Required ECR } \\
\text { (the distance between the } \\
\text { nozzle position and an STSC } \\
\text { wall) }\end{array}$ & $\begin{array}{l}25 \text { inches } \\
17 \text { inches } \\
10 \text { inches } \\
5 \text { inches } \\
1 \text { inch }\end{array}$ & $\begin{array}{l}\text { STSC Design CHPRC (2009) } \\
\text { and Input from STP Engineering } \\
\text { Group }\end{array}$ \\
\hline $\begin{array}{c}\text { Shear Strength of the Stored } \\
\text { Sludge Layer }\end{array}$ & $\begin{array}{l}\text { (not used to estimate the value of } \\
\text { the shear strength threshold of } \\
\text { concern) } \\
\approx 30,000 \sim 200,000 \mathrm{~Pa}\end{array}$ & See Section 1.0 \\
\hline
\end{tabular}

To estimate the shear strength threshold of concern, the ECR equations presented in Section 2.2 need to be rearranged to solve for the shear strength with the given ECR value. For example, the Powell-3 ECR model (Equation 2.3) is rearranged to be 


$$
\tau_{S}=\left(4.0 \frac{U_{j} d_{j}}{E C R}\right)^{2.17}
$$

The Crowe-2 ECR Model (Equations 2.5 and 2.9 through 2.11) is rearranged to be

$$
\tau_{S}=\left(0.913 R_{e j}^{0.2} F_{D}^{0.194} \frac{d_{j}}{E C R}\right)^{5.78}\left(\rho_{L} U_{j}{ }^{2}\right)
$$

\subsection{Parametric Evaluation of Strength Threshold of Concern Using Powell-3 and the Crowe-2 ECR Models}

Estimated values of the shear strength threshold of concern are presented in Table 3.2 through Table 3.4 for using a single 1-, 2-, 3-, or 3.5-mm nozzle diameter at 42-gpm jet discharge. Table 3.7 through Table 3.9 show the estimated shear strength threshold of concern when all seven nozzles were used at $42 \mathrm{gpm}$. These nozzles are two of 1-mm nozzles, two of 3-mm nozzles, and three of 3.5-mm nozzles, the same as the current XAGO system. It was assumed that the jet velocities of all seven nozzles are the same when all of these nozzles are simultaneously used because the exit velocity of each nozzle was not available to this analysis.

Table 3.2. Estimated Shear Strength Threshold of Concern for the Stored K-Basin Sludge by Using a Single Nozzle (42 gpm) at Distance of 25 inches Away from the STSC Tank Wall

\begin{tabular}{ccccc}
\hline ECR & \multicolumn{4}{c}{ Shear Strength Threshold of Concern, kPa } \\
\cline { 2 - 5 } Models & 1-mm Nozzle & 2-mm Nozzle & 3-mm Nozzle & 3.5-mm Nozzle \\
\hline Crowe-1 & 175 & 39 & 16 & 11 \\
Crowe-2 & 661 & 146 & 60 & 43 \\
Powell-1 & 1,450 & 353 & 154 & 113 \\
Powell-2 & 80 & 29 & 16 & 12 \\
Powell-3 & 1,660 & 369 & 153 & 110 \\
Powell-4 & 890 & 198 & 82 & 59 \\
Gauglitz & 943 & 236 & 105 & 77 \\
\hline
\end{tabular}


Table 3.3. Estimated Shear Strength Threshold of Concern for the Stored K-Basin Sludge by Using a Single Nozzle (42 gpm) at Distance of 17 Inches Away from the STSC Tank Wall

\begin{tabular}{ccccc}
\hline ECR & \multicolumn{4}{c}{ Shear Strength Threshold of Concern, kPa } \\
\cline { 2 - 5 } Models & 1-mm Nozzle & 2-mm Nozzle & 3-mm Nozzle & 3.5-mm Nozzle \\
\hline Crowe-1 & 1,620 & 359 & 148 & 106 \\
Crowe-2 & 6138 & 1,355 & 560 & 400 \\
Powell-1 & 3,190 & 775 & 339 & 247 \\
Powell-2 & 143 & 51 & 28 & 22 \\
Powell-3 & 3,840 & 852 & 354 & 253 \\
Powell-4 & 2,060 & 457 & 189 & 136 \\
Gauglitz & 2,040 & 510 & 227 & 166 \\
\hline
\end{tabular}

Table 3.4. Estimated Shear Strength Threshold of Concern for the Stored K-Basin Sludge by Using a Single Nozzle (42 gpm) at Distance of 10 Inches Away from the STSC Tank Wall

\begin{tabular}{crrrr}
\hline ECR & \multicolumn{4}{c}{ Shear Strength Threshold of Concern, kPa } \\
\cline { 2 - 5 } Models & 1-mm Nozzle & 2-mm Nozzle & 3-mm Nozzle & 3.5-mm Nozzle \\
\hline Crowe-1 & 34,900 & 7,700 & 3,180 & 2,280 \\
Crowe-2 & 132,000 & 29,100 & 12,000 & 8,600 \\
Powell-1 & 9,410 & 2,290 & 1,000 & 730 \\
Powell-2 & 315 & 112 & 61 & 49 \\
Powell-3 & 12,100 & 2,700 & 1,120 & 800 \\
Powell-4 & 6,500 & 1,440 & 599 & 429 \\
Gauglitz & 5,890 & 1,470 & 655 & 481 \\
\hline
\end{tabular}

Table 3.5. Estimated Shear Strength Threshold of Concern for the Stored K-Basin Sludge by Using a Single Nozzle (42 gpm) at Distance of 5 Inches Away from the STSC Tank Wall

\begin{tabular}{ccccc}
\hline ECR & \multicolumn{4}{c}{ Shear Strength Threshold of Concern, kPa } \\
\cline { 2 - 5 } Models & 1-mm Nozzle & 2-mm Nozzle & 3-mm Nozzle & 3.5 -mm Nozzle \\
\hline Crowe-1 & $1.9 \times 10^{6}$ & $4.2 \times 10^{5}$ & $1.8 \times 10^{5}$ & $1.3 \times 10^{5}$ \\
Crowe-2 & $7.2 \times 10^{6}$ & $1.6 \times 10^{6}$ & $6.6 \times 10^{5}$ & $4.7 \times 10^{5}$ \\
Powell-1 & 39,000 & 9,400 & 4,100 & 3,000 \\
Powell-2 & 890 & 320 & 170 & 140 \\
Powell-3 & $5.6 \times 10^{4}$ & 12,000 & 5,000 & 3,600 \\
Powell-4 & 29,000 & 6,500 & 2,700 & 1,900 \\
Gauglitz & 24,000 & 5,900 & 2,600 & 1,900 \\
\hline
\end{tabular}


Table 3.6. Estimated Shear Strength Threshold of Concern for the Stored K-Basin Sludge by Using a Single Nozzle (42 gpm) at Distance of 1 Inch Away from the STSC Tank Wall

\begin{tabular}{ccccc}
\hline ECR & \multicolumn{4}{c}{ Shear Strength Threshold of Concern, kPa } \\
\cline { 2 - 5 } Models & 1-mm Nozzle & 2-mm Nozzle & 3 -mm Nozzle & 3.5 -mm Nozzle \\
\hline Crowe-1 & $2.1 \times 10^{10}$ & $4.6 \times 10^{9}$ & $1.9 \times 10^{9}$ & $1.4 \times 10^{9}$ \\
Crowe-2 & $7.9 \times 10^{10}$ & $1.8 \times 10^{10}$ & $7.3 \times 10^{9}$ & $5.2 \times 10^{9}$ \\
Powell-1 & $1.0 \times 10^{6}$ & $2.5 \times 10^{5}$ & $1.1 \times 10^{5}$ & $8.0 \times 10^{4}$ \\
Powell-2 & 9,700 & 3,500 & 1,900 & 1,500 \\
Powell-3 & $1.8 \times 10^{6}$ & $4.0 \times 10^{5}$ & $1.7 \times 10^{5}$ & $1.2 \times 10^{5}$ \\
Powell-4 & $9.6 \times 10^{5}$ & $2.1 \times 10^{5}$ & $8.9 \times 10^{4}$ & $6.3 \times 10^{4}$ \\
Gauglitz & $5.9 \times 10^{5}$ & $1.5 \times 10^{5}$ & $6.6 \times 10^{4}$ & $4.8 \times 10^{4}$ \\
\hline
\end{tabular}

Table 3.7. Estimated Shear Strength Threshold of Concern for the Stored K-Basin Sludge by Using All Seven Nozzles (42 gpm) of the XAGO system at Distance of 25 Inches Away from the STSC Tank Wall

\begin{tabular}{cccc}
\hline ECR & \multicolumn{3}{c}{ Shear Strength Threshold of Concern, kPa } \\
\cline { 2 - 4 } Models & 1 -mm Nozzle & 3 -mm Nozzle & 3.5 -mm Nozzle \\
\hline Crowe-1 & $5 \times 10^{-6}$ & $6 \times 10^{-3}$ & $2 \times 10^{-2}$ \\
Crowe-2 & $2 \times 10^{-5}$ & $2 \times 10^{-2}$ & $6 \times 10^{-2}$ \\
Powell-1 & 0.4 & 3.6 & 4.9 \\
Powell-2 & 0.2 & 1.0 & 1.3 \\
Powell-3 & 0.3 & 2.8 & 3.9 \\
Powell-4 & 0.1 & 1.5 & 2.1 \\
Gauglitz & 0.3 & 2.6 & 3.6 \\
\hline
\end{tabular}

Table 3.8. Estimated Shear Strength Threshold of Concern for the Stored K-Basin Sludge by Using All Seven Nozzles (42 gpm) of the XAGO system at Distance of 17 Inches Away from the STSC Tank Wall

\begin{tabular}{cccc}
\hline \multirow{2}{*}{ ECR } & \multicolumn{3}{c}{ Shear Strength Threshold of Concern, $\mathrm{kPa}$} \\
\cline { 2 - 4 } Models & $1-\mathrm{mm}$ Nozzle & 3 -mm Nozzle & 3.5 -mm Nozzle \\
\hline Crowe-1 & $5 \times 10^{-5}$ & $5 \times 10^{-2}$ & 0.2 \\
Crowe-2 & $2 \times 10^{-4}$ & 0.2 & 0.6 \\
Powell-1 & 0.8 & 7.9 & 10.8 \\
Powell-2 & 0.3 & 1.8 & 2.3 \\
Powell-3 & 0.6 & 6.5 & 9.1 \\
Powell-4 & 0.3 & 3.5 & 4.9 \\
Gauglitz & 0.6 & 5.7 & 7.8 \\
\hline
\end{tabular}


Table 3.9. Estimated Shear Strength Threshold of Concern for the Stored K-Basin Sludge by Using All Seven Nozzles (42 gpm) of the XAGO system at Distance of 10 Inches Away from the STSC Tank Wall

\begin{tabular}{cccc}
\hline ECR & \multicolumn{3}{c}{ Shear Strength Threshold of Concern, $\mathrm{kPa}$} \\
\cline { 2 - 4 } Models & 1-mm Nozzle & 3-mm Nozzle & 3.5-mm Nozzle \\
\hline Crowe-1 & $1 \times 10^{-3}$ & 1.2 & 3.2 \\
Crowe-2 & $4 \times 10^{-3}$ & 4.6 & 12.2 \\
Powell-1 & 2.5 & 23.4 & 32.0 \\
Powell-2 & 0.8 & 3.9 & 5.0 \\
Powell-3 & 1.9 & 20.6 & 28.7 \\
Powell-4 & 1.0 & 11.0 & 15.4 \\
Gauglitz & 1.8 & 16.5 & 22.4 \\
\hline
\end{tabular}

Table 3.10. Estimated Shear Strength Threshold of Concern for the Stored K-Basin Sludge by Using All Seven Nozzles (42 gpm) at Distance of 5 Inches Away from the STSC Tank Wall

\begin{tabular}{cccc}
\hline ECR & \multicolumn{3}{c}{ Shear Strength Threshold of Concern, $\mathrm{kPa}$} \\
\cline { 2 - 4 } Models & 1-mm Nozzle & 3-mm Nozzle & 3.5-mm Nozzle \\
\hline Crowe-1 & 0.06 & 66 & 180 \\
Crowe-2 & 0.23 & 250 & 670 \\
Powell-1 & 10 & 96 & 130 \\
Powell-2 & 2.2 & 11 & 14 \\
Powell-3 & 8.5 & 93 & 130 \\
Powell-4 & 4.6 & 50 & 69 \\
Gauglitz & 7.3 & 66 & 90 \\
\hline
\end{tabular}

Table 3.11. Estimated Shear Strength Threshold of Concern for the Stored K-Basin Sludge by Using All Seven Nozzles (42 gpm) at Distance of 1 Inch Away from the STSC Tank Wall

\begin{tabular}{cccc}
\hline ECR & \multicolumn{3}{c}{ Shear Strength Threshold of Concern, kPa } \\
\cline { 2 - 4 } Models & 1-mm Nozzle & 3 -mm Nozzle & 3.5 -mm Nozzle \\
\hline Crowe-1 & 660 & $7.3 \times 10^{5}$ & $2.0 \times 10^{6}$ \\
Crowe-2 & 2,500 & $2.8 \times 10^{6}$ & $7.4 \times 10^{6}$ \\
Powell-1 & 270 & 2,600 & 3,500 \\
Powell-2 & 24 & 120 & 150 \\
Powell-3 & 280 & 3,000 & 4,300 \\
Powell-4 & 150 & 1,600 & 2,300 \\
Gauglitz & 180 & 1,600 & 2,200 \\
\hline
\end{tabular}

The predicted shear strength of the threshold of concern varies significantly from one ECR model to another, as discussed in Section 2. As stated previously (see Table 2.2), the Powell-3 and the Crowe-2 ECR models are expected to be more accurate than other ECR models. Predictions of the shear strength of threshold of concern by these two models are summarized in Table 3.12. 
Table 3.12. Shear Strength Threshold of Concern for Stored K-Bain Sludge at 42-gpm Jet Discharge Predicted by the Powell-3 and Crowe-2 ECR Models

\begin{tabular}{|c|c|c|c|c|c|c|}
\hline \multirow[b]{2}{*}{$\begin{array}{l}\text { Distance to } \\
\text { Erode, Inches }\end{array}$} & \multirow[b]{2}{*}{$\begin{array}{c}\text { No. of } \\
\text { Nozzles }\end{array}$} & \multirow[b]{2}{*}{ Model } & \multicolumn{4}{|c|}{ Shear Strength Threshold of Concern, $\mathrm{kPa}$} \\
\hline & & & $\begin{array}{c}1-\mathrm{mm} \\
\text { Nozzle }\end{array}$ & $\begin{array}{c}2-\mathrm{mm} \\
\text { Nozzle }\end{array}$ & 3-mm Nozzle & 3.5-mm Nozzle \\
\hline \multirow{4}{*}{25} & \multirow{2}{*}{1} & Powell-3 & 1,660 & 369 & 153 & 110 \\
\hline & & Crowe- 2 & 661 & 146 & 60 & 43 \\
\hline & \multirow{2}{*}{7} & Powell-3 & 0.3 & - & 2.8 & 3.9 \\
\hline & & Crowe-2 & $2 \times 10^{-5}$ & - & $2 \times 10^{-2}$ & $6 \times 10^{-2}$ \\
\hline \multirow{4}{*}{17} & \multirow{2}{*}{1} & Powell-3 & 3,840 & 852 & 354 & 253 \\
\hline & & Crowe-2 & 6140 & 1,360 & 560 & 400 \\
\hline & \multirow{2}{*}{7} & Powell-3 & 0.6 & - & 6.5 & 9.1 \\
\hline & & Crowe-2 & $2 \times 10^{-4}$ & - & 0.2 & 0.6 \\
\hline \multirow{4}{*}{10} & \multirow{2}{*}{1} & Powell-3 & 12,100 & 2,700 & 1,120 & 800 \\
\hline & & Crowe-2 & 132,000 & 29,100 & 12,000 & 8,600 \\
\hline & \multirow{2}{*}{7} & Powell-3 & 1.9 & - & 21 & $0 \quad 29$ \\
\hline & & Crowe-2 & $4 \times 10^{-3}$ & - & 4.6 & o 12 \\
\hline \multirow{4}{*}{5} & \multirow{2}{*}{1} & Powell-3 & $5.5 \times 10^{4}$ & 12,000 & 5,000 & 3,600 \\
\hline & & Crowe- 2 & $7.2 \times 10^{6}$ & $1.6 \times 10^{6}$ & $6.6 \times 10^{5}$ & $4.7 \times 10^{5}$ \\
\hline & \multirow{2}{*}{7} & Powell-3 & 9 & - & 93 & 130 \\
\hline & & Crowe-2 & 0.2 & - & 250 & 670 \\
\hline \multirow{4}{*}{1} & \multirow{2}{*}{1} & Powell-3 & $1.8 \times 10^{6}$ & $4.0 \times 10^{5}$ & $1.7 \times 10^{5}$ & $1.2 \times 10^{5}$ \\
\hline & & Crowe-2 & $7.9 \times 10^{10}$ & $1.7 \times 10^{10}$ & $7.3 \times 10^{9}$ & $5.2 \times 10^{9}$ \\
\hline & \multirow{2}{*}{7} & Powell-3 & 280 & - & 3,000 & 4,300 \\
\hline & & Crowe- 2 & $2.5 \times 10^{3}$ & - & $2.8 \times 10^{6}$ & $7.4 \times 10^{3}$ \\
\hline Color Legend & \multicolumn{6}{|c|}{$\begin{array}{l}\text { No Problem Predicted: Threshold }>200 \mathrm{KPA} \text {; Sludge strength expected to be less than } 200 \mathrm{kPa} \text {. } \\
\text { Caution: Threshold } 30 \text { to } 200 \mathrm{kPa} \text {, some agglomerates of sludge observed in this region. } \\
\text { Significant Concern: Threshold }<30 \mathrm{kPa} \text {, some stored sludge likely to be found at this strength. }\end{array}$} \\
\hline
\end{tabular}

To examine Table 3.12, the variations of the jet velocity and the width with the downstream distance need to be considered. The injected water jet would mix with sludge and liquid in the STSC to dilute itself and would increase its width, resulting in reduced jet velocity, according to Equation 2.15 of the jet centerline velocity. As stated in Section 2, this equation is for a homogeneous free jet, and the variation of the jet velocity in a STSC may be different from that expressed by this equation. Table 3.13 shows the centerline jet velocities estimated by Equation 2.15 and jet widths at $0,1,5,10,17$, and 25 inches downstream from 1-, 2-, 3-, and 3.5-mm nozzles. 
Table 3.13. Calculated Jet Velocity and Width at $0,1,5,10,17$, and 25 Inches Downstream at a Discharge Rate of 42 gpm

\begin{tabular}{|c|c|c|c|c|c|c|c|}
\hline \multirow{2}{*}{$\begin{array}{c}\text { Nozzle } \\
\text { Diameter, } \\
\mathrm{mm}\end{array}$} & \multirow{2}{*}{$\begin{array}{c}\text { Estimated Jet } \\
\text { Velocity and } \\
\text { Width }\end{array}$} & \multicolumn{6}{|c|}{ Downstream Distance, inches } \\
\hline & & 0 & 1 & 5 & 10 & 17 & 25 \\
\hline \multirow{2}{*}{$1 \mathrm{~mm}$} & Velocity, $\mathrm{m} / \mathrm{s}$ & 3,370 & 820 & 170 & 83 & 48 & 33 \\
\hline & Width, inches & 0.039 & 0.44 & 2.0 & 4.0 & 6.8 & 10 \\
\hline \multirow{2}{*}{$2 \mathrm{~mm}$} & Velocity, $\mathrm{m} / \mathrm{s}$ & 843 & 410 & 82 & 41 & 24 & 16 \\
\hline & Width, inches & 0.079 & 0.48 & 2.1 & 4.1 & 6.9 & 10 \\
\hline \multirow{2}{*}{$3 \mathrm{~mm}$} & Velocity, $\mathrm{m} / \mathrm{s}$ & 375 & 280 & 55 & 28 & 16 & 11 \\
\hline & Width, inches & 0.12 & 0.52 & 2.1 & 4.1 & 6.9 & 10 \\
\hline \multirow{2}{*}{$3.5 \mathrm{~mm}$} & Velocity, $\mathrm{m} / \mathrm{s}$ & 275 & 240 & 47 & 24 & 14 & 9.4 \\
\hline & Width, inches & 0.14 & 0.54 & 2.1 & 4.1 & 6.9 & 10 \\
\hline
\end{tabular}

As shown in Table 3.13, the centerline (maximum) jet velocities at 1, 5, 10, 17, and 25 inches from the $3.5-\mathrm{mm}$ nozzle would be approximately $240,47,24,14$, and $9.4 \mathrm{~m} / \mathrm{s}$, respectively, as compared to the jet velocity of $275 \mathrm{~m} / \mathrm{s}$ at the nozzle. Furthermore, the jet widths at these five downstream locations are expected to be $0.54,2.1,4.1,6.9$, and 10 inches wide, respectively. The jet velocity reduction with the downstream distance is even more pronounced for the smaller nozzle diameters at the given downstream location. Thus, as the jet approaches the STSC wall, the original narrow, high-speed jet is significantly slowed down and widely spreads, reducing its sludge erosion capability significantly. This is clearly indicated by Table 3.12 .

Although there are some variations between the Powell-3 and Crowe-2 ECR models, their basic statements in Table 3.12 are very similar. Assuming that the expected stored K-Basin sludge has a shear strength between 30 and $200 \mathrm{kPa}$, Table 3.12 indicates the following:

- When a single nozzle is used at a 42-gpm jet discharge rate, jets injected from the 1-mm and probably the 2-mm nozzle are sufficiently strong to mobilize the stored K-Basin sludge up to 25 inches away.

- When a single $3-\mathrm{mm}$ or $3.5-\mathrm{mm}$ nozzle is used at $42 \mathrm{gpm}$, there is a potential that stored sludge may not be mobilized up to 25 inches.

- If any of these single nozzles are located within 17 inches from the STSC tank wall, the stored K-Basin sludge would be eroded to the tank wall at a jet discharge rate of $42 \mathrm{gpm}$.

- When all seven nozzles of the XAGO water jet system are used at a total jet discharge of $42 \mathrm{gpm}$, it is unlikely that these jets would mobilize all of the sludge with a shear strength of up to $200 \mathrm{kPa}$ in the STSCs, unless the nozzles are located within 1 inch from the STSC wall. However, one needs to make sure that this jet would not erode the STSC wall, as will be evaluated in Section 4. The XAGO system would erode some softer sludge up to the STSC wall, even if the nozzles are located further away from the STSC wall. For example, the Powell-3 model predicts that the XAGO system would erode the sludge with a shear strength of $3 \sim 4 \mathrm{kPa}$ by 3 - and 3.5-mm nozzles located at 25 inches from the wall.

As shown in Table 3.1, the jet nozzle velocity is very high at a 42-gpm jet discharge rate when only a single nozzle is used. In fact, as will be discussed in Section 4, the 1-mm-diameter jet injected at 
25 inches from the wall should operate for less than 4 hours hitting the same point on the STSC tank wall to prevent $10 \%$ of the tank wall from being eroded by this jet. The 3- and 5-mm-diameter jets would not erode $10 \%$ of the tank wall at their velocities at this distance even when a jet impinges the same wall location for 96 hours.

Any potential use of the water jet retrieval system must be in such a way that the water jet would not erode the container's wall by more than $10 \%$ of the wall thickness. The potential tank wall erosion by an impinging jet is presented Section 4. As will be discussed, a wall erosion model used here was developed at the jet velocity of 12 and $14 \mathrm{~m} / \mathrm{s}$ through a 1.049-in. nozzle placed at 1.574 inches from the steel surface. These wall erosion test conditions are not similar to those expected of a K-Basin water jet system. The applicability of the wall erosion model to the stored K-Basin condition and its accuracy is not certain.

The approximate pressure requirements at the single nozzle would possibly be $52,000,11,000$, and 5,500 psi for 2-, 3-, and 3.5-mm nozzles, respectively at $42 \mathrm{gpm}$. Note that the shear strength threshold of concern value for the 1-mm nozzle is $1,670 \mathrm{kPa}$ based on the Powell-3 model. Thus, a much smaller jet discharge is sufficient to erode the 200-kPa sludge up to 25 inches. As presented later in this section, the required discharge for this case is only $16 \mathrm{gpm}$. The use of a 1-mm nozzle located at 25 inches from the STSC wall would require a pressure too high to be realistic for its use at this distance. When all seven nozzles at 42-gpm jet discharge were used, the XAGO system had a pressure of 377 psi (CHPRC 2009).

There are several water jet manufacturers, including Flow International Inc. in Kent, Washington and MC Machinery System, Inc. For example, Flow International manufactures various high-speed, water-jet systems for cutting materials from soft foods and corrugated cardboard with pure water jets to 8-in.-thick steel and titanium with abrasive water jets through $0.5-\mathrm{mm}$ to $1.3-\mathrm{mm}$ nozzles. The nozzle diameters of the pure water jets are 0.1 to $0.25 \mathrm{~mm}$, while the nozzle diameters of abrasive jets are 0.5 to $1.3 \mathrm{~mm}$. The jet velocities are approximately from about $1,000 \mathrm{~m} / \mathrm{s}$ to $1,400 \mathrm{~m} / \mathrm{s}$. Their pressure varies from 55,000 to 87,000 psi. These water jets can cut materials up to 10 inches in air or underwater. High-pressure pumps are also manufactured that generate pressures of 40,000 psi to 94,000 psi. Mitsubishi water jets of MC Machinery System also cut similar materials, e.g., foods, foam, rubber, plastic, stainless steel, etc., with a nozzle jet velocity of approximately $1,000 \mathrm{~m} / \mathrm{s}$. However, these water jet systems are not designed for a radiation environment and have small jet discharges.

As shown in Table 3.12, when a single nozzle is used, a jet at a smaller flow rate than 42 gpm may still mobilize stored K-Basin sludge, especially when the nozzle is located within 17 inches from the tank wall, as discussed below. If a jet is located at the distance of seven nozzle diameters away from the solid surface, the eroded hole would be deep and narrow. When a jet nozzle is located more than seven times the nozzle diameter, an eroded hole would be shallow and wide. The optimal distance between the nozzle and the settled solid layer is usually about 8 times the nozzle diameter (Moore and Masch 1962, Mazurek et al. 2001).

As also will be discussed in Section 5, solids erosion occurs when the shear stress of the flow acting on the surface of the solid layer is more than the critical shear stress for erosion (Krone 1965, 1993, Partheniades 1962, 1993, Onishi et al. 1993). The critical shear stress for erosion is much smaller than the shear strength. As shown in Figure 3.4, the former can be three orders of magnitude smaller than the shear strength (Dunn 1959). Thus, the sludge would be eroded by a jet, even if the jet force exerting on the sludge is less than the shear strength. However, its rate of erosion would be much smaller than that 
obtained with a jet that overcomes the shear strength of the sludge, as will be briefly discussed in Section 5.

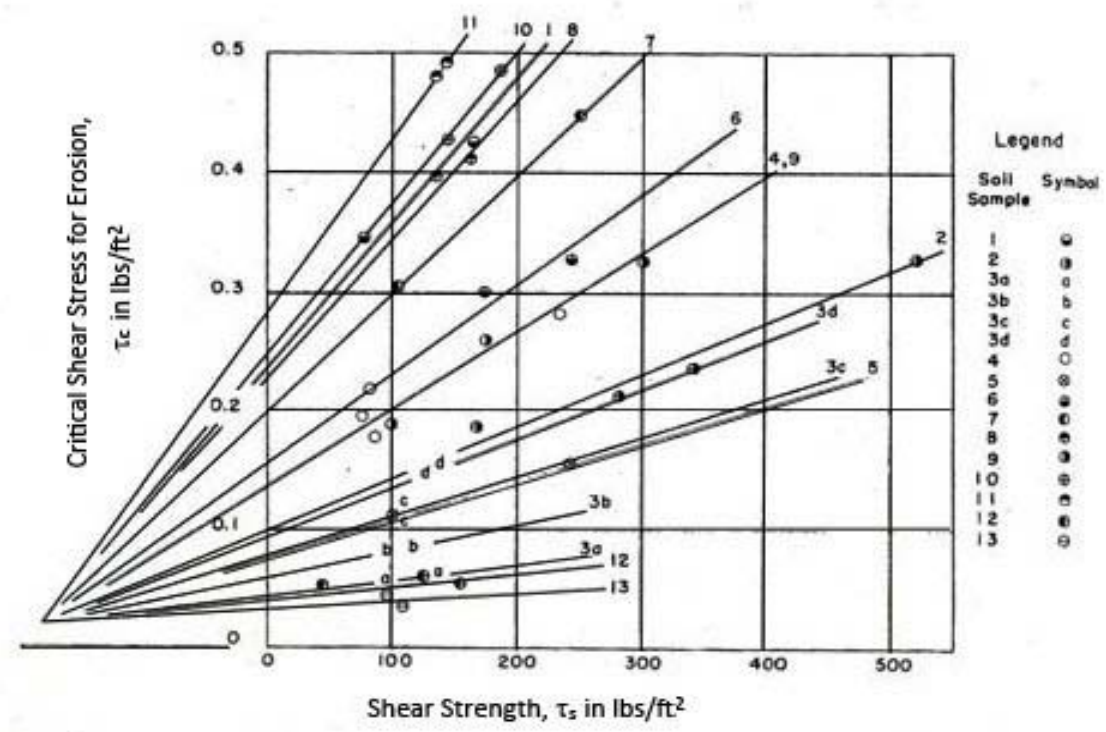

Figure 3.4. Critical Shear Stress for Erosion vs. Shear strength of Soil

Moreover, when the sludge consists of heterogeneous materials with different shear strengths, the whole heterogeneous solid layer may be mobilized when a material forming a weak bond of the heterogeneous sludge is eroded by a small-diameter, impinging jet (Summers 1995). This is especially true if cracks exist in solid materials.

\subsection{Further Assessment of Jet Erosion Using Powell-3 ECR Model}

The Powell-3 ECR model (Equation 2.3) was further used here to explore a wide range of conditions to potentially assist the development of an optimal jet retrieval system for the stored K-Basin sludge, as will be discussed below.

Figure 3.5 shows the estimated shear strength of concern vs. the jet discharge when a single 1-, 2-, 3-, or 3.5-mm nozzle is used and is located at 25 inches away from the STSC tank wall. This figure indicates that the larger the jet discharge, the larger the shear strength threshold of concern, as expected. At the given jet discharge, as the nozzle diameter decreases, the shear strength threshold of concern increases. However, the smaller the nozzle diameter, the greater the required pressure at the nozzle exits. Thus, one needs to balance the required value of the shear strength threshold of concern and the required pressure.

The higher the pressure, the more efficiently a jet can break a material. However, for a given jet flow rate, neither the highest pressure with the smallest nozzle diameter, nor the lower pressure with the largest nozzle would break a material the most, but the best results would be produced by some intermediate combination (Summers 1995). 
It should also be noted that an impulsive water jet needs about $1 / 3$ or less energy required to break the material than a steady jet (Summers 1995). These observations must be taken into account when optimizing a water jet retrieval system.

Nozzles of 2-, 3-, and 3.5-mm need jet discharges of 32, 48, and $55 \mathrm{gpm}$, respectively, to erode stored K-Basin sludge with 200-kPa shear strength, as shown in Figure 3.5. Thus, without accounting for the nozzle pressure losses, the required pressures at these nozzle exits are approximately 30,000,13,000, and 9,400 psi, respectively. The use of a single 1-mm nozzle needs $16 \mathrm{gpm}$ of the jet discharge. The pressure requirement for this case is too high to be realistic for its use, when a 1-mm nozzle jet needs to erode 25 inches of the stored K-Basin sludge with $200-\mathrm{kPa}$ shear strength.

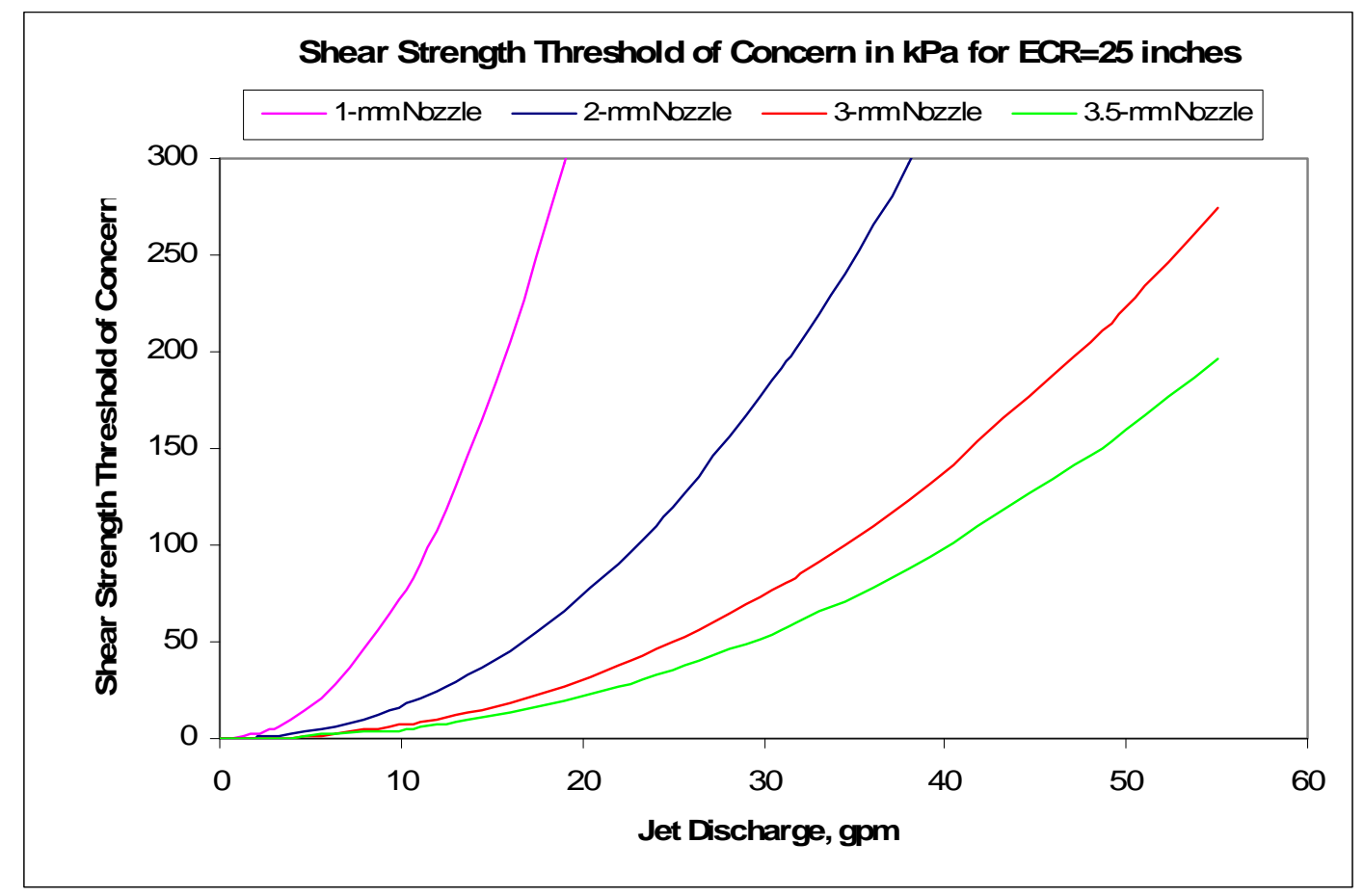

Figure 3.5. Shear Strength Threshold of Concern vs. Discharge of a Single Jet Located 25 Inches Away from the STSC Tank Wall

When these nozzles are placed 17 inches from the tank wall, the shear strength threshold of concern is increased, thus reducing the required jet discharge, as shown in Figure 3.6.

This figure shows that the 1-, 2-, 3-, and 3.5-mm nozzles located 17 inches from the tank wall need a jet discharge of 11, 22, 32, and 38 gpm to erode stored K-Basin sludge with 200-kPa shear strength. Thus, without considering the nozzle pressure loss, the required pressure at the nozzle is approximately $57,000,14,000,5,900$, and 4,500 psi, respectively. 


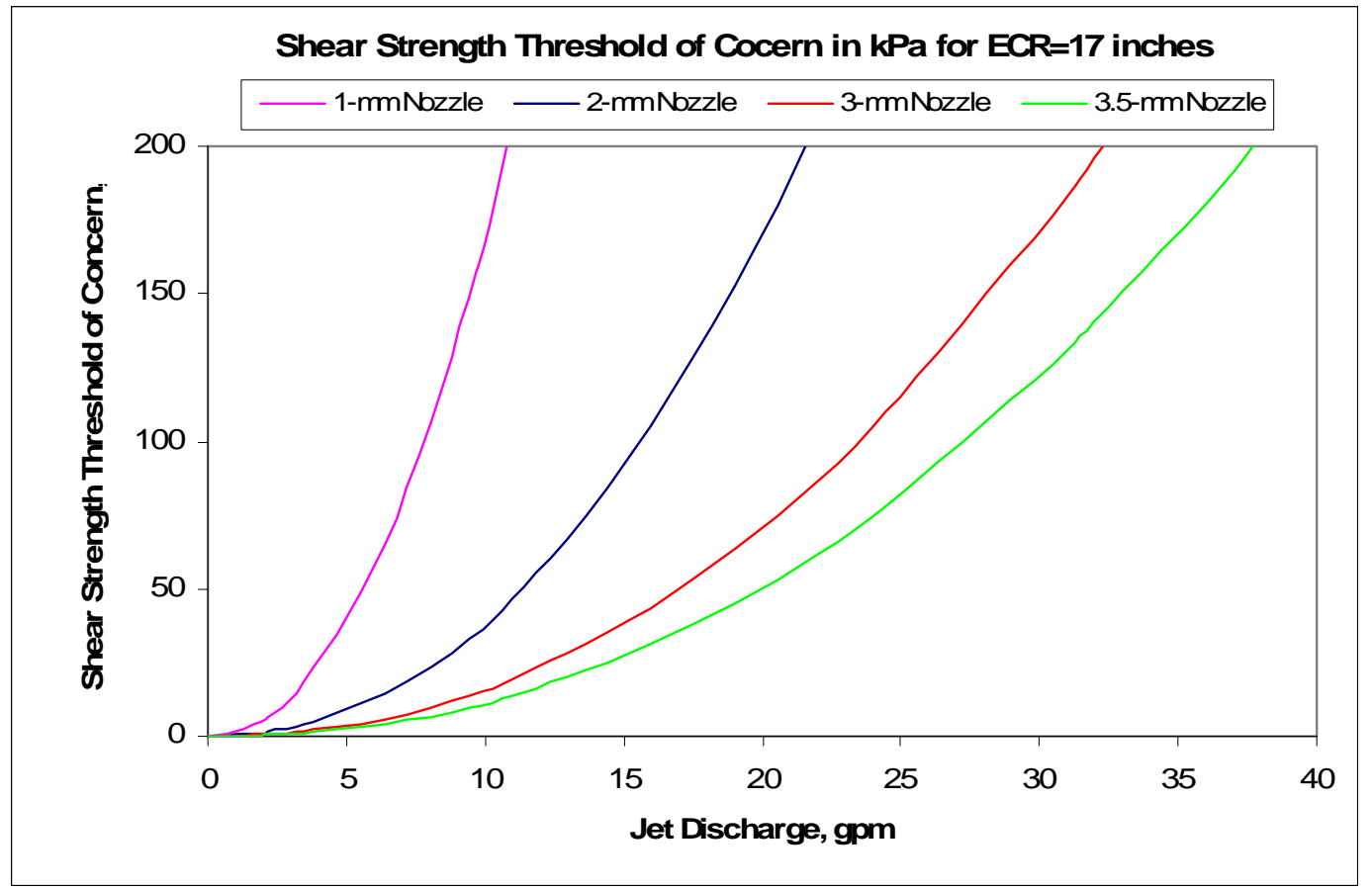

Figure 3.6. Shear Strength Threshold of Concern vs. Discharge of a Single Jet Located 17 Inches Away from the STSC Tank Wall

When these nozzles are placed 10 inches from the tank wall, the shear strength threshold of concern is further increased, thus significantly reducing the required jet discharge, as shown in Figure 3.7.

This figure shows that the 1-, 2-. 3-, and 3.5-mm nozzles located 10 inches from the tank wall need a jet discharge of $6.4,13,19$, and 22 gpm to erode the stored K-Basin sludge with 200-kPa shear strength to the tank wall. Thus, without considering the nozzle pressure loss, the required pressure at the nozzle is approximately $19,000,4,900,2,100$, and $1,500 \mathrm{psi}$, respectively. 


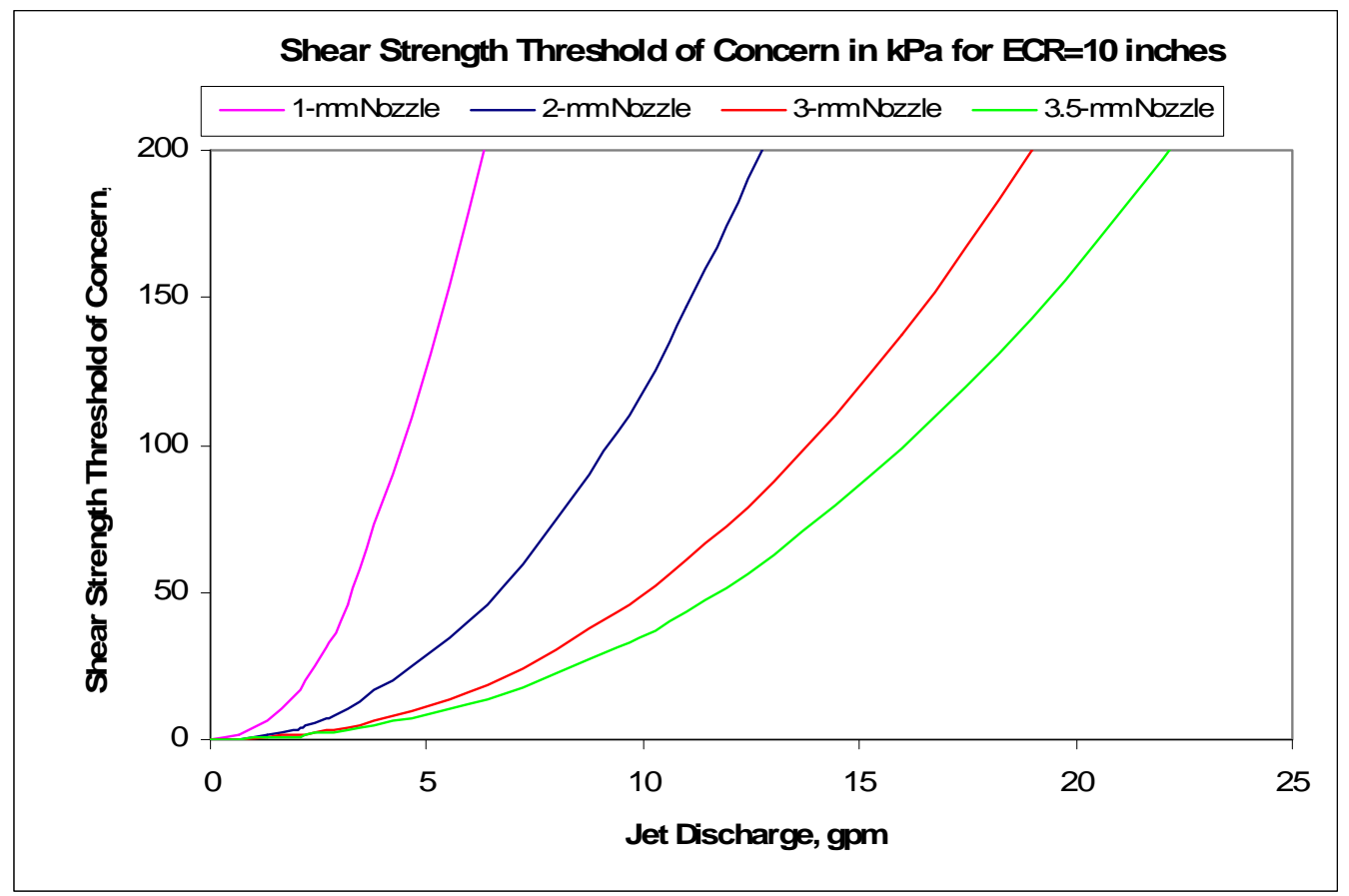

Figure 3.7. Estimated Shear Strength Threshold of Concern vs. Discharge of a Single Jet Located 10 Inches Away from the STSC Tank Wall

When these nozzles are placed 5 inches from the tank wall, the shear strength threshold of concern is further increased, thus significantly reducing the required jet discharge, as shown in Figure 3.7.

This figure shows that the 1-, 2-. 3-, and 3.5-mm nozzles located 5 inches from the tank wall need a jet discharge of 3.2,6.4, 9.4, and $11 \mathrm{gpm}$ to erode the stored K-Basin sludge with 200-kPa shear strength to the tank wall. Thus, without considering the nozzle pressure loss, the required pressure at the nozzle is approximately 4,800, 1,200, 510, and 380 psi, respectively. 


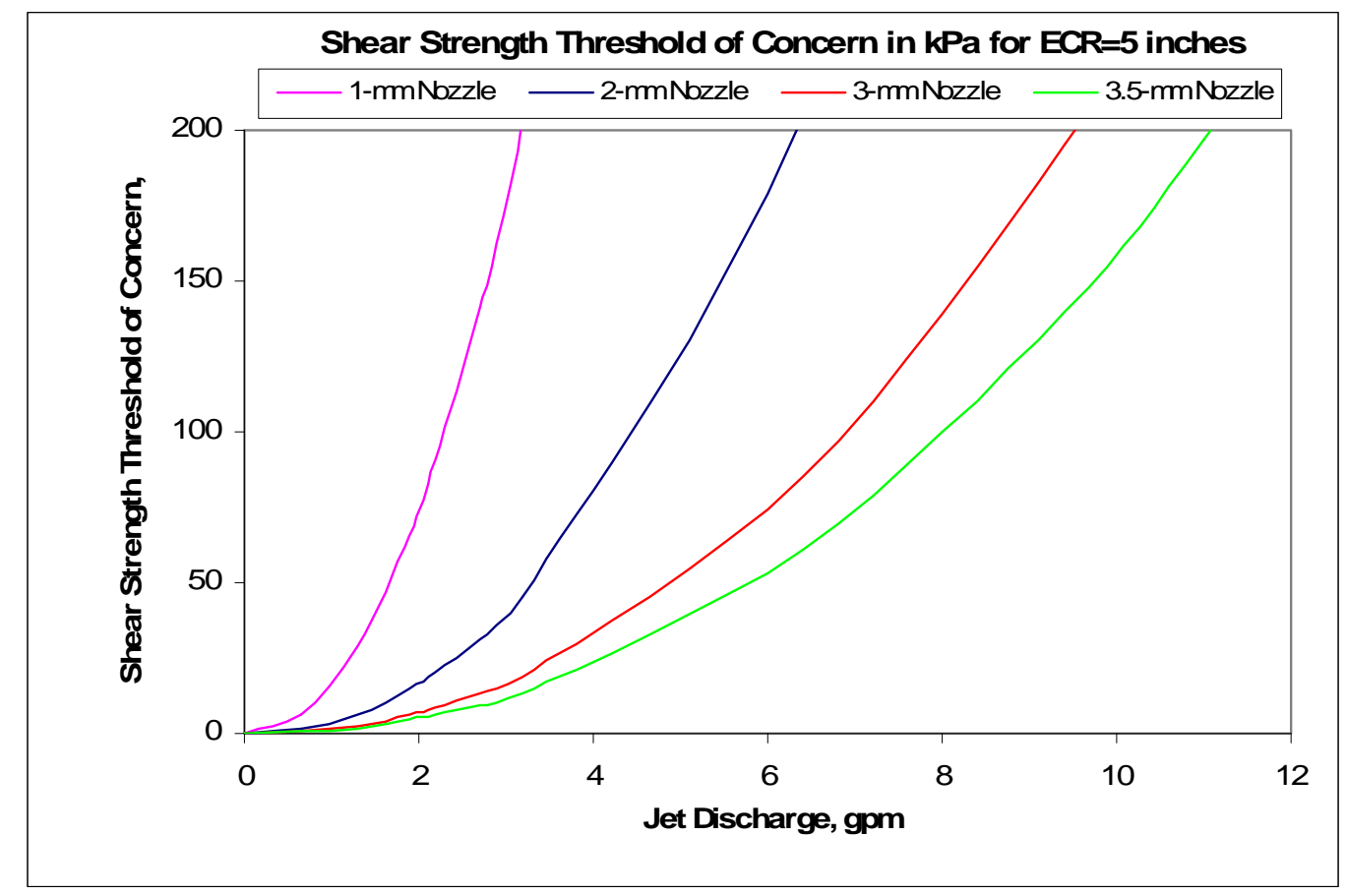

Figure 3.8. Estimated Shear Strength Threshold of Concern vs. Discharge of a Single Jet Located 5 Inches Away from the STSC Tank Wall

When these nozzles are placed 1 inch from the tank wall, the shear strength threshold of concern is further increased, thus significantly reducing the required jet discharge, as shown in Figure 3.7.

This figure shows that the 1-, 2-, 3-, and 3.5-mm nozzles located 1 inch from the tank wall need a jet discharge of $0.65,1.3,1.9$, and 2.2 gpm to erode the stored K-Basin sludge with 200-kPa shear strength to the tank wall. Thus, without considering the nozzle pressure loss, the required pressure at the nozzle is approximately 200, 49, 21, and 15 psi, respectively. 


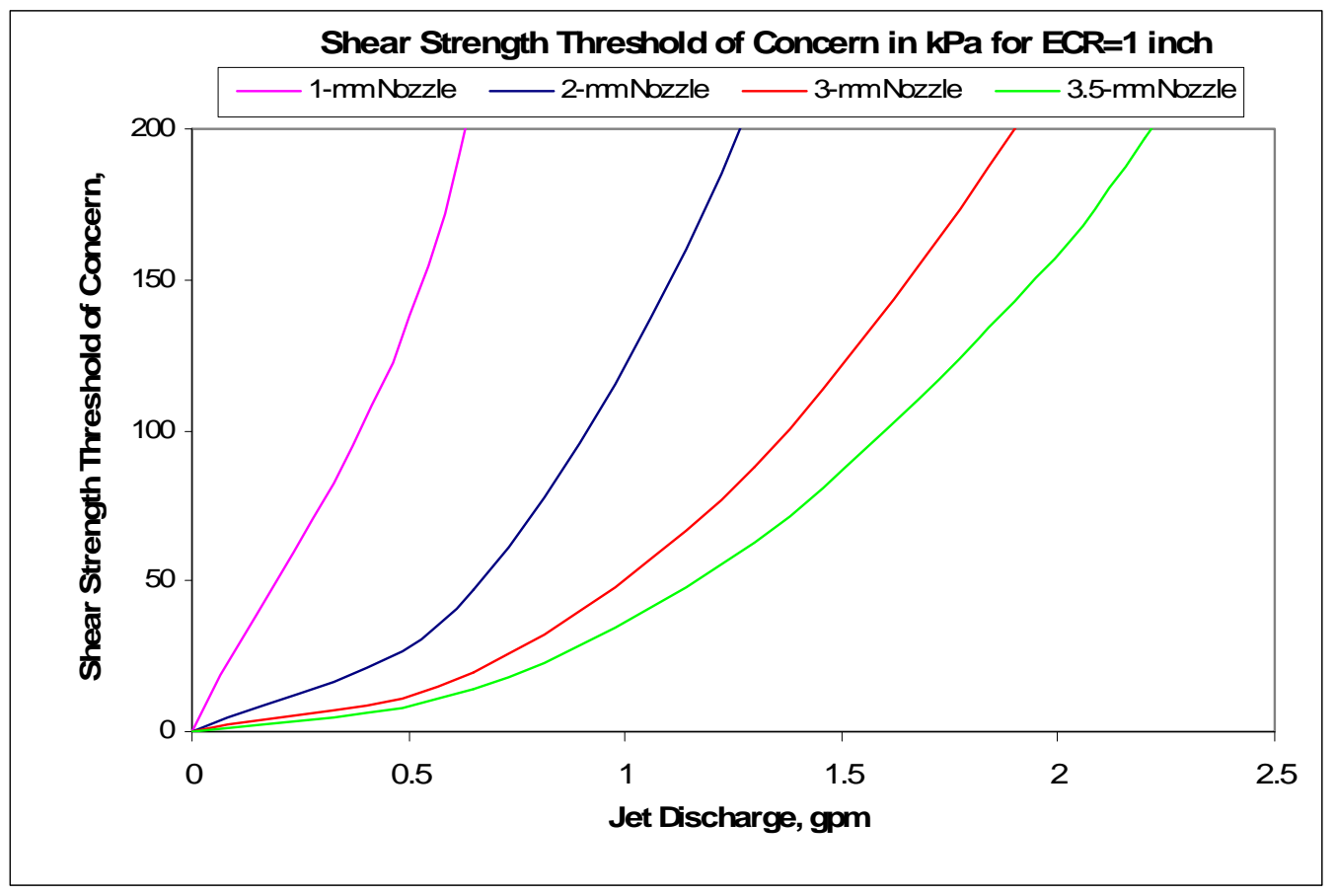

Figure 3.9. Estimated Shear Strength Threshold of Concern vs. Discharge of a Single Jet Located 1 Inch Away from the STSC Tank Wall

These figures reflect the jet velocity and width variations with downstream distance, as shown in Table 3.13. As discussed above, one needs to balance the required value of the shear strength threshold of concern (or the ECR) and required pressure and appropriate nozzle diameter. To provide additional insight, further analyses are provided here.

The stored K-Basin sludge may have a shear strength of between 30 and $200 \mathrm{kPa}$ (Delegard et al. 2007, Wells et al. 2009), as indicated in Table 3.1. The variation of the ECR with respect to the shear strength was examined with the use of the Powell-3 ECR model. Figure 3.10 shows the ECR variation with the jet discharge for a single nozzle of 1-, 2-, 3-, or 3.5-mm diameter, assuming that the stored K-Basin sludge would have a shear strength of $200 \mathrm{kPa}$. As expected, as the jet flow rate increases, the ECR also increases. It also shows that the smaller the nozzle diameter, the greater the ECR based on the Powell-3 model, although this may or may not be true in reality, as indicated previously. 


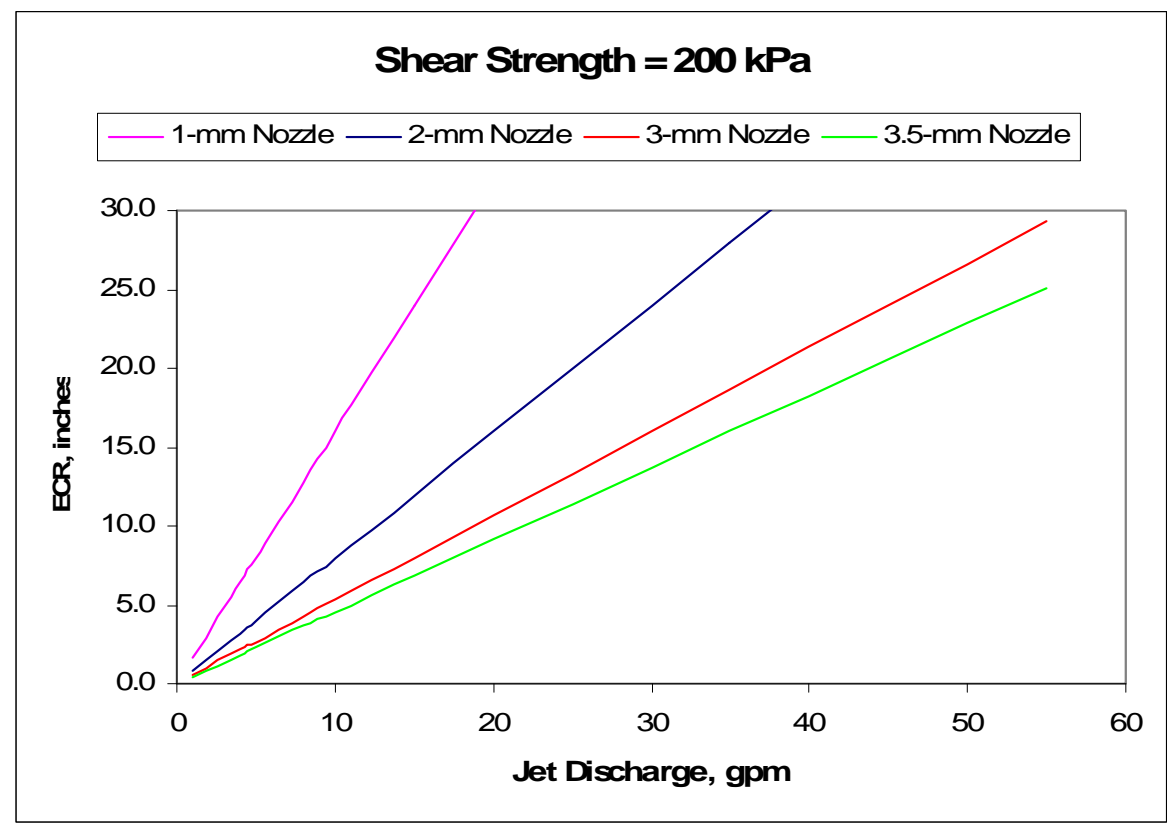

Figure 3.10. Estimated ECR vs. Jet Discharge of a Single Jet of 1-, 2-, 3-, or 3.5-mm Diameter Nozzle for a Shear Strength of $200 \mathrm{kPa}$

Figure 3.11 and Figure 3.12 present ECR variations with jet discharge when the shear strength is assumed to be 100 and $30 \mathrm{kPa}$, respectively.

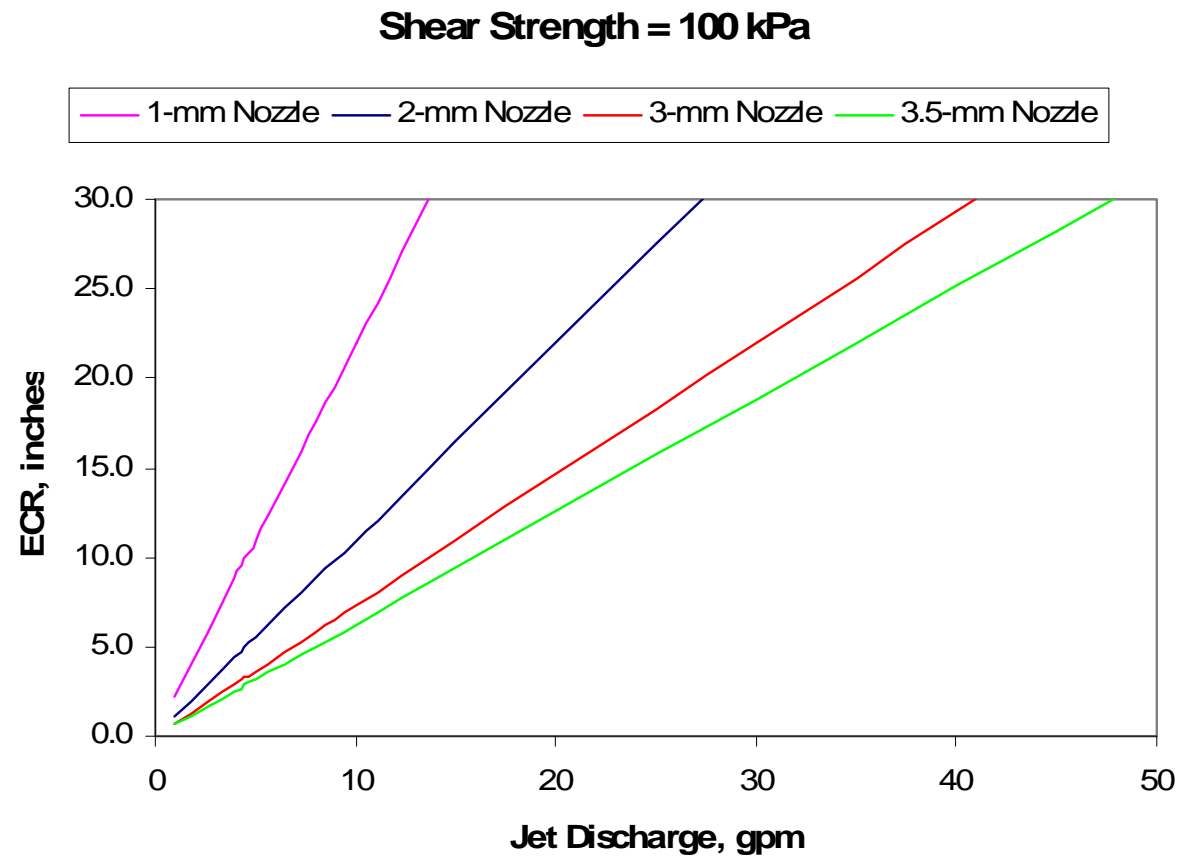

Figure 3.11. Estimated ECR vs. Jet Discharge of a Single Jet of 1-, 2-, 3-, or 3.5-mm Diameter Nozzle for a Shear Strength of $100 \mathrm{kPa}$ 


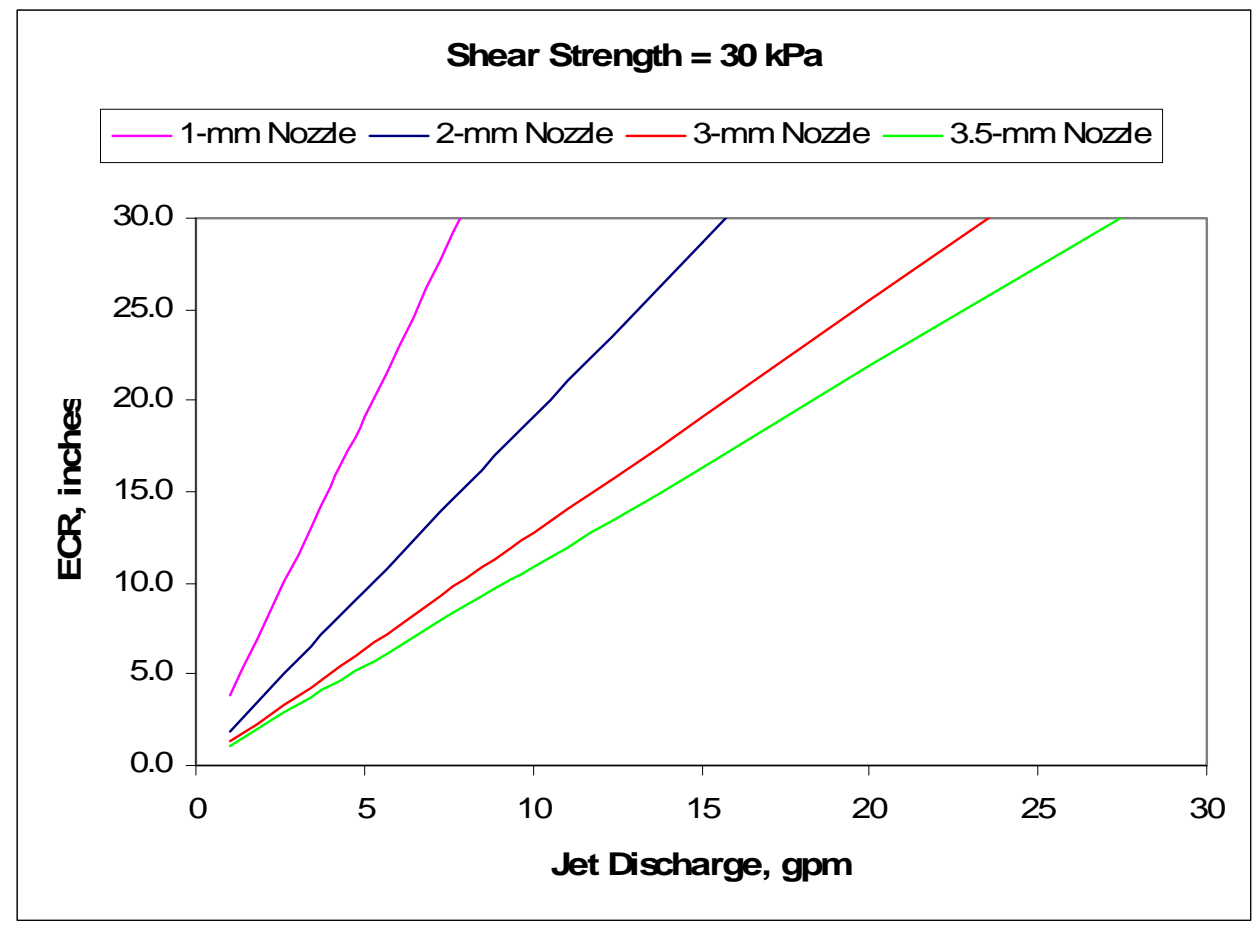

Figure 3.12. Estimated ECR vs. Jet Discharge of a Single Jet of 1-, 2-, 3-, or 3.5-mm Diameter Nozzle for a Shear Strength of $30 \mathrm{kPa}$

These three figures show that the greater the jet discharge, the larger the ECR, as expected. For a given jet discharge, the smaller the nozzle diameter, the greater the ECR. However, the pressure requirement increases with smaller nozzle diameter.

The variation of ECR with shear strength was also examined, as shown in Figure 3.13 through Figure 3.15. Figure 3.13 is at a jet discharge rate of $55 \mathrm{gpm}$ while Figure 3.14 through Figure 3.15 are at a discharge rate of $30,15,7$, and 2 gpm, respectively. 


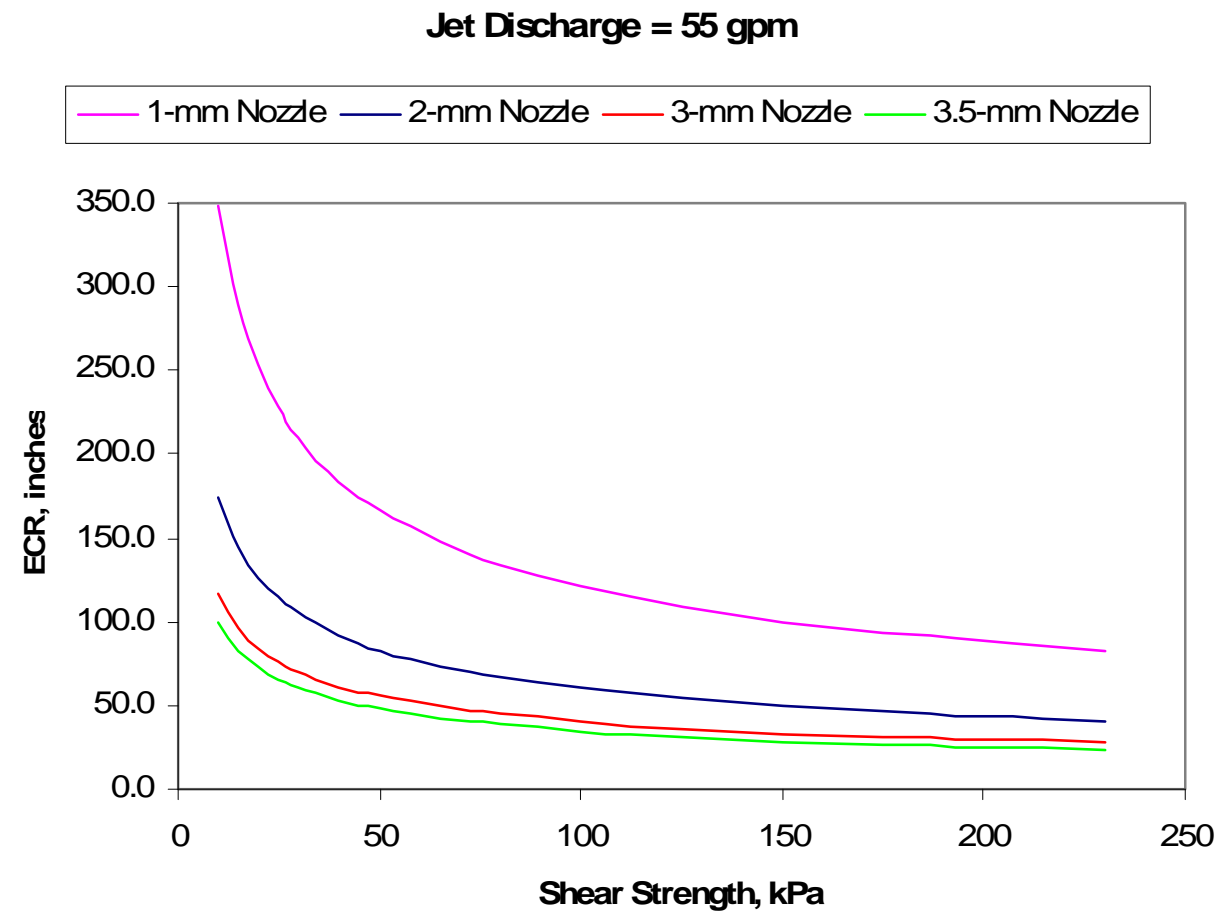

Figure 3.13. Estimated Variation of ECR with Shear Strength at Discharge of 55 gpm of a Single Jet

Jet Discharge $=\mathbf{3 0} \mathrm{gpm}$

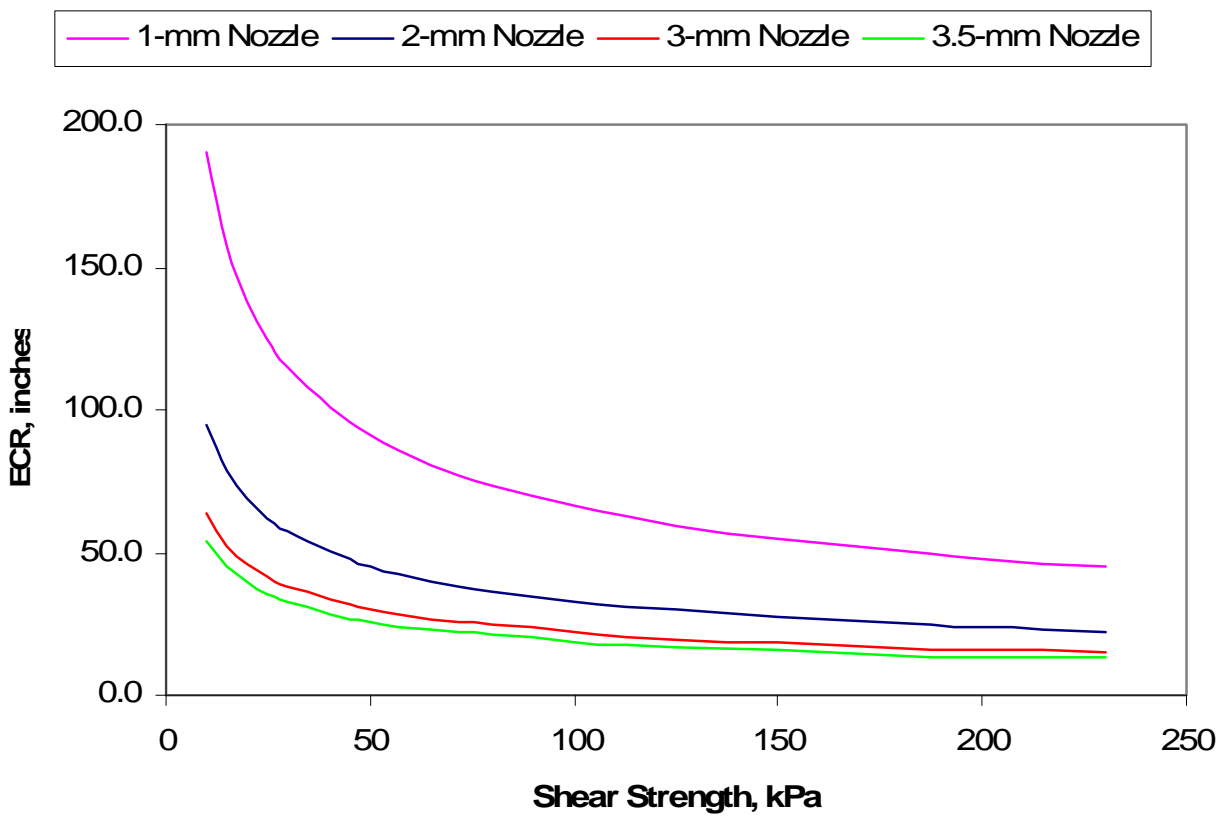

Figure 3.14. Estimated Variation of ECR with Shear Strength at Jet Discharge of $30 \mathrm{gpm}$ of a Single Jet 


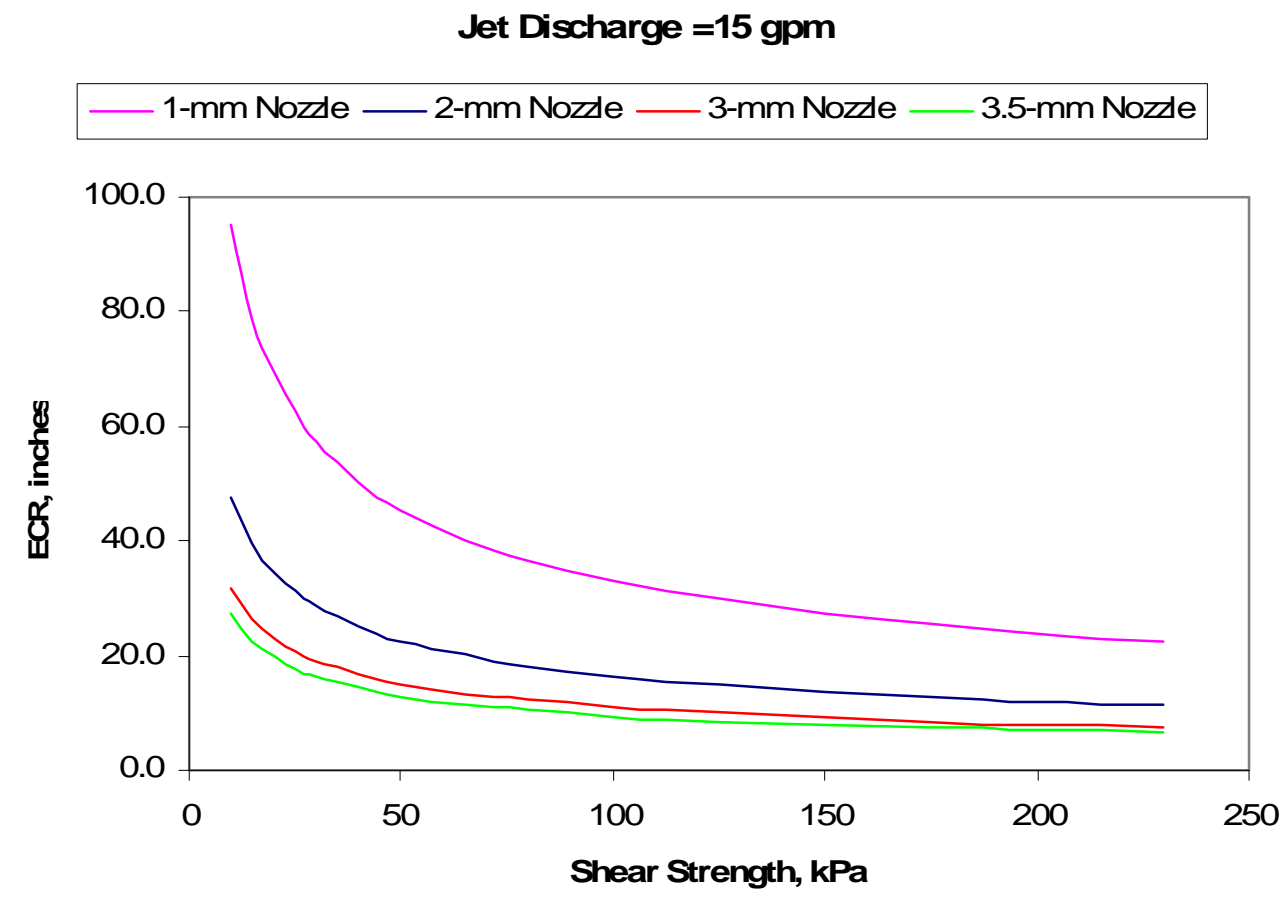

Figure 3.15. Estimated Variation of ECR with Shear Strength at Jet Discharge of 15 gpm of a Single Jet

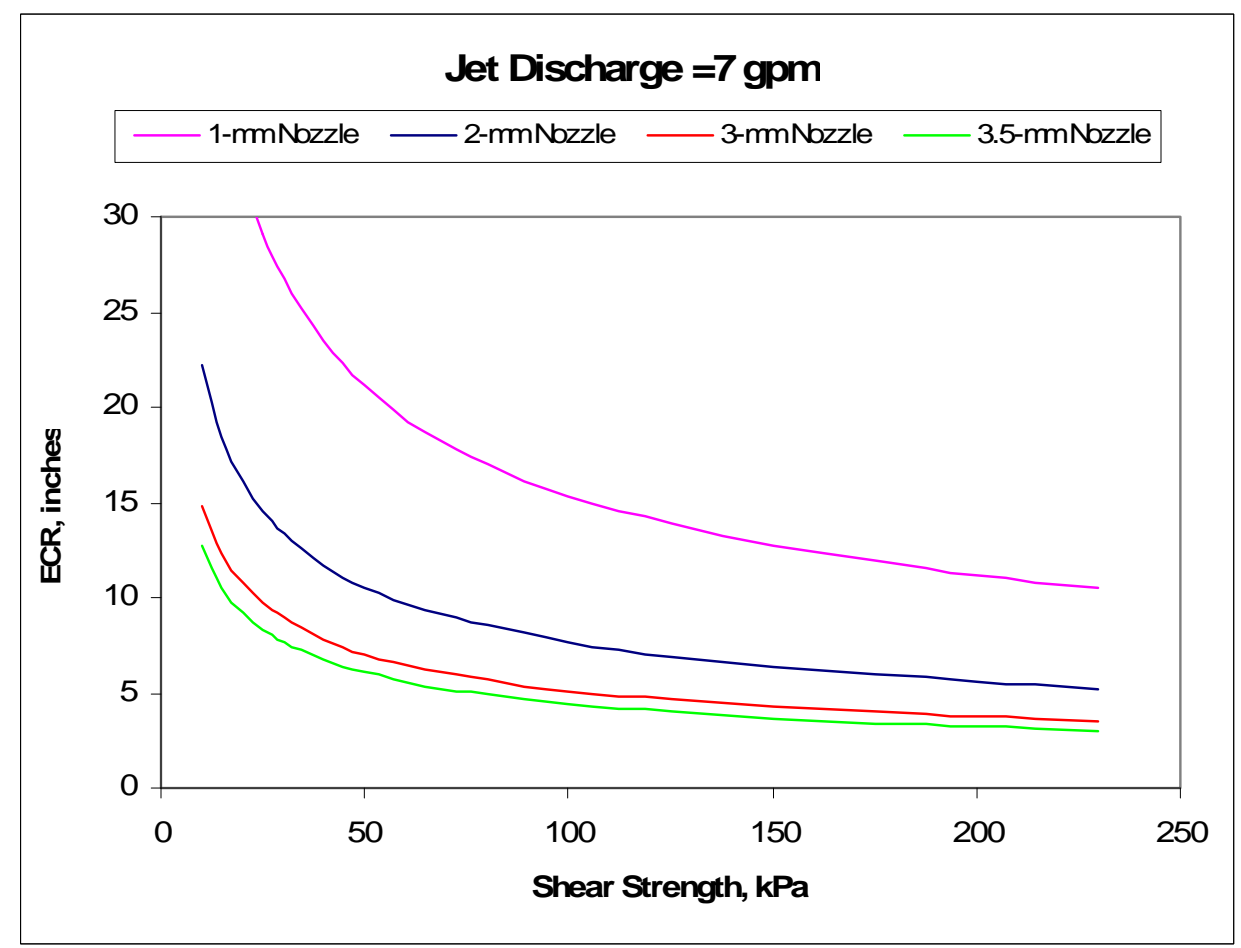

Figure 3.16. Estimated Variation of ECR with Shear Strength at Jet Discharge of $7 \mathrm{gpm}$ of a Single Jet 


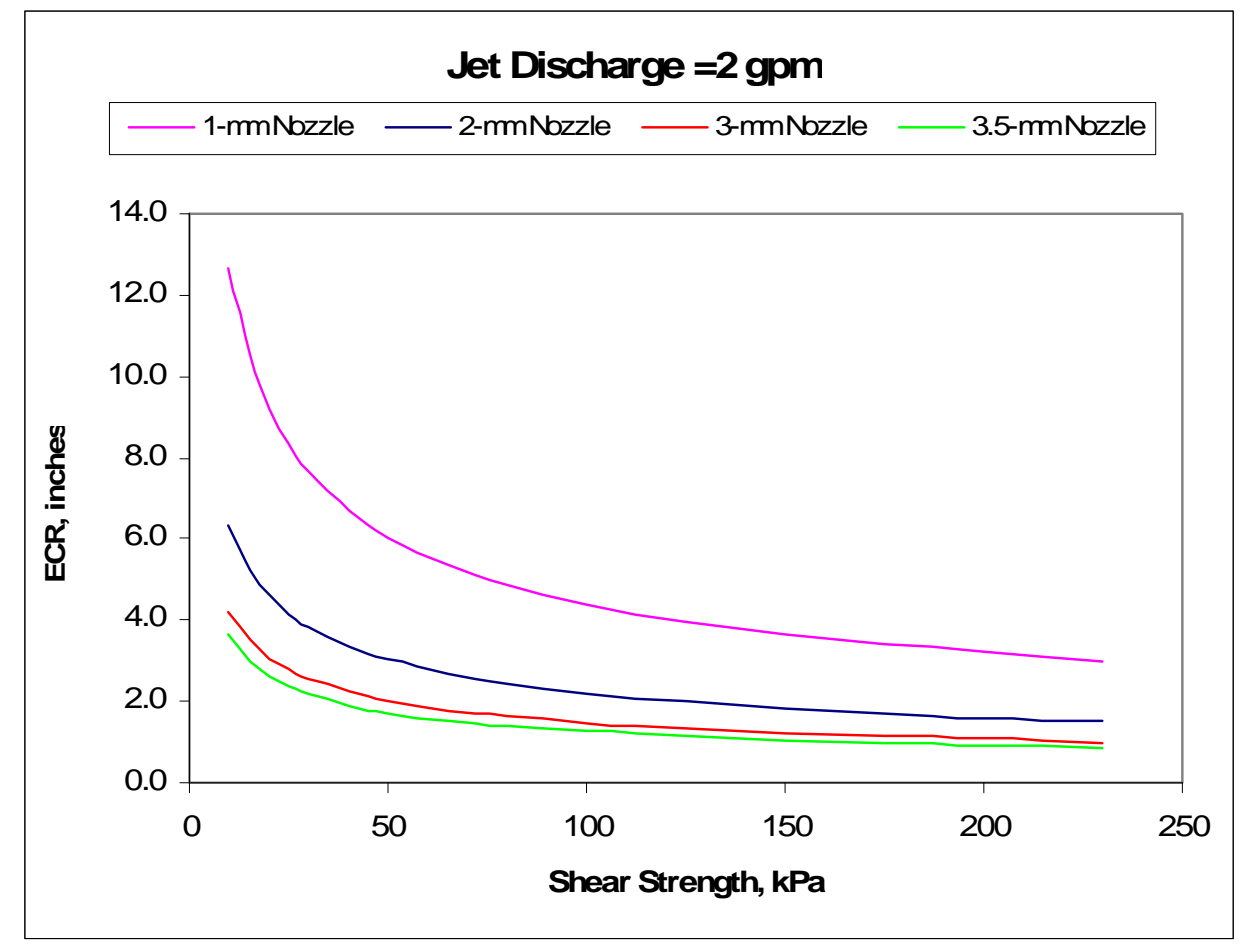

Figure 3.17. Estimated Variation of ECR with Shear Strength at Jet Discharge of $2 \mathrm{gpm}$ of a Single Jet

As expected, as the shear strength increases, the ECR decreases. These figures also indicate that for a given jet discharge, nozzles with smaller diameters could erode sludge more. However, as discussed previously, this may not be true. If the nozzles are placed very close to the STSC wall, e.g., 1 inch from the wall, the minimum required jet discharge to erode sludge for 1 inch may be 2 gallons per minute or less. This discharge might be too small to yield a large enough sludge erosion rate to be practical. If the jet discharge is increased, the wall erosion must be carefully examined.

Figure 3.5 through Figure 3.15 indicate that there are large variations of the shear strength threshold of concern and the ECR with the shear strength. Thus, it is important to estimate the shear strength of the stored K-Basin sludge. However, as will be further discussed in Section 5, the jet force may not have to be strong enough to overcome the shear strength of the sludge (see Figure 3.4).

Moreover, the nozzle diameter and jet discharge as well as the distance between the nozzle and the STSC tank wall significantly affect values of the shear strength threshold of concern. In some cases, pressure requirements to move water through a small nozzle are very large. It is anticipated that a reasonably large jet discharge is desirable to obtain an acceptable sludge erosion rate to retrieve the stored $\mathrm{K}$-Basin sludge. Thus, various combinations of these parameters may achieve the goal of mobilizing the stored K-Basin sludge in the STSCs by a water jet.

Furthermore, if one moves a nozzle position forward (toward the non-mobilized portion of the sludge), the required force to mobilize the sludge would be reduced. This is because the optimal distance between the nozzle and the sludge to be eroded would be approximately eight times the nozzle diameter, as stated previously (Moore and Masch 1962). If a nozzle is located within 7 times the nozzle diameter, a scoured hole is deep and narrow. If the nozzle is located further away from the sludge, an eroded hole 
would be shallow and wide, as stated previously. Moving a nozzle as a jet erodes the sludge, the jet would not be steady; thus, its impact on the sludge would be stronger.

As shown in these figures above, one of the key parameters is the shear strength of the stored K-Basin sludge. The shear strength is subject to many factors, including

- agglomerate formation with time

- shear strength changes with time and overburden weight

- K-Basin sludge chemistry (e.g., hydrothermal treatment affecting the sludge chemistry and rheology) and physical characteristics (e.g., particle sizes and density, settling velocity).

Agglomerate formation is a function of various factors, e.g., the solid size, suspended solid concentration, and waste chemistry (Hill 2010). When suspended solids settle on the surface of the solid layers, solids consolidate over time because of the overburden weight. Agglomeration and solids settling will be briefly discussed in Section 5.4.

As also will be further discussed in Section 5, solids erosion occurs when the shear stress of the flow acting on the surface of the solid layer is more than the critical shear stress for erosion. The critical shear stress for erosion is much smaller (as much as three orders of magnitude smaller) than the shear strength (see Figure 3.4).

When the jet force exceeds the shear strength, that portion of the solid layer cannot maintain the solid form and would be mobilized. Thus, if the shear strength is less than the shear strength threshold of concern value, there is no significant issue with the sludge removal from the STCSs after the long-term storage at the T Plant. Direct measurements of the stored K-Basin sludge with a pocket penetrometer or its simulant representing the shear strength with shear vane rheometer are potentially feasible to obtain an appropriate shear strength value for the ECR calculations.

As indicated above, various combinations of the nozzle diameter, jet flow rate, the distance between the nozzle and the tank wall, and potential use of a non-steady (impulsing) jet may achieve the goal of mobilizing the stored K-Basin sludge in the STSCs by a water jet.

Besides the XAGO water jet system, other water jet systems might provide additional insight for mobilization of the stored K-Basin sludge. These include the Sand Mantis remote vehicle waste mobilization system to retrieve the waste of Tank 18 at the Savannah River Site (Krementz and Daugherty 2007). It was also tested with a non-cohesive solid waste simulant in Hanford's Cold Test Facility (Enderlin 2007). As also stated above, there are several water jet manufacturers, including Flow International Inc. in Kent, Washington, and MC Machinery System, Inc.

\subsection{Parametric Evaluation of Strength Threshold of Concern using SRS-1, -2, -3 and ORNL-1 ECR Models}

For completeness, a limited parametric evaluation was performed using the ECR models developed at Savannah River Site (SRS) and Oak Ridge National Laboratory (ORNL). While these models have been used successfully at SRS and ORNL, they were developed from testing with low-strength kaolin simulants. As stated in Section 2.3, The SRS-1, SRS-2, and SRS-3 Models (Equations 2.17 through 2.19) 
do not consistently match with the ECRs measured for Hanford Tanks 241-SY-101 and 241-AZ-101. Moreover, these models do not have terms to present the strength of the settled solid layer, either with shear strength or yield stress. The input parameter for these models is limited to jet discharge velocity and nozzle diameter.

The predictions for the required jet velocity by the SRS-1, $-2,-3$, and ORNL-1 ECR models (Equations 2.17 through 2.20) to erode sludge up to 25, 17, 10, 5, and 1 inch from the nozzle are presented in Table 3.14 through Table 3.23. Comparing these required velocity values with the jet velocities shown in Table 3.1 indicates that these jet velocities at $42 \mathrm{gpm}$ are mostly sufficient to mobilize the sludge, except the 1-mm nozzle, when all seven nozzles located less than 17 inches away from the STSC wall are simultaneously used. When they are located within 10 inches from the STSC wall, all seven nozzles of the XAGO system would erode the sludge up to the wall. However, as stated in Section 2.3, the applicability of these required nozzle velocity models to the stored K-Basin sludge conditions is highly questionable.

Table 3.14. Required Jet Velocity to Erode 25 Inches of Stored K-Bain Sludge Predicted by SRS-1,-2,-3, and ORNL-1 ECR Models when a Single Nozzle is Used

\begin{tabular}{ccccc}
\hline ECR & \multicolumn{4}{c}{ Required Jet Velocity to Erode 25 Inches, m/s } \\
\cline { 2 - 5 } Models & 1-mm Nozzle & 2-mm Nozzle & 3-mm Nozzle & 3.5-mm Nozzle \\
\hline SRS-1 & 141 & 71 & 47 & 40 \\
SRS-2 & 99 & 50 & 33 & 28 \\
SRS-3 & 148 & 74 & 49 & 42 \\
ORNL-1 & 45 & 22 & 15 & 13 \\
\hline
\end{tabular}

Table 3.15. Required Jet Velocity to Erode 17 Inches of Stored K-Bain Sludge Predicted by SRS-1,-2,-3, and ORNL-1 ECR Models when a Single Nozzle Is Used

\begin{tabular}{ccccc}
\hline ECR & \multicolumn{4}{c}{ Required Jet Velocity to Erode 25 Inches, m/s } \\
\cline { 2 - 5 } Models & 1-mm Nozzle & 2-mm Nozzle & 3-mm Nozzle & 3.5-mm Nozzle \\
\hline SRS-1 & 96 & 48 & 32 & 27 \\
SRS-2 & 67 & 34 & 22 & 19 \\
SRS-3 & 100 & 50 & 33 & 29 \\
ORNL-1 & 30 & 15 & 10 & 9 \\
\hline
\end{tabular}

Table 3.16. Required Jet Velocity to Erode 10 inches of Stored K-Bain Sludge Predicted by SRS-1,-2,-3, and ORNL-1 ECR Models when a Single Nozzle Is Used

\begin{tabular}{ccccc}
\hline ECR & \multicolumn{4}{c}{ Required Jet Velocity to Erode 25 Inches, m/s } \\
\cline { 2 - 5 } Models & 1-mm Nozzle & 2-mm Nozzle & 3-mm Nozzle & 3.5-mm Nozzle \\
\hline SRS-1 & 56 & 28 & 19 & 16 \\
SRS-2 & 40 & 20 & 13 & 11 \\
SRS-3 & 59 & 30 & 20 & 17 \\
ORNL-1 & 18 & 8.9 & 6.0 & 5.1 \\
\hline
\end{tabular}


Table 3.17. Required Jet Velocity to Erode 5 inches of Stored K-Bain Sludge Predicted by SRS-1,-2,-3, and ORNL-1 ECR Models when a Single Nozzle Is Used

\begin{tabular}{ccccc}
\hline ECR & \multicolumn{4}{c}{ Required Jet Velocity to Erode 25 Inches, $\mathrm{m} / \mathrm{s}$} \\
\cline { 2 - 5 } Models & 1-mm Nozzle & 2-mm Nozzle & 3-mm Nozzle & 3.5-mm Nozzle \\
\hline SRS-1 & 28 & 14 & 9.4 & 8.1 \\
SRS-2 & 20 & 10 & 6.6 & 5.7 \\
SRS-3 & 30 & 15 & 10 & 8.4 \\
ORNL-1 & 8.9 & 4.5 & 3.0 & 2.6 \\
\hline
\end{tabular}

Table 3.18. Required Jet Velocity to Erode 1 inch of Stored K-Bain Sludge Predicted by SRS-1,-2,-3, and ORNL-1 ECR Models when a Single Nozzle Is Used

\begin{tabular}{ccccc}
\hline \multirow{2}{*}{ ECR } & \multicolumn{4}{c}{ Required Jet Velocity to Erode 25 Inches, m/s } \\
\cline { 2 - 5 } Models & 1-mm Nozzle & 2-mm Nozzle & 3-mm Nozzle & 3.5-mm Nozzle \\
\hline SRS-1 & 5.6 & 2.8 & 1.9 & 1.6 \\
SRS-2 & 4.0 & 2.0 & 1.3 & 1.1 \\
SRS-3 & 5.9 & 3.0 & 2.0 & 1.7 \\
ORNL-1 & 1.8 & 0.9 & 0.6 & 0.5 \\
\hline
\end{tabular}

Table 3.19. Required Jet Velocity to Erode 25 Inches of Stored K-Bain Sludge Predicted by SRS-1,-2,-3, and ORNL-1 ECR Models when All Seven Nozzles of the XAGO System Are Used

\begin{tabular}{cccc}
\hline & \multicolumn{3}{c}{ Required Jet Velocity to Erode 25 Inches, $\mathrm{m} / \mathrm{s}$} \\
\cline { 2 - 4 } ECR Models & 1-mm Nozzle & 3-mm Nozzle & 3.5-mm Nozzle \\
\hline SRS-1 & 141 & 47 & 40 \\
SRS-2 & 99 & 33 & 28 \\
SRS-3 & 148 & 49 & 42 \\
ORNL-1 & 45 & 15 & 13 \\
\hline
\end{tabular}

Table 3.20. Required Jet Velocity to Erode 17 Inches of Stored K-Bain Sludge Predicted by SRS-1,-2,-3, and ORNL-1 ECR Models when All Seven Nozzles of the XAGO System Are Used

\begin{tabular}{cccc}
\hline & \multicolumn{3}{c}{ Required Jet Velocity to Erode 17 Inches, $\mathrm{m} / \mathrm{s}$} \\
\cline { 2 - 4 } ECR Models & 1-mm Nozzle & 3-mm Nozzle & 3.5-mm Nozzle \\
\hline SRS-1 & 96 & 32 & 27 \\
SRS-2 & 67 & 22 & 19 \\
SRS-3 & 100 & 33 & 29 \\
ORNL-1 & 30 & 10 & 9 \\
\hline
\end{tabular}


Table 3.21. Required Jet Velocity to Erode 10 Inches of Stored K-Bain Sludge Predicted by SRS-1,-2,-3, and ORNL-1 ERC Models when All Seven Nozzles of the XAGO System Are Used

\begin{tabular}{cccc}
\hline & \multicolumn{3}{c}{ Required Jet Velocity to Erode 10 Inches, $\mathrm{m} / \mathrm{s}$} \\
\cline { 2 - 4 } ECR Models & 1-mm Nozzle & 3-mm Nozzle & 3.5-mm Nozzle \\
\hline SRS-1 & 56 & 19 & 16 \\
SRS-2 & 40 & 13 & 11 \\
SRS-3 & 59 & 20 & 17 \\
ORNL-1 & 18 & 6.0 & 5.1 \\
\hline
\end{tabular}

Table 3.22. Required Jet Velocity to Erode 5 Inches of Stored K-Bain Sludge Predicted by SRS-1,-2,-3, and ORNL-1 ERC Models when All Seven Nozzles of the XAGO System Are Used

\begin{tabular}{cccc}
\hline & \multicolumn{3}{c}{ Required Jet Velocity to Erode 10 Inches, $\mathrm{m} / \mathrm{s}$} \\
\cline { 2 - 4 } ECR Models & 1-mm Nozzle & 3-mm Nozzle & 3.5-mm Nozzle \\
\hline SRS-1 & 28 & 9.4 & 8.1 \\
SRS-2 & 20 & 6.6 & 5.7 \\
SRS-3 & 30 & 10 & 8.4 \\
ORNL-1 & 8.9 & 3.0 & 2.6 \\
\hline
\end{tabular}

Table 3.23. Required Jet Velocity to Erode 1 Inches of Stored K-Bain Sludge Predicted by SRS-1,-2,-3, and ORNL-1 ERC Models when All Seven Nozzles of the XAGO System Are Used

\begin{tabular}{cccc}
\hline & \multicolumn{3}{c}{ Required Jet Velocity to Erode 10 Inches, $\mathrm{m} / \mathrm{s}$} \\
\cline { 2 - 4 } ECR Models & 1-mm Nozzle & 3-mm Nozzle & 3.5-mm Nozzle \\
\hline SRS-1 & 5.6 & 1.9 & 1.6 \\
SRS-2 & 4.0 & 1.3 & 1.1 \\
SRS-3 & 5.9 & 2.0 & 1.7 \\
ORNL-1 & 1.8 & 0.6 & 0.5 \\
\hline
\end{tabular}




\subsection{Vessel Wall/Bottom Erosion}

This section describes the theory of the erosion of the vessel walls and bottoms and its application to the STSCs.

\subsection{Vessel Wall/Bottom Erosion Theory}

One of the safety issues of K-Basin sludge mobilization in the STSCs by a water-jet retrieval system is container wall erosion caused by the jet flow steam impinging on the wall. In order to respond to this issue, maximum water-jet nozzle velocities are limited to values at which the erosion is ensured not to exceed $10 \%$ of the container wall thickness $(0.5 \mathrm{inch})$. This section presents the maximum allowable water-jet nozzle velocities.

A study of mixing vessel wall erosion by jet impinging on the wall for the WTP has been conducted and reported by Papp (2008) and Papp and Duncan (2009). In their reports, the wall erosion was characterized by a number of parameters such as the jet velocity, the mean particle size, the slurry concentration, and impingement angle, and formulated in an algebraic expression. The mathematical formula given by Papp (2008) and Papp and Duncan (2009) was simplified in order to make it more appropriated to the evaluation of maximum allowable water-jet nozzle velocities. The equation used here is:

$$
\frac{E}{E_{r e f}}=\left[\frac{U_{w}}{U_{w r e f}}\right]^{3.08588}\left[\frac{P}{P_{r e f}}\right]^{1.982}\left[\frac{C}{C_{r e f}}\right]^{0.8247} T
$$

where

$$
\begin{aligned}
E & =\text { erosion depth } \\
E_{r e f} & =\text { reference erosion depth rate } \\
U_{w} & =\text { wall eroding jet nozzle velocity } \\
U_{w}{ }_{r f} & =\text { reference wall eroding jet nozzle velocity } \\
P & =\text { particle mean diameter } \\
P_{r e f} & =\text { reference particle mean diameter } \\
C & =\text { slurry concentration } \\
C_{r e f} & =\text { reference slurry concentration } \\
T & =\text { jet operation time. }
\end{aligned}
$$

A schematic diagram of the test setup used to derive Equation 4.1 is shown in Figure 4.1. 


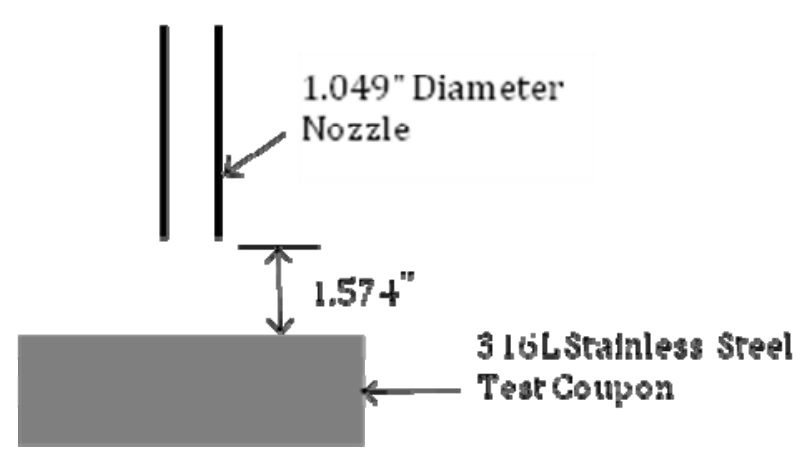

Figure 4.1. Schematic Diagram of Test Setup

Values of the parameters used to derive Equation 4.1 were 12 and $14 \mathrm{~m} / \mathrm{s}$ for jet nozzle velocity; 150 , 250 , and $350 \mathrm{~g} / \mathrm{L}$ for slurry concentration; and 24,39 , and $54 \mu \mathrm{m}$ for the particle mean diameter. Two stainless steel types of $304 \mathrm{~L}$ and $316 \mathrm{~L}$ were used as test coupons, and they were determined to be similar in wear resistance.

A flow structure of a free jet, where a jet is injected into a homogenous fluid medium, has been a subject of interest. The flow profile of a homogenous free jet is given by Equation 2.15.

To evaluate the maximum water-jet nozzle velocities, Equations 2.15 and 4.1 are used in the following two steps:

1. The wall eroding jet nozzle velocity, $U_{w}$, is evaluated from Equation 4.1 with a given erosion depth $E$, a reference erosion depth rate $E_{\text {ref }}$, a reference wall eroding jet nozzle velocity $U_{w \text { ref }}$, a particle mean diameter $P$, a reference particle mean diameter ${ }_{P_{r f}}$, a slurry concentration $C^{*}$, a reference slurry concentration $_{C_{\text {ref }}}$, and a jet operation time $T$.

2. The nozzle jet velocity, $U_{j}$, is evaluated from Equation 2.15 with a given nozzle diameter, $d_{j}$, a jet distance $X$, and a jet velocity $U$ where the wall-eroding jet nozzle velocity, $U_{w}$, evaluated in the previous Step 1, is used for jet velocity $U$.

In this procedure, the jet distance $X$ is considered to be the distance between the nozzle and a point located 1.574 inches from the container wall (see Figure 4.1).

By using $10 \%$ of the container wall thickness for the erosion depth $E$, the nozzle jet velocity $U_{0}$, evaluated in Step 2 of the procedure, provides the maximum allowable water-jet nozzle velocities at which the erosion is ensured to not exceed $10 \%$ of the container wall thickness.

\subsection{Results and Discussion}

The parameters used for Equation 4.1 were $\mathscr{H}^{*}=0.05$ (inches), $E_{\text {ref }}=0.000021$ (inches/hour), $U_{w \text { ref }}$ $=12(\mathrm{~m} / \mathrm{s}), P=100 \mu \mathrm{m}, P_{\text {ref }}=54 \mu \mathrm{m}$, and $C_{\text {ref }}=350(\mathrm{~g} / \mathrm{L})$. These parameters were used to evaluate the wall eroding jet nozzle velocities $U_{w}$ by applying Equation 4.1 for four concentration cases: $C^{*}=700 \mathrm{~g} / \mathrm{L}$ for $10 \mathrm{vol} \%, 1400 \mathrm{~g} / \mathrm{L}$ for $20 \mathrm{vol} \%, 2100 \mathrm{~g} / \mathrm{L}$ for $30 \mathrm{vol} \%$, and $2800 \mathrm{~g} / \mathrm{L}$ for $40 \mathrm{vol} \%$ where a particle density of $7 \mathrm{~g} / \mathrm{mL}$ was used. 
The erosion depth $H^{\prime}=0.05$ inch was based on $10 \%$ of the container wall thickness for the 0.5 -in.thick 304/304L stainless steel of the container.

The wall eroding jet nozzle velocities, $U_{w}$, obtained from Equation 4.1, were used to evaluate the nozzle jet velocities, $U_{j}$, by applying Equation 2.15 for three nozzle diameters of $d_{j}=1,3$, and $3.5 \mathrm{~mm}$ and for two jet distances of $X=1,5,17$ and 25 inches.

Evaluated nozzle jet velocities are plotted in Figure 4.2 through Figure 4.5 as a function of operation time. The numerical values of Figure 4.2 through Figure 4.5 are provided in Table 4.1 through Table 4.16. These nozzle jet velocities presented in Figure 4.2 through Figure 4.5 and Table 4.1 through Table 4.16 are the maximum allowable water-jet nozzle velocities used to ensure safe water-jet operation for the conditions specified in the figures and tables.

The general characteristics of the results are summarized as follows:

- Allowable nozzle jet velocity decreases as operation time increases.

- Allowable nozzle jet velocity decreases as nozzle diameter increases.

- Allowable nozzle jet velocity decreases as slurry concentration increases.

- Allowable nozzle jet velocity decreases as jet distance decreases.

Assumptions and rationales to use Equations 2.15 and 4.1 for the maximum allowable water-jet nozzle velocity evaluations are summarized as:

- The water-jet operation includes containers of 304 and 304L stainless steels while 304L stainless steel was used to derive Equation 4.1. Equation 4.1 is conservative, because the hardness of 304 stainless steel is greater than that of $304 \mathrm{~L}$ stainless steel.

- Equation 4.1 was derived for wall eroding jet nozzle velocities of 12 and $14 \mathrm{~m} / \mathrm{s}$, while the highest wall eroding jet nozzle velocity evaluated was up to $84 \mathrm{~m} / \mathrm{s}$ (not shown here). It is assumed that Equation 4.1 is applicable for a jet velocity as high as $84 \mathrm{~m} / \mathrm{s}$.

- The jet velocity impinging on the wall is assumed to be the same as the wall eroding jet nozzle velocity, $U_{w}$, because the distance of 1.5 times the nozzle diameter between the nozzle and the test coupon was used to derive Equation 4.1 as shown in Figure 4.1. Therefore, the jet distance $X$ is the distance between the nozzle and the container wall.

- The flow structure of water-jet operation is different from that of a homogenous free jet for Equation 2.15. In the sludge mobilization process, a water-jet is introduced into a multi-component and multiphase fluid, and a reduction of flow velocity is expected because of the flow momentum loss by the presence of heavy solid particles. But the sludge mobilization process is expected to generate a flow profile of a converged shape in the direction of centerline jet flow as confined in un-mobilized sludge. The flow velocity in such a funnel shape is expected to be higher than that of a free jet. Lastly, sludge mobilization by a water-jet is processed in containers, and the jet velocity is expected to be significantly reduced because of the presence of the container wall where the jet back-pressure is significantly higher than that of the free jet flow field. Therefore, there are significant uncertainties on the jet velocity estimates, but nozzle jet velocities, $U_{j}$, evaluated by applying Equation 2.15 , might be conservative. 
The use of Figure 4.2 through Figure 4.9 and Table 4.1 through Table 4.16 is described by using the following example. The nozzle jet velocity of $5,464 \mathrm{~m} / \mathrm{s}$ for a 4-hour operation time and a $1-\mathrm{mm}$ diameter nozzle from Table 4.1 is interpreted as follows: if the total duration of the water-jet operation is 4 hours, the water-jet nozzle velocity cannot exceed 5,464 m/s; conversely, if the water-jet nozzle velocity is $5,464 \mathrm{~m} / \mathrm{s}$, the total operation should not exceed 4 hours.

It is important to make sure that a jet would not erode the STSC wall more than $10 \%$ of the wall thickness. This evaluation indicates that wall erosion would be a minor risk if a single 3- or 3.5-mm nozzle at $42 \mathrm{gpm}$ is located at least 17 inches away from the STSC wall. If these nozzles are located at 5 inches or less from the wall, wall erosion may become an issue if a jet at $42 \mathrm{gpm}$ impinges the same wall location for more than $2 \sim 4$ hours. If $1-\mathrm{mm}$ nozzle at $42 \mathrm{gpm}$ is placed, wall erosion would become an issue. If seven XAGO nozzles at $42 \mathrm{gpm}$ are located at 1 inch from the wall, wall erosion may become an issue if jets continue to hit the same wall locations for 2 hours or more. 


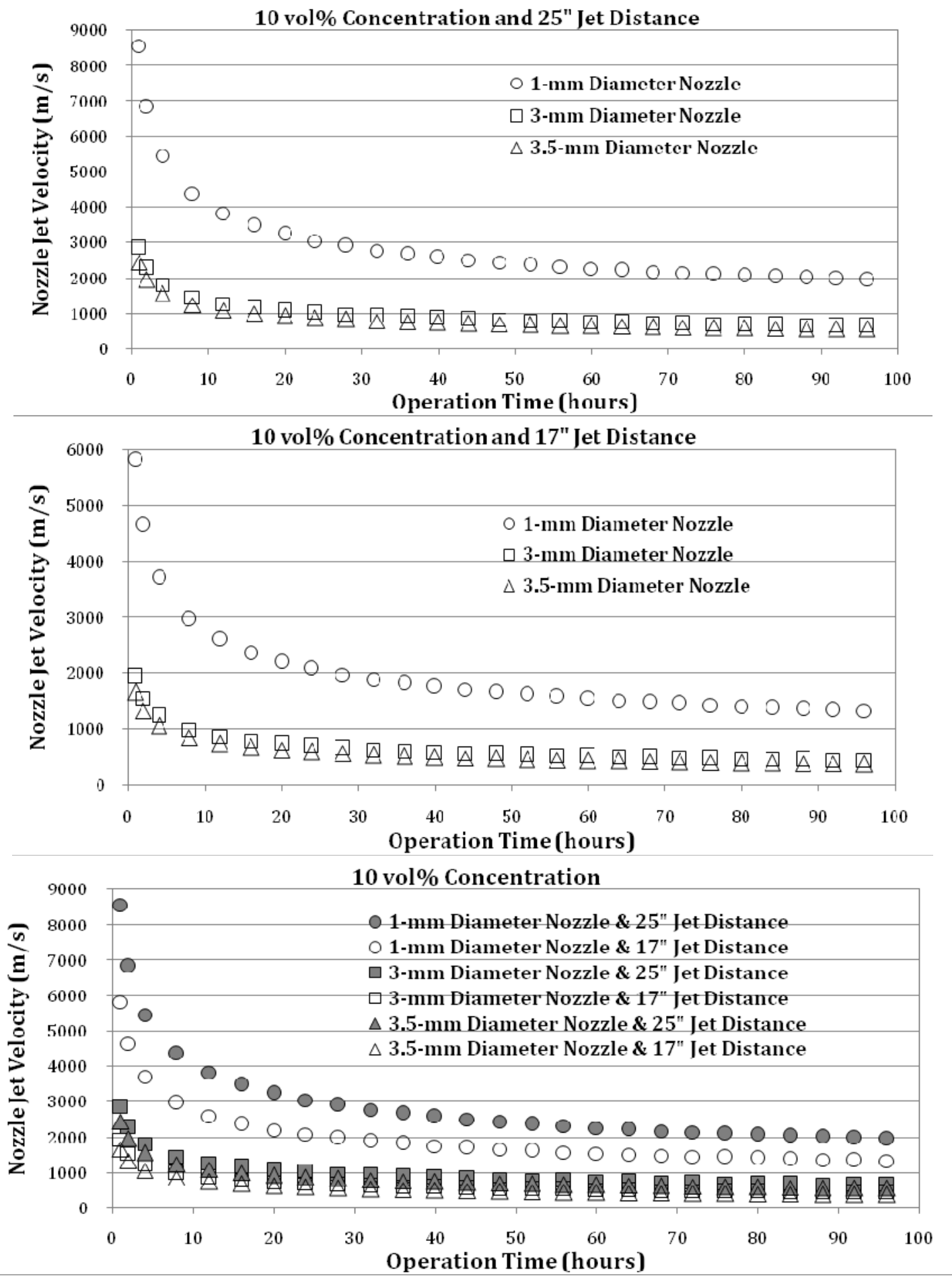

Figure 4.2. Nozzle Jet Velocity vs. Operation Time for 10\% Container Wall Erosion with 10-vol\% Concentration and Various Nozzle Diameters: Top Is of 25-in. Jet Distance from Nozzle, Middle Is 17-in. Jet Distance from Nozzle, and Bottom Is a Combination of 25-in. and 17-in. Jet Distances from Nozzle 

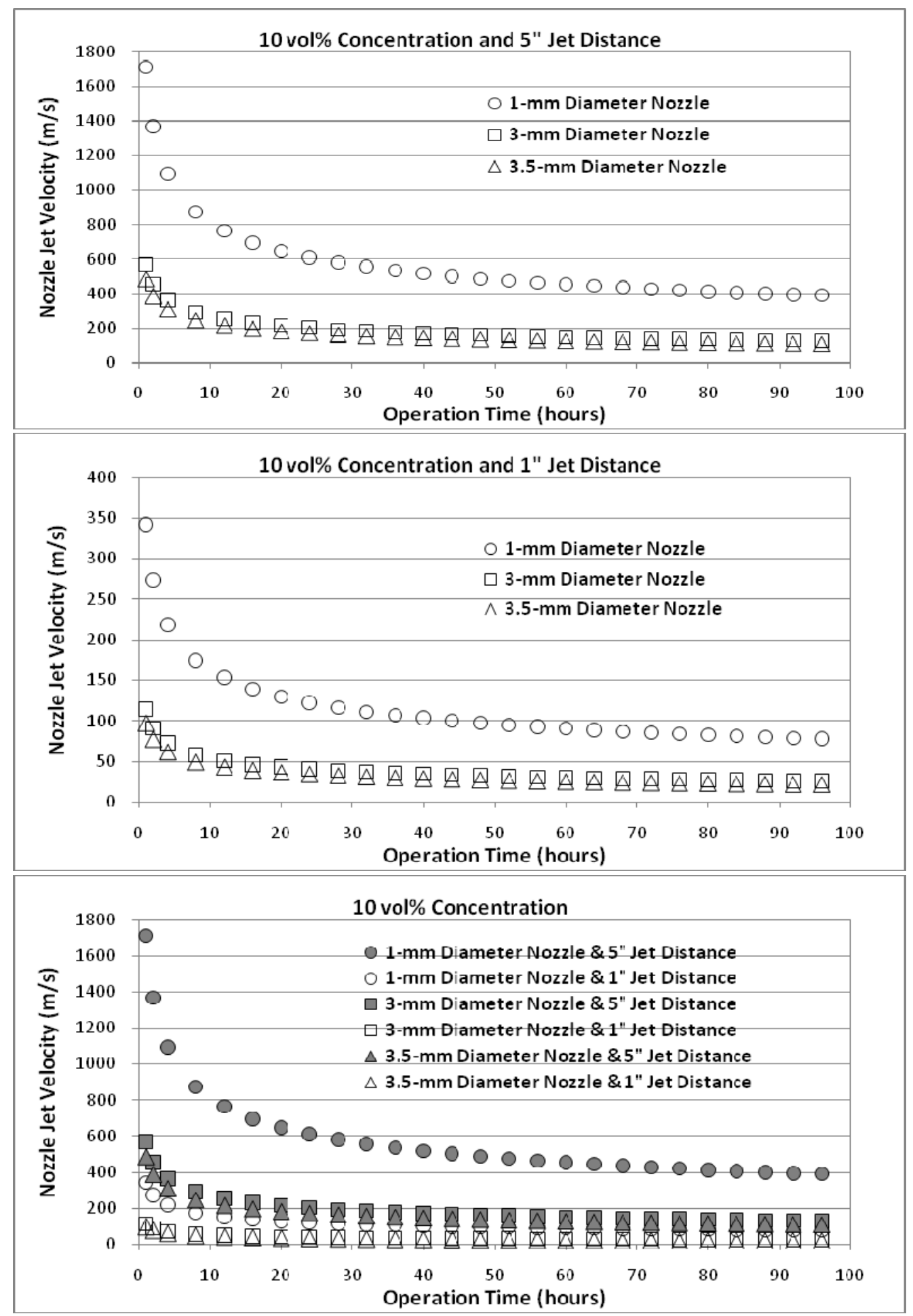

Figure 4.3. Nozzle Jet Velocity vs. Operation Time for $10 \%$ Container Wall Erosion with 10-vol\% Concentration and Various Nozzle Diameters: Top Is of 5-in. Jet Distance from Nozzle, Middle Is 1-in. Jet Distance from Nozzle, and Bottom Is a Combination of 5-in. and 1-in. Jet Distances from Nozzle 

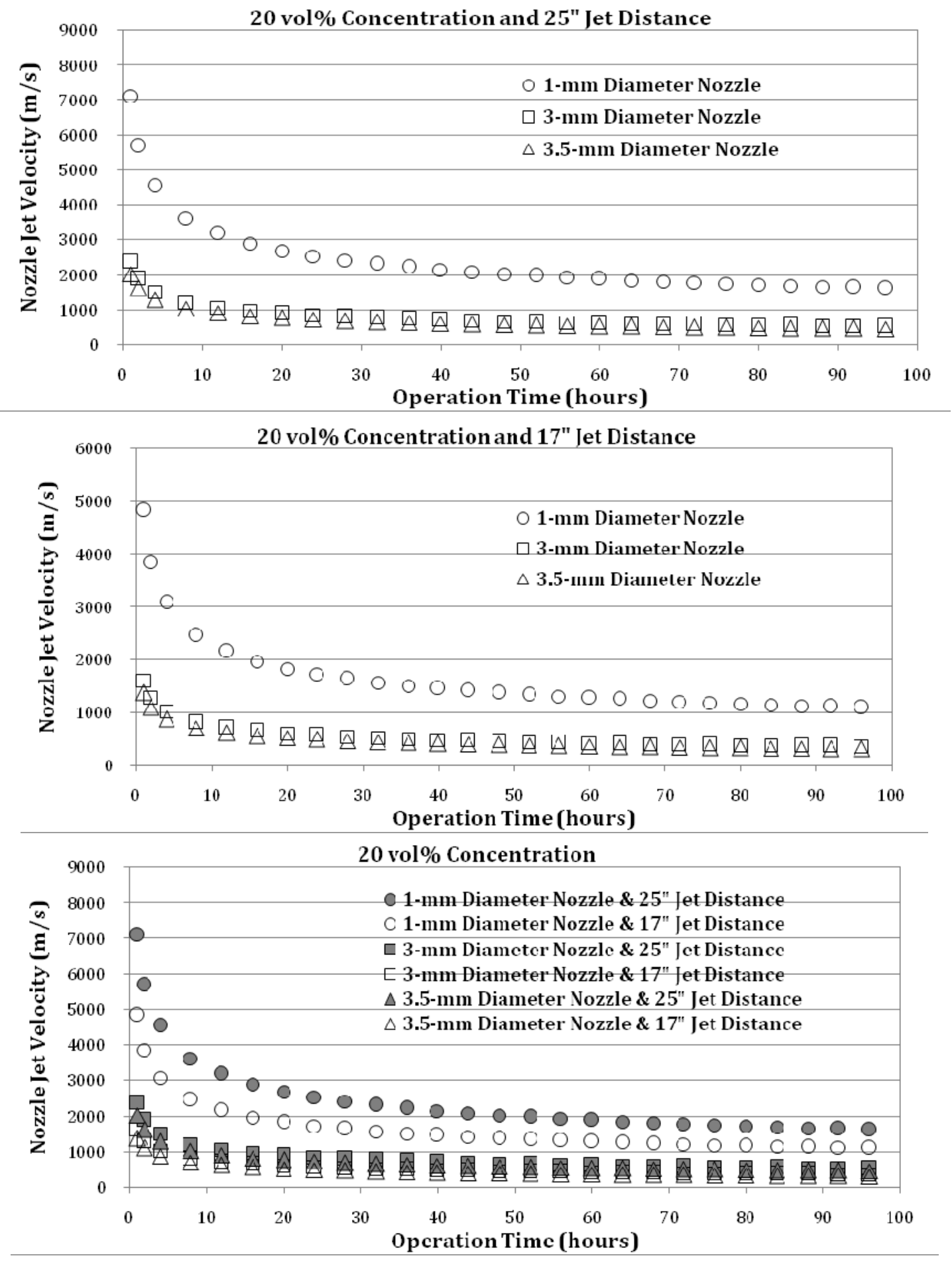

Figure 4.4. Nozzle Jet Velocity vs. Operation Time for 10\% Container Wall Erosion with 20-vol\% Concentration and Various Nozzle Diameters: Top Is of 25-in. Jet Distance from Nozzle, Middle Is of 17-in. Jet Distance from Nozzle, and Bottom Is of Combination of 25-in. and 17-in. Jet Distances from Nozzle 


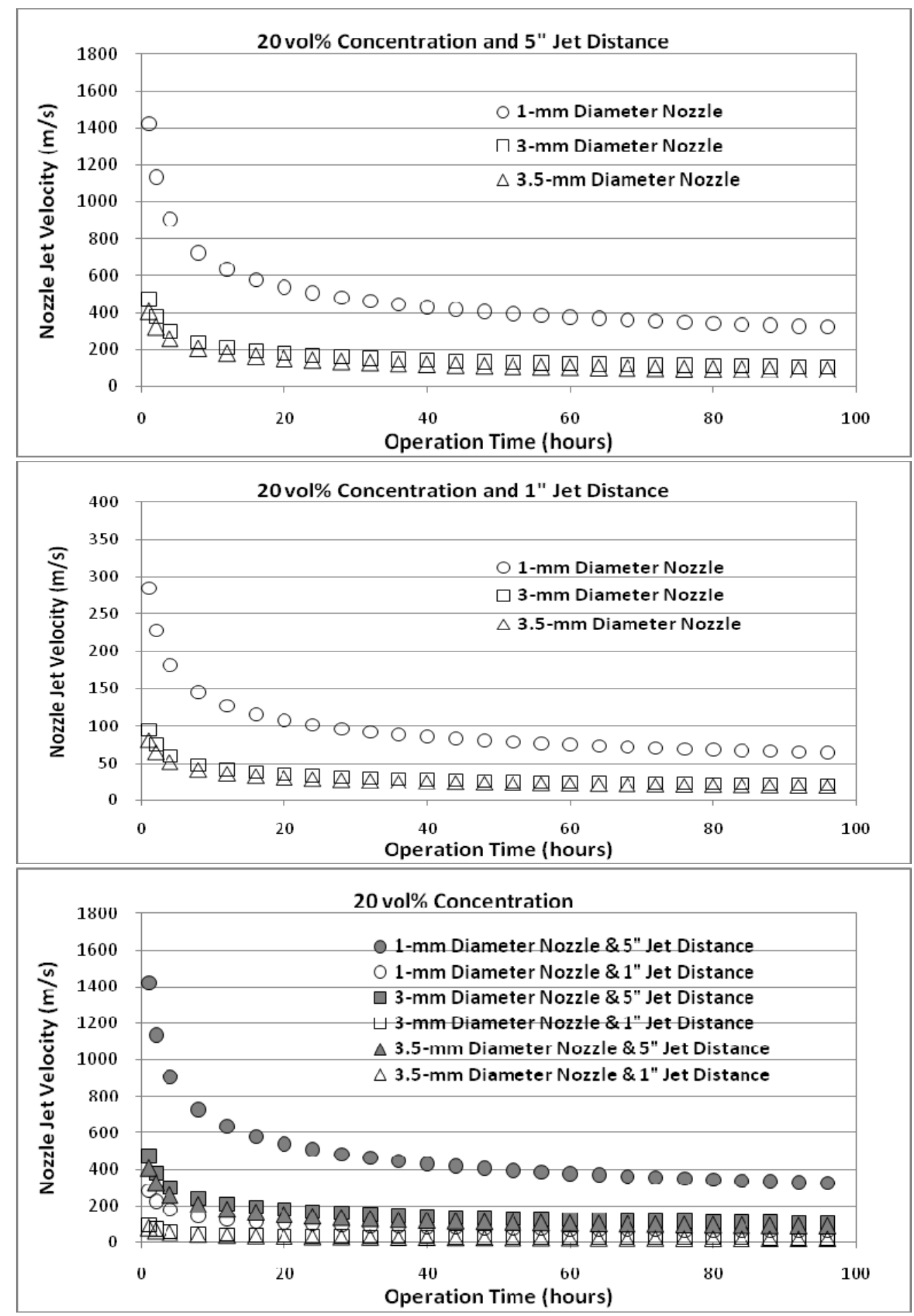

Figure 4.5. Nozzle Jet Velocity vs. Operation Time for 10\% Container Wall Erosion with 20-vol\% Concentration and Various Nozzle Diameters: Top Is of 5-in. Jet Distance from Nozzle, Middle Is of 1-in. Jet Distance from Nozzle, and Bottom Is of Combination of 5-in. and 1-in. Jet Distances from Nozzle 

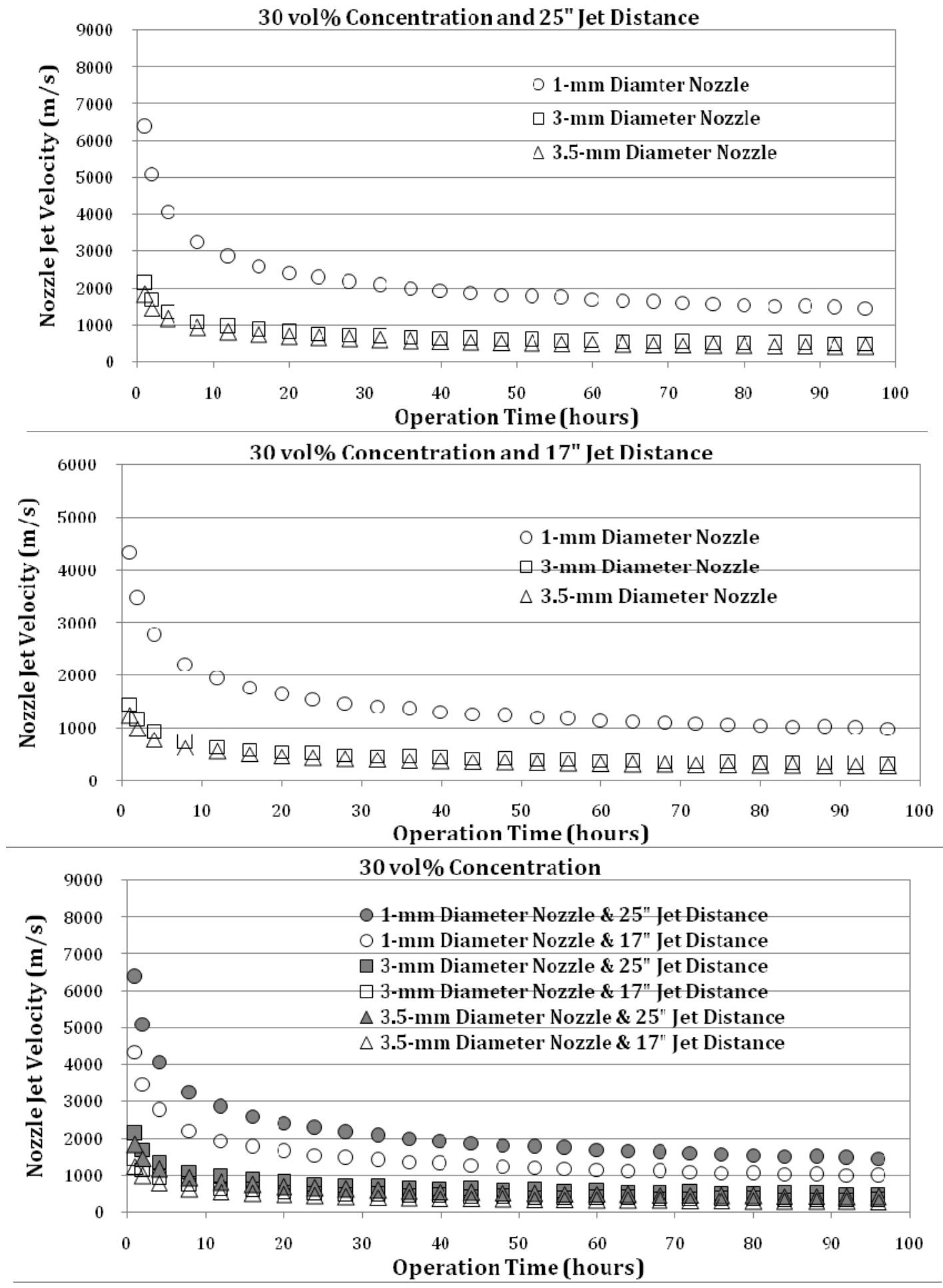

Figure 4.6. Nozzle Jet Velocity vs. Operation Time for 10\% Container Wall Erosion with 30-vol\% Concentration and Various Nozzle Diameters: Top Is of 25-in. Jet Distance from Nozzle, Middle Is of 17-in. Jet Distance from Nozzle, and Bottom Is of Combination of 25-in. and 17-in. Jet Distances from Nozzle 


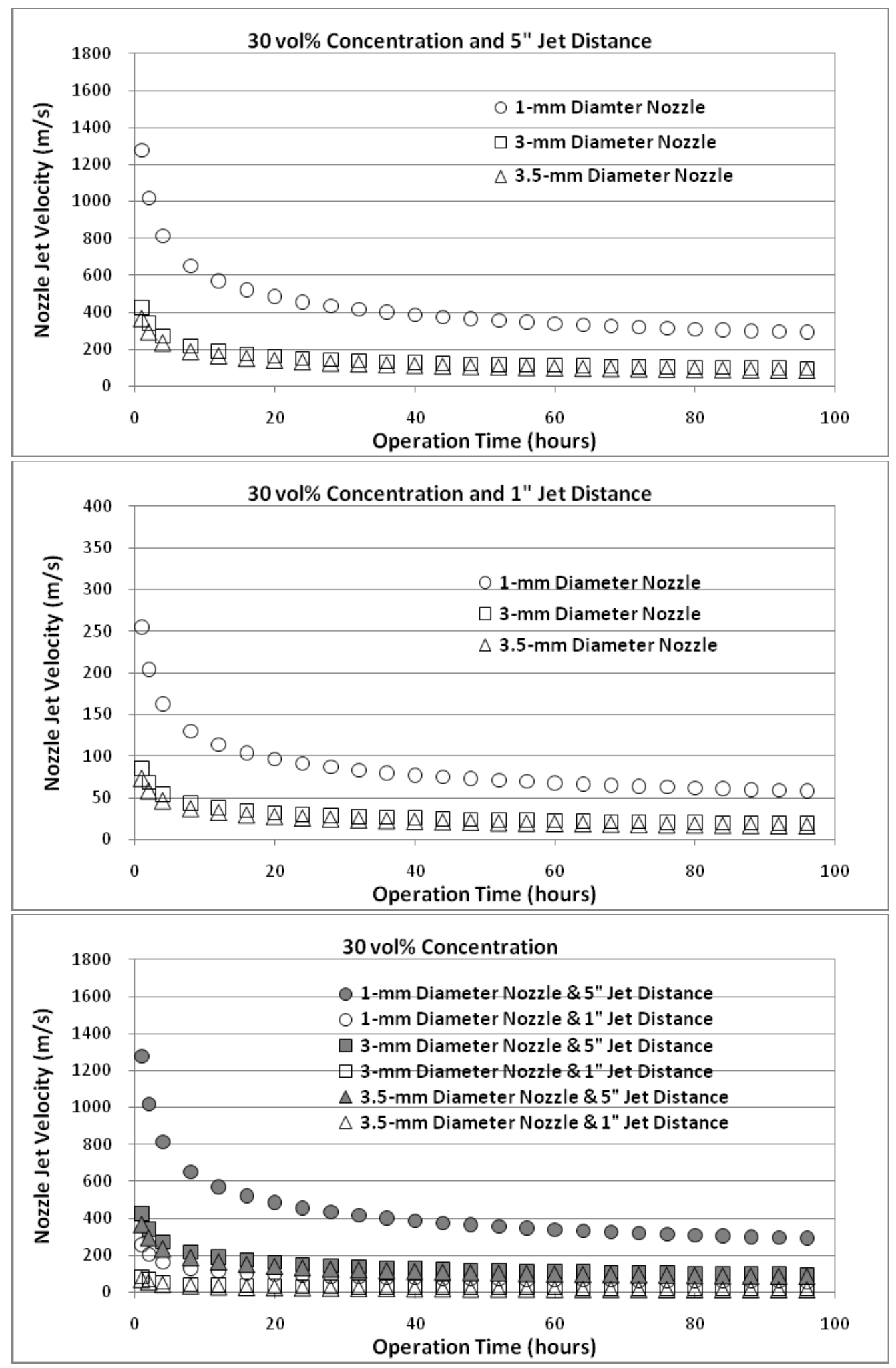

Figure 4.7. Nozzle Jet Velocity vs. Operation Time for 10\% Container Wall Erosion with 30-vol\% Concentration and Various Nozzle Diameters: Top Is of 5-in. Jet Distance from Nozzle, Middle Is of 1-in. Jet Distance from Nozzle, and Bottom Is of Combination of 5-in. and 1-in. Jet Distances from Nozzle 

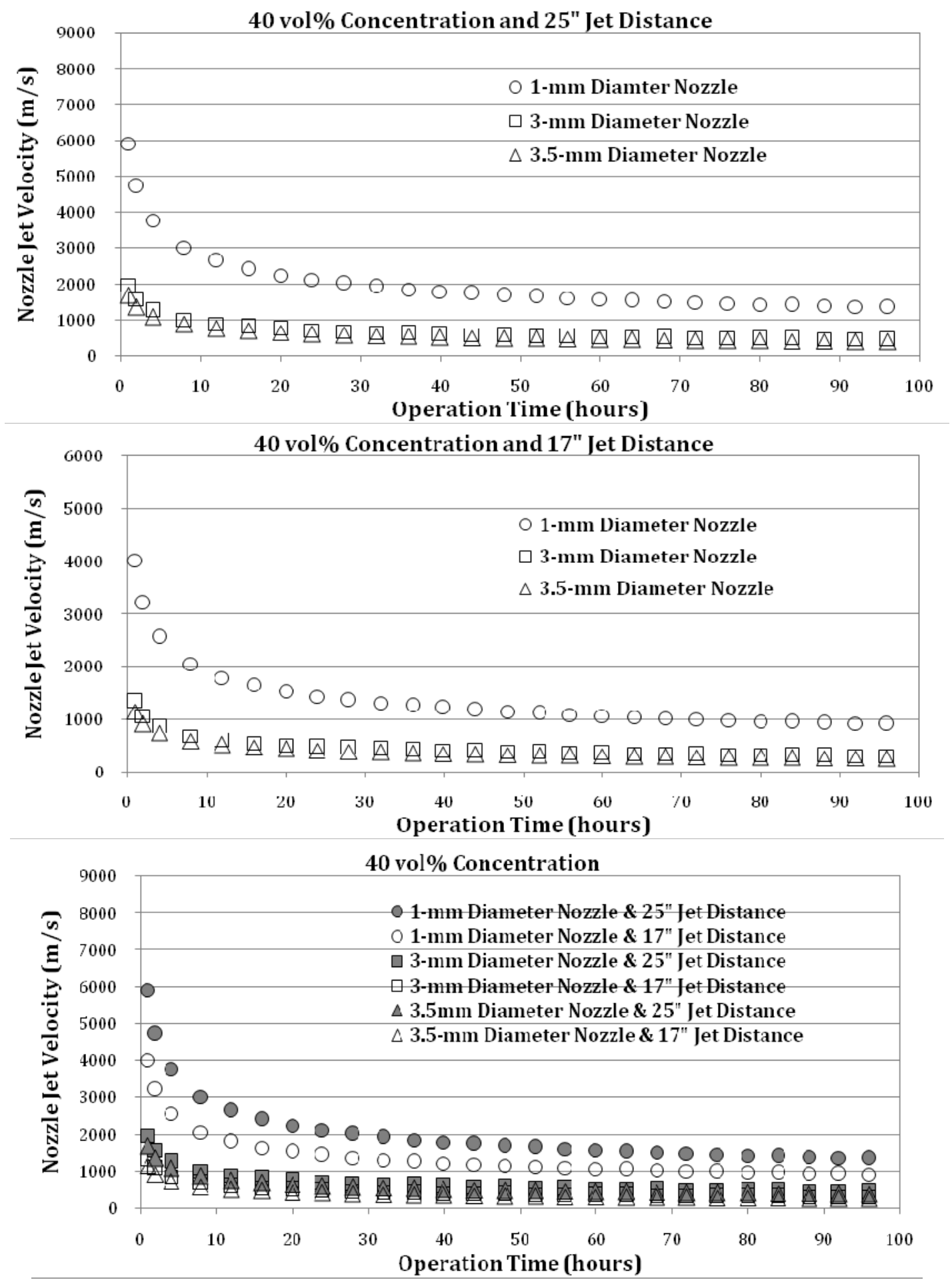

Figure 4.8. Nozzle Jet Velocity vs. Operation Time for 10\% Container Wall Erosion with 40-vol\% Concentration and Various Nozzle Diameters: Top Is of 25-in. Jet Distance from Nozzle, Middle Is of 17-in. Jet Distance from Nozzle, and Bottom Is of Combination of 25-in. and 17-in. Jet Distances from Nozzle 


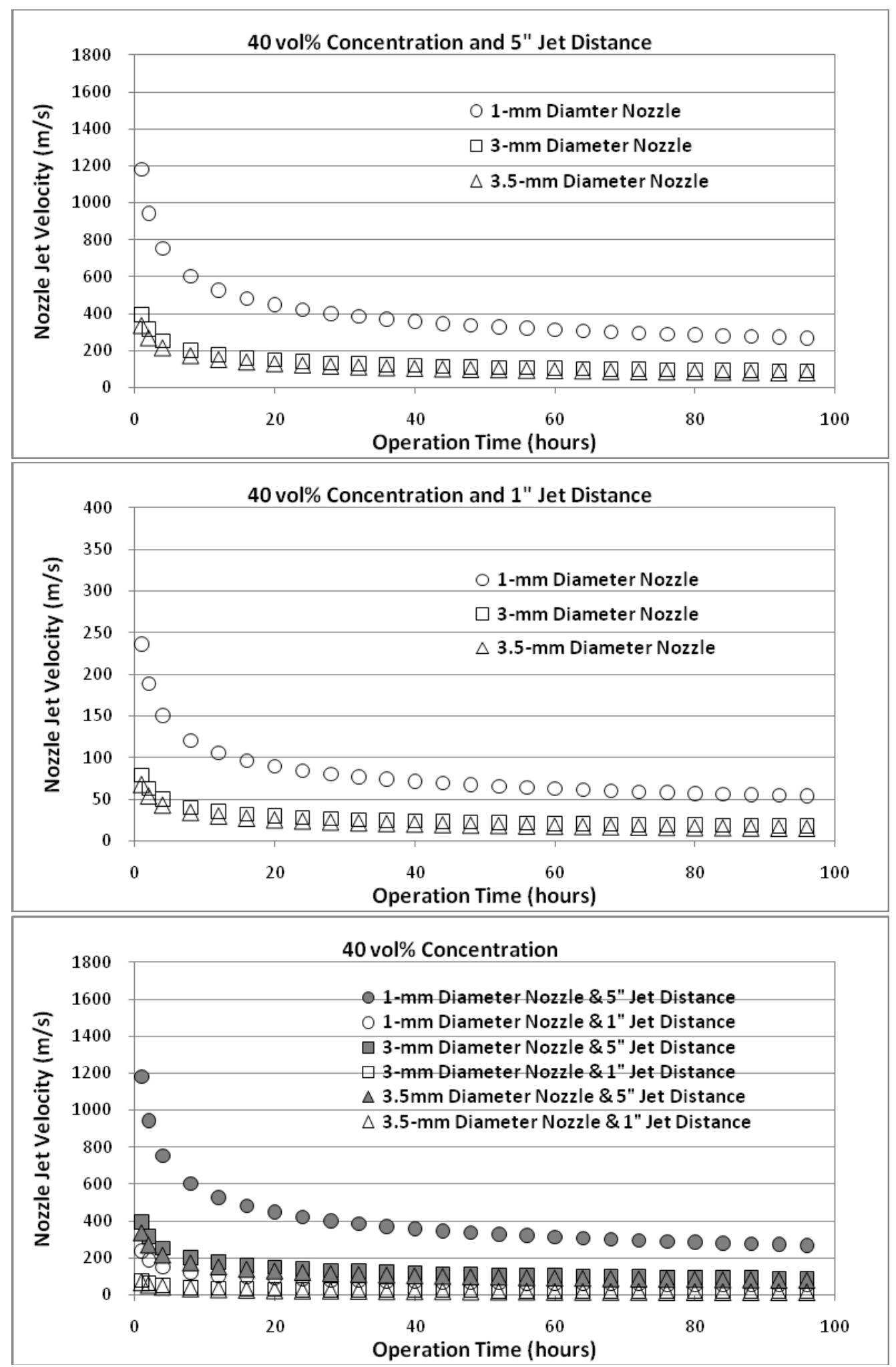

Figure 4.9. Nozzle Jet Velocity vs. Operation Time for $10 \%$ Container Wall Erosion with 40 -vol\% Concentration and Various Nozzle Diameters: Top Is of 5-in. Jet Distance from Nozzle, Middle Is of 1-in. Jet Distance from Nozzle, and Bottom Is of Combination of 5-in. and 1-in. Jet Distances from Nozzle 
Table 4.1. Nozzle Jet Velocities for 10\% Container Wall Erosion with 10-vol\% Concentration, 25-in. Jet Distance from Nozzle, and Various Nozzle Diameters

\begin{tabular}{|c|c|c|c|}
\hline \multicolumn{4}{|c|}{10 vol\% Concentration and 25-in. Jet Distance } \\
\hline $\begin{array}{l}\text { Operation Time } \\
\text { (hours) }\end{array}$ & $\begin{array}{c}\text { 1-mm Nozzle Jet } \\
\text { Velocity }(\mathrm{m} / \mathrm{s})\end{array}$ & $\begin{array}{c}\text { 3-mm Nozzle Jet } \\
\text { Velocity }(\mathrm{m} / \mathrm{s})\end{array}$ & $\begin{array}{c}\text { 3.5-mm Nozzle Jet } \\
\text { Velocity }(\mathrm{m} / \mathrm{s})\end{array}$ \\
\hline 1 & 8563 & 2854 & 2447 \\
\hline 2 & 6840 & 2280 & 1954 \\
\hline 4 & 5464 & 1821 & 1561 \\
\hline 8 & 4365 & 1455 & 1247 \\
\hline 12 & 3827 & 1276 & 1094 \\
\hline 16 & 3487 & 1162 & 996 \\
\hline 20 & 3243 & 1081 & 927 \\
\hline 24 & 3057 & 1019 & 874 \\
\hline 28 & 2908 & 969 & 831 \\
\hline 32 & 2785 & 928 & 796 \\
\hline 36 & 2681 & 894 & 766 \\
\hline 40 & 2591 & 864 & 740 \\
\hline 44 & 2512 & 837 & 718 \\
\hline 48 & 2442 & 814 & 698 \\
\hline 52 & 2380 & 793 & 680 \\
\hline 56 & 2323 & 774 & 664 \\
\hline 60 & 2272 & 757 & 649 \\
\hline 64 & 2225 & 742 & 636 \\
\hline 68 & 2182 & 727 & 623 \\
\hline 72 & 2142 & 714 & 612 \\
\hline 76 & 2104 & 701 & 601 \\
\hline 80 & 2070 & 690 & 591 \\
\hline 84 & 2037 & 679 & 582 \\
\hline 88 & 2007 & 669 & 573 \\
\hline 92 & 1978 & 659 & 565 \\
\hline 96 & 1951 & 650 & 557 \\
\hline
\end{tabular}


Table 4.2. Nozzle Jet Velocities for 10\% Container Wall Erosion with 10-vol\% Concentration, 17 -in. Jet Distance from Nozzle, and Various Nozzle Diameters

\begin{tabular}{|c|c|c|c|}
\hline \multicolumn{4}{|c|}{10 vol\% Concentration and 17-in. Jet Distance } \\
\hline $\begin{array}{l}\text { Operation } \\
\text { Time } \\
\text { [hours] }\end{array}$ & $\begin{array}{c}\text { 1-mm Nozzle } \\
\text { Jet Velocity } \\
(\mathrm{m} / \mathrm{s})\end{array}$ & $\begin{array}{c}\text { 3-mm Nozzle } \\
\text { Jet Velocity } \\
(\mathrm{m} / \mathrm{s})\end{array}$ & $\begin{array}{c}3.5-\mathrm{mm} \\
\text { Nozzle Jet } \\
\text { Velocity }(\mathrm{m} / \mathrm{s})\end{array}$ \\
\hline 1 & 5823 & 1941 & 1664 \\
\hline 2 & 4651 & 1550 & 1329 \\
\hline 4 & 3716 & 1239 & 1062 \\
\hline 8 & 2968 & 989 & 848 \\
\hline 12 & 2603 & 868 & 744 \\
\hline 16 & 2371 & 790 & 677 \\
\hline 20 & 2206 & 735 & 630 \\
\hline 24 & 2079 & 693 & 594 \\
\hline 28 & 1978 & 659 & 565 \\
\hline 32 & 1894 & 631 & 541 \\
\hline 36 & 1823 & 608 & 521 \\
\hline 40 & 1762 & 587 & 503 \\
\hline 44 & 1708 & 569 & 488 \\
\hline 48 & 1661 & 554 & 475 \\
\hline 52 & 1618 & 539 & 462 \\
\hline 56 & 1580 & 527 & 451 \\
\hline 60 & 1545 & 515 & 441 \\
\hline 64 & 1513 & 504 & 432 \\
\hline 68 & 1484 & 495 & 424 \\
\hline 72 & 1456 & 485 & 416 \\
\hline 76 & 1431 & 477 & 409 \\
\hline 80 & 1407 & 469 & 402 \\
\hline 84 & 1385 & 462 & 396 \\
\hline 88 & 1365 & 455 & 390 \\
\hline 92 & 1345 & 448 & 384 \\
\hline 96 & 1327 & 442 & 379 \\
\hline
\end{tabular}


Table 4.3. Nozzle Jet Velocities for $10 \%$ Container Wall Erosion with 10 -vol $\%$ Concentration, 5 -in. Jet Distance from Nozzle, and Various Nozzle Diameters

\begin{tabular}{|c|c|c|c|}
\hline \multicolumn{4}{|c|}{10 vol\% Concentration and 5" Jet Distance } \\
\hline $\begin{array}{l}\text { Operation Time } \\
\text { (hours) }\end{array}$ & $\begin{array}{c}\text { 1-mm Nozzle Jet } \\
\text { Velocity }(\mathrm{m} / \mathrm{s})\end{array}$ & $\begin{array}{c}\text { 3-mm Nozzle Jet } \\
\text { Velocity }(\mathrm{m} / \mathrm{s})\end{array}$ & $\begin{array}{l}\text { 3.5-mm Nozzle Jet } \\
\text { Velocity }(\mathrm{m} / \mathrm{s})\end{array}$ \\
\hline 1 & 1713 & 571 & 489 \\
\hline 2 & 1368 & 456 & 391 \\
\hline 4 & 1093 & 364 & 312 \\
\hline 8 & 873 & 291 & 249 \\
\hline 12 & 765 & 255 & 219 \\
\hline 16 & 697 & 232 & 199 \\
\hline 20 & 649 & 216 & 185 \\
\hline 24 & 611 & 204 & 175 \\
\hline 28 & 582 & 194 & 166 \\
\hline 32 & 557 & 186 & 159 \\
\hline 36 & 536 & 179 & 153 \\
\hline 40 & 518 & 173 & 148 \\
\hline 44 & 502 & 167 & 144 \\
\hline 48 & 488 & 163 & 140 \\
\hline 52 & 476 & 159 & 136 \\
\hline 56 & 465 & 155 & 133 \\
\hline 60 & 454 & 151 & 130 \\
\hline 64 & 445 & 148 & 127 \\
\hline 68 & 436 & 145 & 125 \\
\hline 72 & 428 & 143 & 122 \\
\hline 76 & 421 & 140 & 120 \\
\hline 80 & 414 & 138 & 118 \\
\hline 84 & 407 & 136 & 116 \\
\hline 88 & 401 & 134 & 115 \\
\hline 92 & 396 & 132 & 113 \\
\hline 96 & 390 & 130 & 111 \\
\hline
\end{tabular}


Table 4.4. Nozzle Jet Velocities for 10\% Container Wall Erosion with 10 -vol\% Concentration, 1 -in. Jet Distance from Nozzle, and Various Nozzle Diameters

\begin{tabular}{cccc}
\hline \multicolumn{4}{c}{ 10 vol\% Concentration and 1" Jet Distance } \\
\hline $\begin{array}{c}\text { Operation Time } \\
\text { (hours) }\end{array}$ & $\begin{array}{c}\text { 1-mm Nozzle Jet } \\
\text { Velocity }(\mathrm{m} / \mathrm{s})\end{array}$ & $\begin{array}{c}\text { 3-mm Nozzle Jet } \\
\text { Velocity }(\mathrm{m} / \mathrm{s})\end{array}$ & $\begin{array}{c}3.5 \text {-mm Nozzle Jet } \\
\text { Velocity }(\mathrm{m} / \mathrm{s})\end{array}$ \\
\hline 1 & 343 & 114 & 98 \\
2 & 274 & 91 & 78 \\
4 & 219 & 73 & 62 \\
8 & 175 & 58 & 50 \\
12 & 153 & 51 & 44 \\
16 & 139 & 46 & 40 \\
20 & 130 & 43 & 37 \\
24 & 122 & 41 & 35 \\
28 & 116 & 39 & 33 \\
32 & 111 & 37 & 32 \\
36 & 107 & 36 & 31 \\
40 & 104 & 35 & 29 \\
44 & 100 & 33 & 28 \\
48 & 98 & 33 & 27 \\
52 & 95 & 32 & 27 \\
56 & 93 & 31 & 26 \\
60 & 91 & 30 & 25 \\
64 & 89 & 30 & 25 \\
68 & 87 & 29 & 24 \\
72 & 86 & 29 & 24 \\
76 & 84 & 28 & 24 \\
80 & 83 & 28 & 23 \\
84 & 81 & 27 & 23 \\
88 & 80 & 27 & 26 \\
92 & 79 & 26 & \\
96 & 78 & & 23 \\
\hline
\end{tabular}


Table 4.5. Nozzle Jet Velocities for 10\% Container Wall Erosion with 20-vol\% Concentration, 25-in. Jet Distance from Nozzle, and Various Nozzle Diameters

\begin{tabular}{|c|c|c|c|}
\hline \multicolumn{4}{|c|}{20 vol\% Concentration and 25-in. Jet Distance } \\
\hline $\begin{array}{l}\text { Operation } \\
\text { Time } \\
\text { [hours] }\end{array}$ & $\begin{array}{c}\text { 1-mm Nozzle } \\
\text { Jet Velocity } \\
(\mathrm{m} / \mathrm{s})\end{array}$ & $\begin{array}{c}\text { 3-mm Nozzle } \\
\text { Jet Velocity } \\
(\mathrm{m} / \mathrm{s})\end{array}$ & $\begin{array}{c}3.5-\mathrm{mm} \\
\text { Nozzle Jet } \\
\text { Velocity }(\mathrm{m} / \mathrm{s})\end{array}$ \\
\hline 1 & 7115 & 2372 & 2033 \\
\hline 2 & 5683 & 1894 & 1624 \\
\hline 4 & 4540 & 1513 & 1297 \\
\hline 8 & 3627 & 1209 & 1036 \\
\hline 12 & 3180 & 1060 & 909 \\
\hline 16 & 2897 & 966 & 828 \\
\hline 20 & 2695 & 898 & 770 \\
\hline 24 & 2540 & 847 & 726 \\
\hline 28 & 2417 & 806 & 690 \\
\hline 32 & 2314 & 771 & 661 \\
\hline 36 & 2228 & 743 & 636 \\
\hline 40 & 2153 & 718 & 615 \\
\hline 44 & 2087 & 696 & 596 \\
\hline 48 & 2029 & 676 & 580 \\
\hline 52 & 1977 & 659 & 565 \\
\hline 56 & 1930 & 643 & 552 \\
\hline 60 & 1888 & 629 & 539 \\
\hline 64 & 1849 & 616 & 528 \\
\hline 68 & 1813 & 604 & 518 \\
\hline 72 & 1779 & 593 & 508 \\
\hline 76 & 1749 & 583 & 500 \\
\hline 80 & 1720 & 573 & 491 \\
\hline 84 & 1693 & 564 & 484 \\
\hline 88 & 1667 & 556 & 476 \\
\hline 92 & 1644 & 548 & 470 \\
\hline 96 & 1621 & 540 & 463 \\
\hline
\end{tabular}


Table 4.6. Nozzle Jet Velocities for $10 \%$ Container Wall Erosion with 20 -vol\% Concentration, 17 -in. Jet Distance from Nozzle, and Various Nozzle Diameters

\begin{tabular}{|c|c|c|c|}
\hline \multicolumn{4}{|c|}{20 vol\% Concentration and 17-in. Jet Distance } \\
\hline $\begin{array}{l}\text { Operation } \\
\text { Time } \\
\text { [hours] }\end{array}$ & $\begin{array}{c}\text { 1-mm Nozzle } \\
\text { Jet Velocity } \\
(\mathrm{m} / \mathrm{s})\end{array}$ & $\begin{array}{c}\text { 3-mm Nozzle } \\
\text { Jet Velocity } \\
(\mathrm{m} / \mathrm{s})\end{array}$ & $\begin{array}{c}3.5-\mathrm{mm} \\
\text { Nozzle Jet } \\
\text { Velocity }(\mathrm{m} / \mathrm{s})\end{array}$ \\
\hline 1 & 4838 & 1613 & 1382 \\
\hline 2 & 3865 & 1288 & 1104 \\
\hline 4 & 3087 & 1029 & 882 \\
\hline 8 & 2466 & 822 & 705 \\
\hline 12 & 2163 & 721 & 618 \\
\hline 16 & 1970 & 657 & 563 \\
\hline 20 & 1833 & 611 & 524 \\
\hline 24 & 1727 & 576 & 494 \\
\hline 28 & 1643 & 548 & 470 \\
\hline 32 & 1574 & 525 & 450 \\
\hline 36 & 1515 & 505 & 433 \\
\hline 40 & 1464 & 488 & 418 \\
\hline 44 & 1419 & 473 & 406 \\
\hline 48 & 1380 & 460 & 394 \\
\hline 52 & 1345 & 448 & 384 \\
\hline 56 & 1313 & 438 & 375 \\
\hline 60 & 1284 & 428 & 367 \\
\hline 64 & 1257 & 419 & 359 \\
\hline 68 & 1233 & 411 & 352 \\
\hline 72 & 1210 & 403 & 346 \\
\hline 76 & 1189 & 396 & 340 \\
\hline 80 & 1169 & 390 & 334 \\
\hline 84 & 1151 & 384 & 329 \\
\hline 88 & 1134 & 378 & 324 \\
\hline 92 & 1118 & 373 & 319 \\
\hline 96 & 1102 & 367 & 315 \\
\hline
\end{tabular}


Table 4.7. Nozzle Jet Velocities for $10 \%$ Container Wall Erosion with 20 -vol $\%$ Concentration, 5 -in. Jet Distance from Nozzle, and Various Nozzle Diameters

\begin{tabular}{|c|c|c|c|}
\hline \multicolumn{4}{|c|}{20 vol\% Concentration and 5" Jet Distance } \\
\hline \multicolumn{4}{|c|}{$\overline{\text { Operation Time1-mm Nozzle Jet3-mm Nozzle Jet3.5-mm Nozzle Jet }}$} \\
\hline (hours) & Velocity $(\mathrm{m} / \mathrm{s})$ & Velocity $(\mathrm{m} / \mathrm{s})$ & Velocity $(\mathrm{m} / \mathrm{s})$ \\
\hline 1 & 1423 & 474 & 407 \\
\hline 2 & 1137 & 379 & 325 \\
\hline 4 & 908 & 303 & 259 \\
\hline 8 & 725 & 242 & 207 \\
\hline 12 & 636 & 212 & 182 \\
\hline 16 & 579 & 193 & 166 \\
\hline 20 & 539 & 180 & 154 \\
\hline 24 & 508 & 169 & 145 \\
\hline 28 & 483 & 161 & 138 \\
\hline 32 & 463 & 154 & 132 \\
\hline 36 & 446 & 149 & 127 \\
\hline 40 & 431 & 144 & 123 \\
\hline 44 & 417 & 139 & 119 \\
\hline 48 & 406 & 135 & 116 \\
\hline 52 & 395 & 132 & 113 \\
\hline 56 & 386 & 129 & 110 \\
\hline 60 & 378 & 126 & 108 \\
\hline 64 & 370 & 123 & 106 \\
\hline 68 & 363 & 121 & 104 \\
\hline 72 & 356 & 119 & 102 \\
\hline 76 & 350 & 117 & 100 \\
\hline 80 & 344 & 115 & 98 \\
\hline 84 & 339 & 113 & 97 \\
\hline 88 & 333 & 111 & 95 \\
\hline 92 & 329 & 110 & 94 \\
\hline 96 & 324 & 108 & 93 \\
\hline
\end{tabular}


Table 4.8. Nozzle Jet Velocities for 10\% Container Wall Erosion with 20 -vol\% Concentration, 1-in. Jet Distance from Nozzle, and Various Nozzle Diameters

\begin{tabular}{|c|c|c|c|}
\hline \multicolumn{4}{|c|}{20 vol\% Concentration and 1" Jet Distance } \\
\hline $\begin{array}{c}\text { Operation Time } \\
\text { (hours) }\end{array}$ & $\begin{array}{c}\text { 1-mm Nozzle Jet } \\
\text { Velocity }(\mathrm{m} / \mathrm{s})\end{array}$ & $\begin{array}{c}\text { 3-mm Nozzle Jet } \\
\text { Velocity }(\mathrm{m} / \mathrm{s})\end{array}$ & $\begin{array}{l}\text { 3.5-mm Nozzle Jet } \\
\text { Velocity }(\mathrm{m} / \mathrm{s})\end{array}$ \\
\hline 1 & 285 & 95 & 81 \\
\hline 2 & 227 & 76 & 65 \\
\hline 4 & 182 & 61 & 52 \\
\hline 8 & 145 & 48 & 41 \\
\hline 12 & 127 & 42 & 36 \\
\hline 16 & 116 & 39 & 33 \\
\hline 20 & 108 & 36 & 31 \\
\hline 24 & 102 & 34 & 29 \\
\hline 28 & 97 & 32 & 28 \\
\hline 32 & 93 & 31 & 26 \\
\hline 36 & 89 & 30 & 25 \\
\hline 40 & 86 & 29 & 25 \\
\hline 44 & 83 & 28 & 24 \\
\hline 48 & 81 & 27 & 23 \\
\hline 52 & 79 & 26 & 23 \\
\hline 56 & 77 & 26 & 22 \\
\hline 60 & 76 & 25 & 22 \\
\hline 64 & 74 & 25 & 21 \\
\hline 68 & 73 & 24 & 21 \\
\hline 72 & 71 & 24 & 20 \\
\hline 76 & 70 & 23 & 20 \\
\hline 80 & 69 & 23 & 20 \\
\hline 84 & 68 & 23 & 19 \\
\hline 88 & 67 & 22 & 19 \\
\hline 92 & 66 & 22 & 19 \\
\hline 96 & 65 & 22 & 19 \\
\hline
\end{tabular}


Table 4.9. Nozzle Jet Velocities for 10\% Container Wall Erosion with 30-vol\% Concentration, 25-in. Jet Distance from Nozzle, and Various Nozzle Diameters

\begin{tabular}{|c|c|c|c|}
\hline \multicolumn{4}{|c|}{30 vol\% Concentration and 25-in. Jet Distance } \\
\hline $\begin{array}{l}\text { Operation } \\
\text { Time } \\
\text { [hours] }\end{array}$ & $\begin{array}{c}\text { 1-mm Nozzle } \\
\text { Jet Velocity } \\
(\mathrm{m} / \mathrm{s})\end{array}$ & $\begin{array}{c}\text { 3-mm Nozzle } \\
\text { Jet Velocity } \\
(\mathrm{m} / \mathrm{s})\end{array}$ & $\begin{array}{c}3.5-\mathrm{mm} \\
\text { Nozzle Jet } \\
\text { Velocity }(\mathrm{m} / \mathrm{s})\end{array}$ \\
\hline 1 & 6384 & 2128 & 1824 \\
\hline 2 & 5100 & 1700 & 1457 \\
\hline 4 & 4074 & 1358 & 1164 \\
\hline 8 & 3254 & 1085 & 930 \\
\hline 12 & 2854 & 951 & 815 \\
\hline 16 & 2600 & 867 & 743 \\
\hline 20 & 2418 & 806 & 691 \\
\hline 24 & 2279 & 760 & 651 \\
\hline 28 & 2168 & 723 & 620 \\
\hline 32 & 2077 & 692 & 593 \\
\hline 36 & 1999 & 666 & 571 \\
\hline 40 & 1932 & 644 & 552 \\
\hline 44 & 1873 & 624 & 535 \\
\hline 48 & 1821 & 607 & 520 \\
\hline 52 & 1774 & 591 & 507 \\
\hline 56 & 1732 & 577 & 495 \\
\hline 60 & 1694 & 565 & 484 \\
\hline 64 & 1659 & 553 & 474 \\
\hline 68 & 1627 & 542 & 465 \\
\hline 72 & 1597 & 532 & 456 \\
\hline 76 & 1569 & 523 & 448 \\
\hline 80 & 1543 & 514 & 441 \\
\hline 84 & 1519 & 506 & 434 \\
\hline 88 & 1496 & 499 & 427 \\
\hline 92 & 1475 & 492 & 421 \\
\hline 96 & 1455 & 485 & 416 \\
\hline
\end{tabular}


Table 4.10. Nozzle Jet Velocities for $10 \%$ Container Wall Erosion with 30-vol\% Concentration, 17-in. Jet Distance from Nozzle, and Various Nozzle Diameters

\begin{tabular}{|c|c|c|c|}
\hline \multicolumn{4}{|c|}{30 vol\% Concentration and 17-in. Jet Distance } \\
\hline $\begin{array}{l}\text { Operation } \\
\text { Time } \\
\text { [hours] }\end{array}$ & $\begin{array}{c}\text { 1-mm Nozzle } \\
\text { Jet Velocity } \\
(\mathrm{m} / \mathrm{s})\end{array}$ & $\begin{array}{c}\text { 3-mm Nozzle } \\
\text { Jet Velocity } \\
(\mathrm{m} / \mathrm{s})\end{array}$ & $\begin{array}{c}3.5-\mathrm{mm} \\
\text { Nozzle Jet } \\
\text { Velocity }(\mathrm{m} / \mathrm{s})\end{array}$ \\
\hline 1 & 4341 & 1447 & 1240 \\
\hline 2 & 3468 & 1156 & 991 \\
\hline 4 & 2770 & 923 & 791 \\
\hline 8 & 2213 & 738 & 632 \\
\hline 12 & 1940 & 647 & 554 \\
\hline 16 & 1768 & 589 & 505 \\
\hline 20 & 1644 & 548 & 470 \\
\hline 24 & 1550 & 517 & 443 \\
\hline 28 & 1475 & 492 & 421 \\
\hline 32 & 1412 & 471 & 403 \\
\hline 36 & 1359 & 453 & 388 \\
\hline 40 & 1314 & 438 & 375 \\
\hline 44 & 1274 & 425 & 364 \\
\hline 48 & 1238 & 413 & 354 \\
\hline 52 & 1207 & 402 & 345 \\
\hline 56 & 1178 & 393 & 337 \\
\hline 60 & 1152 & 384 & 329 \\
\hline 64 & 1128 & 376 & 322 \\
\hline 68 & 1106 & 369 & 316 \\
\hline 72 & 1086 & 362 & 310 \\
\hline 76 & 1067 & 356 & 305 \\
\hline 80 & 1049 & 350 & 300 \\
\hline 84 & 1033 & 344 & 295 \\
\hline 88 & 1017 & 339 & 291 \\
\hline 92 & 1003 & 334 & 287 \\
\hline 96 & 989 & 330 & 283 \\
\hline
\end{tabular}


Table 4.11. Nozzle Jet Velocities for $10 \%$ Container Wall Erosion with 30-vol\% Concentration, 5-in. Jet Distance from Nozzle, and Various Nozzle Diameters

\begin{tabular}{|c|c|c|c|}
\hline \multicolumn{4}{|c|}{$30 \mathrm{vol} \%$ Concentration and 5" Jet Distance } \\
\hline $\begin{array}{l}\text { Operation Time } \\
\text { (hours) }\end{array}$ & $\begin{array}{l}\text { 1-mm Nozzle Jet } \\
\text { Velocity }(\mathrm{m} / \mathrm{s})\end{array}$ & $\begin{array}{c}\text { 3-mm Nozzle Jet } \\
\text { Velocity }(\mathrm{m} / \mathrm{s})\end{array}$ & $\begin{array}{l}\text { 3.5-mm Nozzle Jet } \\
\text { Velocity }(\mathrm{m} / \mathrm{s})\end{array}$ \\
\hline 1 & 1277 & 426 & 365 \\
\hline 2 & 1020 & 340 & 291 \\
\hline 4 & 815 & 272 & 233 \\
\hline 8 & 651 & 217 & 186 \\
\hline 12 & 571 & 190 & 163 \\
\hline 16 & 520 & 173 & 149 \\
\hline 20 & 484 & 161 & 138 \\
\hline 24 & 456 & 152 & 130 \\
\hline 28 & 434 & 145 & 124 \\
\hline 32 & 415 & 138 & 119 \\
\hline 36 & 400 & 133 & 114 \\
\hline 40 & 386 & 129 & 110 \\
\hline 44 & 375 & 125 & 107 \\
\hline 48 & 364 & 121 & 104 \\
\hline 52 & 355 & 118 & 101 \\
\hline 56 & 346 & 115 & 99 \\
\hline 60 & 339 & 113 & 97 \\
\hline 64 & 332 & 111 & 95 \\
\hline 68 & 325 & 108 & 93 \\
\hline 72 & 319 & 106 & 91 \\
\hline 76 & 314 & 105 & 90 \\
\hline 80 & 309 & 103 & 88 \\
\hline 84 & 304 & 101 & 87 \\
\hline 88 & 299 & 100 & 85 \\
\hline 92 & 295 & 98 & 84 \\
\hline 96 & 291 & 97 & 83 \\
\hline
\end{tabular}


Table 4.12. Nozzle Jet Velocities for $10 \%$ Container Wall Erosion with 30 -vol\% Concentration, 1-in. Jet Distance from Nozzle, and Various Nozzle Diameters

\begin{tabular}{cccc}
\hline \multicolumn{4}{c}{ 30 vol\% Concentration and 1" Jet Distance } \\
\hline $\begin{array}{c}\text { Operation Time } \\
\text { [hours }]\end{array}$ & $\begin{array}{c}\text { 1-mm Nozzle } \\
\text { Jet Velocity }(\mathrm{m} / \mathrm{s})\end{array}$ & $\begin{array}{c}\text { 3-mm Nozzle } \\
\text { Jet Velocity }(\mathrm{m} / \mathrm{s})\end{array}$ & $\begin{array}{c}3.5 \text {-mm Nozzle } \\
\text { Jet Velocity }(\mathrm{m} / \mathrm{s})\end{array}$ \\
\hline 1 & 255 & 85 & 73 \\
2 & 204 & 68 & 58 \\
4 & 163 & 54 & 47 \\
8 & 130 & 43 & 37 \\
12 & 114 & 38 & 33 \\
16 & 104 & 35 & 30 \\
20 & 97 & 32 & 28 \\
\hline 24 & 91 & 30 & 26 \\
28 & 87 & 29 & 25 \\
32 & 83 & 28 & 24 \\
36 & 80 & 27 & 23 \\
40 & 77 & 26 & 22 \\
44 & 75 & 25 & 21 \\
48 & 73 & 24 & 21 \\
52 & 71 & 24 & 20 \\
56 & 69 & 23 & 20 \\
60 & 68 & 23 & 19 \\
64 & 66 & 22 & 19 \\
68 & 65 & 22 & 19 \\
72 & 64 & 21 & 18 \\
76 & 63 & 21 & 18 \\
80 & 62 & 21 & 18 \\
84 & 61 & 20 & 17 \\
88 & 60 & 20 & 17 \\
92 & 59 & 20 & \\
96 & 58 & 19 & \\
\hline
\end{tabular}


Table 4.13. Nozzle Jet Velocities for 10\% Container Wall Erosion with 40-vol\% Concentration, 25-in. Jet Distance from Nozzle, and Various Nozzle Diameters

\begin{tabular}{|c|c|c|c|}
\hline \multicolumn{4}{|c|}{$40 \mathrm{vol} \%$ Concentration and 25-in. Jet Distance } \\
\hline $\begin{array}{l}\text { Operation } \\
\text { Time } \\
\text { [hours] }\end{array}$ & $\begin{array}{c}\text { 1-mm Nozzle } \\
\text { Jet Velocity } \\
(\mathrm{m} / \mathrm{s})\end{array}$ & $\begin{array}{c}\text { 3-mm Nozzle } \\
\text { Jet Velocity } \\
(\mathrm{m} / \mathrm{s})\end{array}$ & $\begin{array}{c}3.5-\mathrm{mm} \\
\text { Nozzle Jet } \\
\text { Velocity }(\mathrm{m} / \mathrm{s})\end{array}$ \\
\hline 1 & 5912 & 1971 & 1689 \\
\hline 2 & 4722 & 1574 & 1349 \\
\hline 4 & 3772 & 1257 & 1078 \\
\hline 8 & 3013 & 1004 & 861 \\
\hline 12 & 2642 & 881 & 755 \\
\hline 16 & 2407 & 802 & 688 \\
\hline 20 & 2239 & 746 & 640 \\
\hline 24 & 2111 & 704 & 603 \\
\hline 28 & 2008 & 669 & 574 \\
\hline 32 & 1923 & 641 & 549 \\
\hline 36 & 1851 & 617 & 529 \\
\hline 40 & 1789 & 596 & 511 \\
\hline 44 & 1734 & 578 & 496 \\
\hline 48 & 1686 & 562 & 482 \\
\hline 52 & 1643 & 548 & 469 \\
\hline 56 & 1604 & 535 & 458 \\
\hline 60 & 1569 & 523 & 448 \\
\hline 64 & 1536 & 512 & 439 \\
\hline 68 & 1506 & 502 & 430 \\
\hline 72 & 1479 & 493 & 422 \\
\hline 76 & 1453 & 484 & 415 \\
\hline 80 & 1429 & 476 & 408 \\
\hline 84 & 1406 & 469 & 402 \\
\hline 88 & 1385 & 462 & 396 \\
\hline 92 & 1366 & 455 & 390 \\
\hline 96 & 1347 & 449 & 385 \\
\hline
\end{tabular}


Table 4.14. Nozzle Jet Velocities for $10 \%$ Container Wall Erosion with 40-vol\% Concentration, 17 -in. Jet Distance from Nozzle, and Various Nozzle Diameters

\begin{tabular}{|c|c|c|c|}
\hline \multicolumn{4}{|c|}{40 vol\% Concentration and 17-in. Jet Distance } \\
\hline $\begin{array}{l}\text { Operation } \\
\text { Time } \\
\text { [hours] }\end{array}$ & $\begin{array}{c}\text { 1-mm Nozzle } \\
\text { Jet Velocity } \\
(\mathrm{m} / \mathrm{s})\end{array}$ & $\begin{array}{c}\text { 3-mm Nozzle } \\
\text { Jet Velocity } \\
(\mathrm{m} / \mathrm{s})\end{array}$ & $\begin{array}{c}3.5-\mathrm{mm} \\
\text { Nozzle Jet } \\
\text { Velocity }(\mathrm{m} / \mathrm{s})\end{array}$ \\
\hline 1 & 4020 & 1340 & 1149 \\
\hline 2 & 3211 & 1070 & 917 \\
\hline 4 & 2565 & 855 & 733 \\
\hline 8 & 2049 & 683 & 585 \\
\hline 12 & 1797 & 599 & 513 \\
\hline 16 & 1637 & 546 & 468 \\
\hline 20 & 1523 & 508 & 435 \\
\hline 24 & 1435 & 478 & 410 \\
\hline 28 & 1365 & 455 & 390 \\
\hline 32 & 1308 & 436 & 374 \\
\hline 36 & 1259 & 420 & 360 \\
\hline 40 & 1216 & 405 & 348 \\
\hline 44 & 1179 & 393 & 337 \\
\hline 48 & 1147 & 382 & 328 \\
\hline 52 & 1117 & 372 & 319 \\
\hline 56 & 1091 & 364 & 312 \\
\hline 60 & 1067 & 356 & 305 \\
\hline 64 & 1045 & 348 & 298 \\
\hline 68 & 1024 & 341 & 293 \\
\hline 72 & 1005 & 335 & 287 \\
\hline 76 & 988 & 329 & 282 \\
\hline 80 & 972 & 324 & 278 \\
\hline 84 & 956 & 319 & 273 \\
\hline 88 & 942 & 314 & 269 \\
\hline 92 & 929 & 310 & 265 \\
\hline 96 & 916 & 305 & 262 \\
\hline
\end{tabular}


Table 4.15. Nozzle Jet Velocities for 10\% Container Wall Erosion with 40-vol\% Concentration, 5-in. Jet Distance from Nozzle, and Various Nozzle Diameters

\begin{tabular}{|c|c|c|c|}
\hline \multicolumn{4}{|c|}{$40 \mathrm{vol} \%$ Concentration and 5" Jet Distance } \\
\hline $\begin{array}{c}\text { Operation Time } \\
\text { [hours] }\end{array}$ & $\begin{array}{c}\text { 1-mm Nozzle Jet } \\
\text { Velocity }(\mathrm{m} / \mathrm{s})\end{array}$ & $\begin{array}{c}\text { 3-mm Nozzle Jet } \\
\text { Velocity }(\mathrm{m} / \mathrm{s})\end{array}$ & $\begin{array}{l}\text { 3.5-mm Nozzle Jet } \\
\text { Velocity }(\mathrm{m} / \mathrm{s})\end{array}$ \\
\hline 1 & 1182 & 394 & 338 \\
\hline 2 & 944 & 315 & 270 \\
\hline 4 & 754 & 251 & 216 \\
\hline 8 & 603 & 201 & 172 \\
\hline 12 & 528 & 176 & 151 \\
\hline 16 & 481 & 160 & 138 \\
\hline 20 & 448 & 149 & 128 \\
\hline 24 & 422 & 141 & 121 \\
\hline 28 & 402 & 134 & 115 \\
\hline 32 & 385 & 128 & 110 \\
\hline 36 & 370 & 123 & 106 \\
\hline 40 & 358 & 119 & 102 \\
\hline 44 & 347 & 116 & 99 \\
\hline 48 & 337 & 112 & 96 \\
\hline 52 & 329 & 110 & 94 \\
\hline 56 & 321 & 107 & 92 \\
\hline 60 & 314 & 105 & 90 \\
\hline 64 & 307 & 102 & 88 \\
\hline 68 & 301 & 100 & 86 \\
\hline 72 & 296 & 99 & 84 \\
\hline 76 & 291 & 97 & 83 \\
\hline 80 & 286 & 95 & 82 \\
\hline 84 & 281 & 94 & 80 \\
\hline 88 & 277 & 92 & 79 \\
\hline 92 & 273 & 91 & 78 \\
\hline 96 & 269 & 90 & 77 \\
\hline
\end{tabular}


Table 4.16. Nozzle Jet Velocities for $10 \%$ Container Wall Erosion with 40 -vol\% Concentration, 1 -in. Jet Distance from Nozzle, and Various Nozzle Diameters

\begin{tabular}{|c|c|c|c|}
\hline \multicolumn{4}{|c|}{40 vol\% Concentration and 1" Jet Distance } \\
\hline $\begin{array}{l}\text { Operation Time } \\
\text { (hours) }\end{array}$ & $\begin{array}{c}\text { 1-mm Nozzle Jet } \\
\text { Velocity }(\mathrm{m} / \mathrm{s})\end{array}$ & $\begin{array}{c}\text { 3-mm Nozzle Jet } \\
\text { Velocity }(\mathrm{m} / \mathrm{s})\end{array}$ & $\begin{array}{l}\text { 3.5-mm Nozzle Jet } \\
\text { Velocity }(\mathrm{m} / \mathrm{s})\end{array}$ \\
\hline 1 & 236 & 79 & 68 \\
\hline 2 & 189 & 63 & 54 \\
\hline 4 & 151 & 50 & 43 \\
\hline 8 & 121 & 40 & 34 \\
\hline 12 & 106 & 35 & 30 \\
\hline 16 & 96 & 32 & 28 \\
\hline 20 & 90 & 30 & 26 \\
\hline 24 & 84 & 28 & 24 \\
\hline 28 & 80 & 27 & 23 \\
\hline 32 & 77 & 26 & 22 \\
\hline 36 & 74 & 25 & 21 \\
\hline 40 & 72 & 24 & 20 \\
\hline 44 & 69 & 23 & 20 \\
\hline 48 & 67 & 22 & 19 \\
\hline 52 & 66 & 22 & 19 \\
\hline 56 & 64 & 21 & 18 \\
\hline 60 & 63 & 21 & 18 \\
\hline 64 & 61 & 20 & 18 \\
\hline 68 & 60 & 20 & 17 \\
\hline 72 & 59 & 20 & 17 \\
\hline 76 & 58 & 19 & 17 \\
\hline 80 & 57 & 19 & 16 \\
\hline 84 & 56 & 19 & 16 \\
\hline 88 & 55 & 18 & 16 \\
\hline 92 & 55 & 18 & 16 \\
\hline 96 & 54 & 18 & 15 \\
\hline
\end{tabular}




\subsection{Brief Discussions on Solid Erosion and Settling, and Possible Exploratory Evaluation}

This section discusses possible ECR experimental evaluations, the solid erosion, solid erosion and deposition rates, and solids settling.

\subsection{Water Jet Testing with High-Strength Simulants for Measurements of Effective Cleaning Radius}

The stored K-Basin sludge in STSCs is planned to be retrieved by a water jet to mobilize settled solids and to withdraw the resulting slurry from the tanks. Thus, it is critical to confirm that a water jet is capable of eroding the solids in STSCs.

As discussed in Sections 2 and 3, among 14 ECR models reviewed, two ECR models, the Powell-3 (or its non-dimensional form, the Gauglitz ECR model) and the Crowe-2 ECR models are more applicable to the K-Basin condition than other ECR models. These two models matched reasonably well with measured ECR values of the SY-101 and AZ-101 Tanks (see Table 2.2 in Section 2). Shear strengths of SY-101 and AZ-101 sludges are 0.73 and $1.77 \mathrm{kPa}$, respectively, as compared to up to 200 $\mathrm{kPa}$ of the expected shear strength of the stored K-Basin sludge. Moreover, these ECR models are based on experiments with sludge simulants, whose shear strengths are at least one-order of magnitude smaller than the expected shear strength of the stored K-Basin sludge. Also, jet velocities of Powell's experiments were fixed at $18.3 \mathrm{~m} / \mathrm{s}$ through 10 - and 6-mm nozzles to derive these two ECR models, as compared to much higher expected required jet velocities.

These two ECR models predicted that the current XAGO water jet system would mobilize soft sludge of several $\mathrm{kPa}$ shear strength up to 25 inches away when all seven jets are used simultaneously at a total discharge of $42 \mathrm{gpm}$. However, it is unlikely to mobilize the high-strength stored K-Basin sludge with the shear strength up to $200 \mathrm{kPa}$, unless these seven nozzles are placed at about 1 inch from the STSC wall.

The analysis presented in Section 3 would assist in developing an adequate water jet retrieval system and in operational planning. However, the predicted values of the shear strength threshold of concern and the required jet velocities, discharge, etc. have significant uncertainty, as stated above.

It is known in the mining and construction industries that when they use a high-speed water jet to blast rocks (or other solid materials), they do not necessarily need to completely destroy the rocks, which consist of several different minerals (Summers 1995). They only need to break a weak rock mineral (or minerals) bonding the various rock minerals together to form the rock. Thus, they design their water jet system to break the weaker link of the rock. Once the weaker part of the rock is broken by the water jet, the rest of the rock cannot hold together, and it crumbles. An example of this so called "hydrodemolition" is removal of deteriorated concrete of a road. Deteriorated concrete is removed by a water jet to fill and pressurize its cracks with water to break the deteriorated concrete, but the pressure is set below that required for crack growth in the healthier underlying concrete. 
The stored K-Basin sludge is expected to have a shear strength of up to approximately $200 \mathrm{kPa}$. But the sludge is reported to have a weak "paste" with a shear strength of only $3 \sim 5 \mathrm{kPa}$, bonding with the hard "chunks," which have an estimated shear strength of $380 \sim 770 \mathrm{kPa}$ (Delegard et al. 2007, Wells et al. 2009). Thus, if a water jet needs to break only the paste for the sludge to crumble, the water jet requirement would be significantly reduced, and the probability of success of a water-jet sludge retrieval system would be greatly increased. However, this experience of the mining and construction industries must be tested for the stored K-Basin sludge conditions to confirm the validity of this concept for the KBasin application.

To obtain a more accurate evaluation of the adequacy of a required water jet system, more accurate and realistic water jet experiments should be performed with high-strength sludge simulants covering the entire range of the expected shear strength of the stored K-Basin sludge, from several $\mathrm{kPa}$ up to $200 \mathrm{kPa}$. Under separate K-Basin tasks, PNNL developed several high-strength homogeneous simulants, whose shear strength varies from approximately $3 \mathrm{kPa}$ to $200 \mathrm{kPa}$. PNNL is also developing heterogeneous simulants whose shear strength would be of the same range as that of the homogeneous simulants.

It is useful to use these homogeneous and heterogeneous simulants to conduct water jet experimental testing using expected nozzle sizes and jet velocities. The purpose of the testing would be to obtain an accurate ECR for a given water jet and to evaluate whether the water jet can adequately erode the stored $\mathrm{K}$-Basin sludge. These experiments would also determine whether the jet needs to destroy only the weaker link of the stored K-Basin sludge or needs to overcome the overall shear strength of the sludge If so desired, the testing would also provide the critical shear stress for erosion and the erodibility coefficient, which would provide the rate of the solid erosion and the duration (time) required to erode the required amount of sludge, as will be discussed in Sections 5.2 and 5.3. It may be useful to conduct additional testing for selected water jets to evaluate possible stainless steel wall erosion.

This water jet testing would be conducted with simulants having $3 \sim 200 \mathrm{kPa}$ shear strength and highspeed jets produced by a high-pressure pump to realistically duplicate the expected stored K-Basin sludge conditions. A conceptual set-up of a small-scale water jet testing is shown in Figure 5.1. 


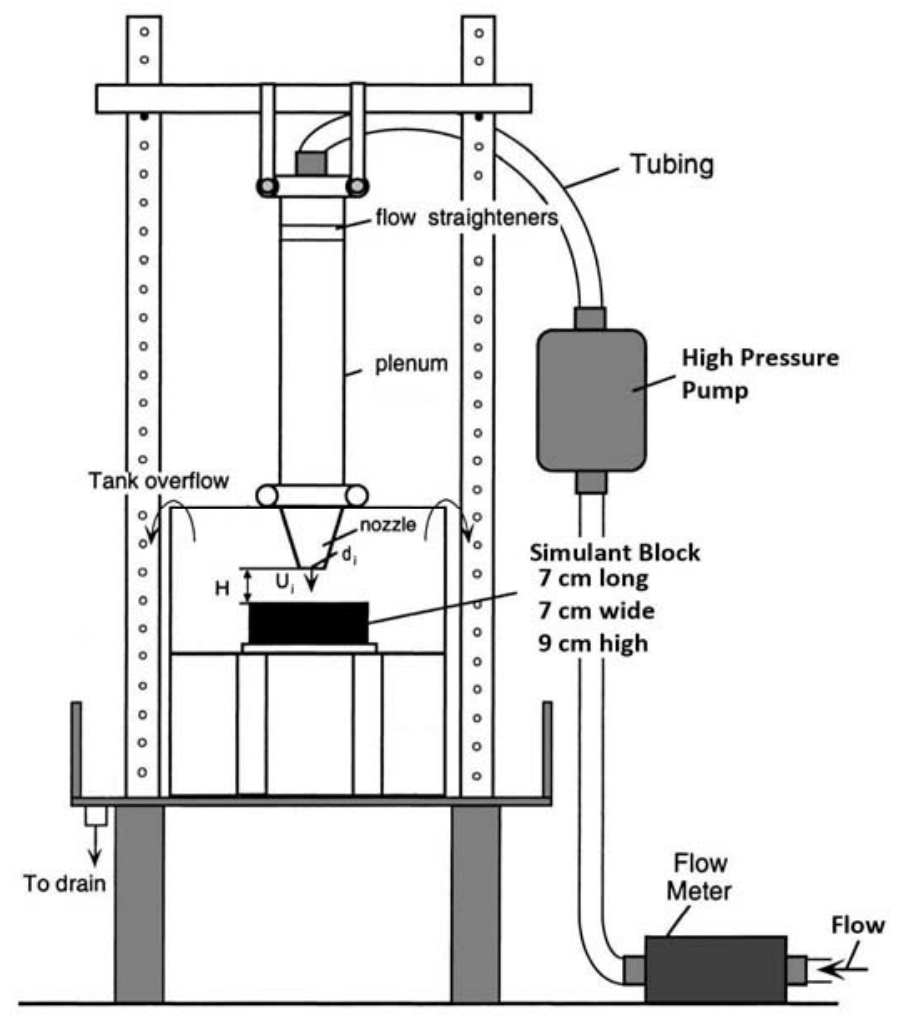

Figure 5.1. Conceptual Small-Scale Water Jet Test Set-up

The simulant block and a nozzle would be placed under water, as shown in this figure. The K-Basin sludge will be stored under water in the STSCs. Most of the water above the stored K-Basin sludge can be pumped out. Thus, the scaled model would match the expected remaining water depth above the sludge surface in the testing if needed. The simulant would be placed in a stainless steel simulant container of $7 \mathrm{~cm}$ long, $7 \mathrm{~cm}$ wide and $9 \mathrm{~cm}$ deep, as used in the separate homogeneous simulant task being conducted for CHPRC.

Simulants shown in Figure 5.1 as a simulant block would have three shear strengths, approximately 30,100 , and $200 \mathrm{kPa}$. For each of these three shear strengths, there may be up to three homogeneous simulants and up to three heterogeneous simulants, all having similar shear strength. Thus, a total of up to 18 simulants is expected to be used. Three nozzle diameters would be selected, e.g., 2-, 3-, and 4-mm nozzles. For each simulant and a nozzle diameter size, the jet velocity would be increased (or the distance between the nozzle and the surface of the sludge would be reduced) to erode a test simulant. The test should be run until no more erosion occurs, as shown in Figure 5.2. The distance $H$ in this figure is the distance between the original sludge surface and the nozzle. $\mathrm{H}_{\mathrm{e}}$ is the same distance but after the jet reaches its maximum erosion depth. $\mathrm{H}_{\mathrm{p}}$ is the jet core length, which still has the original nozzle jet velocity along the jet centerline. The core length is about six times the nozzle diameter for a water jet injected into water. This is a main reason that the optimal nozzle position is about 8 times the distance from the solid surface to be cut (Moore and Masch 1962, Mazurek et al. 2001), as stated previously. As will be discussed, the values of $\mathrm{H}_{\mathrm{e}}$ and $\mathrm{H}_{\mathrm{p}}$ could be used to estimate the critical shear stress for erosion (Hanson and Simon 2001). 


$$
\tau_{C}=\tau_{0}\left(\frac{H_{p}}{H_{e}}\right)
$$

where $\tau_{0}$ is the maximum applied shear stress within the potential core, and $\tau_{\mathrm{C}}$ is the critical shear stress for erosion.

These tests would provide the nozzle diameter and jet velocity needed to erode the sludge of known shear strength and required erosion depth.

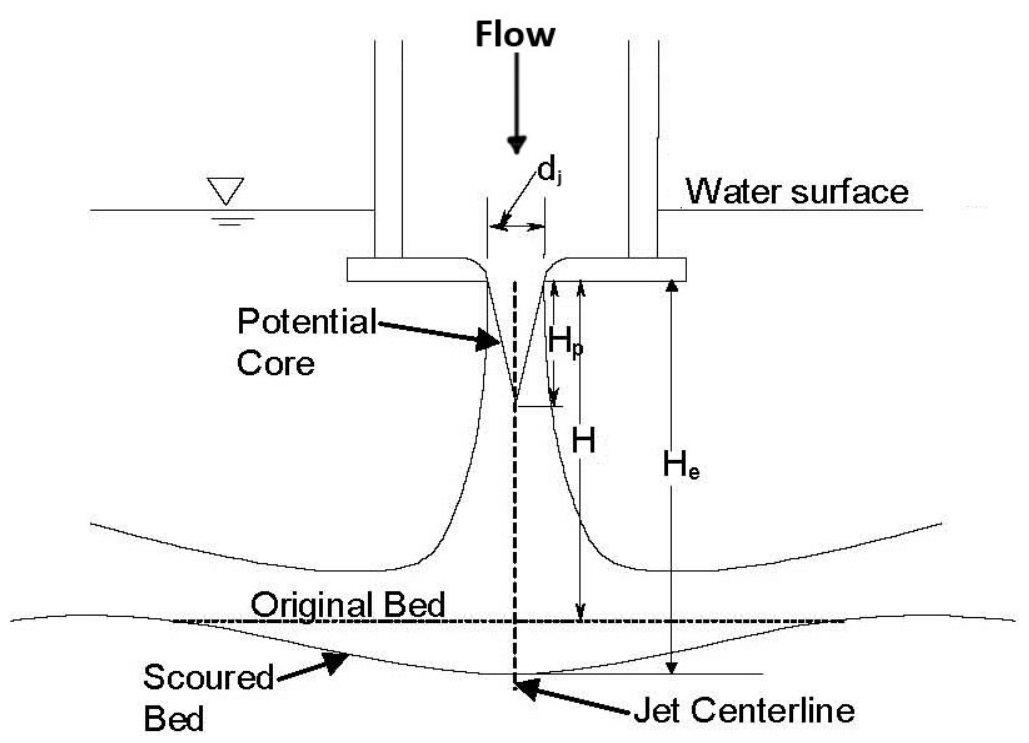

Figure 5.2. Schematic of Sludge Erosion

The water jet testing may be conducted in the following two phases:

- Phase 1: Feasibility of Stored K-Basin Sludge Retrieval

- Stage 1: Small-scale water jet testing (see Figure 5.1)

o Use up to three homogeneous simulants developed by PNNL

o Use up to six heterogeneous simulants being developed by PNNL to conduct the several sets of the heterogeneous simulant testing with

- Weaker weak paste and very hard chunks

- Stronger weak paste and very hard chunks.

- Stage 2: Large-scale water jet testing to repeat selected sets of the small-scale testing conditions with 3- and/or 4-mm nozzle and expected ECR of 10 inches or less. This large-scale testing may be performed with a required pressure of 5,000 psi or less.

o Use PNNL homogeneous simulants selected by the small-scale water jet testing.

o Use PNNL heterogeneous simulants selected by the small-scale water jet testing.

- Phase 2: Detailed Evaluation of Sludge Erosion by Jets to Determine the Solid Erosion Rate, Erodibility Coefficient, and Required Erosion Duration

- Stage 1: Small-scale water jet testing (see Figure 5.1 and Figure 5.2) 
o Obtain the critical shear stress for erosion and the erodibility coefficient.

o Validate or modify Equations 5.3, 5.6, and 5.12 to be able to estimate the critical shear stress for erosion and the erodibility coefficient so that in the future, these values may be determined without conducting water jet testing.

o These tests would be conducted with simulants of several different shear strengths. For each fixed shear strength testing, there would be two tests with homogeneous and heterogeneous simulants having the same shear strength to examine the ECRs.

- Stage 2: Large-scale water jet testing to repeat selected sets of the small-scale testing conditions with 3- and/or 4-mm nozzle and expected ECR of 10 inches or less. This large-scale testing would be performed with a required pressure of 5,000 psi or less

o Use PNNL homogeneous simulants selected by the small-scale water jet testing.

o Use PNNL heterogeneous simulants selected by the small-scale water jet testing.

These two phases (each with two stages) of the experimental water jet testing would provide a sound scientific basis to develop the required water jet system for the stored K-Basin sludge retrieval operation.

As discussed in Section 4, the Papp wall erosion model was developed at the jet velocity of 12 and $14 \mathrm{~m} / \mathrm{s}$ through a 1.049-in. nozzle placed at 1.574 inches from the steel surface. These wall erosion test conditions are not similar to those expected of a K-Basin water jet system. The applicability of the wall erosion model to the stored K-Basin condition and its accuracy are not certain.

Thus, the small scale testing would also include the stainless steel wall erosion testing. As indicated above, the homogeneous and heterogeneous simulants would be placed in a stainless steel simulant container. Thus, after sludge erosion testing, a simulant container with the stimulant and/or a stainless steel plate would be placed under water for wall erosion testing under some selected conditions. The objective of this wall erosion testing would not be necessary to confirm or modify the Papp wall erosion model, but rather to confirm that the selected water jet systems would not erode more than $10 \%$ of the STSC wall.

\subsection{Critical Shear Stresses for Erosion and Deposition}

Much has been published on solid erosion by water jets and streams (Partheniades 1962, Onishi et al. 1993, Hanson and Simon 2001, Clark and Wynn 2007). Most of them quantify solid erosion and its rate by using the critical shear stress for erosion, rather than using the shear strength or yield stress of the settled solid layer (Mazurek et al. 2001, Mazurek and Hossain 2009, Clark and Wynn 2007, Partheniades 1993). The critical shear stress for erosion is the shear stress value above which a settled solid starts to move. Even in the case of a solid erosion caused by an impinging jet, the shear stress acting on the surface of the solid layer is considered to be responsible for the solid erosion (Hollick 1976, Tolhurst et al. 1999, Hanson and Simons 2001, Clark and Wynn 2007). However, this approach has not been adopted by the Hanford, Savannah River, and Oak Ridge Sites when the solid erosion by a water jet has been evaluated, as stated in Section 2. If the concept of the critical shear stress for erosion were to be adopted at the Hanford Site, a considerable amount of erosion rate data and knowledge may be available to evaluate the K-Basin sludge retrieval. 
Waste solids greater than $20 \mu \mathrm{m}$ are usually non-cohesive (Wells et al. 2007). It is much more difficult (sometimes up to 50 times more difficult) to mobilize a mixture of cohesive and non-cohesive solids than non-cohesive sediments alone even for the same median particle diameter of the mixture (Kothyan and Jain 2008). Because waste solids greater than $20 \mu \mathrm{m}$ are usually non-cohesive, sludge consisting of solids of both smaller and greater than $20 \mu \mathrm{m}$ tends to be a mixture of cohesive and noncohesive solids.

Cohesive and non-cohesive solids significantly differ in their erosion, deposition, and transport behavior. The diagram of solid erosion and deposition rates of a cohesive solid is shown in Figure 5.3.

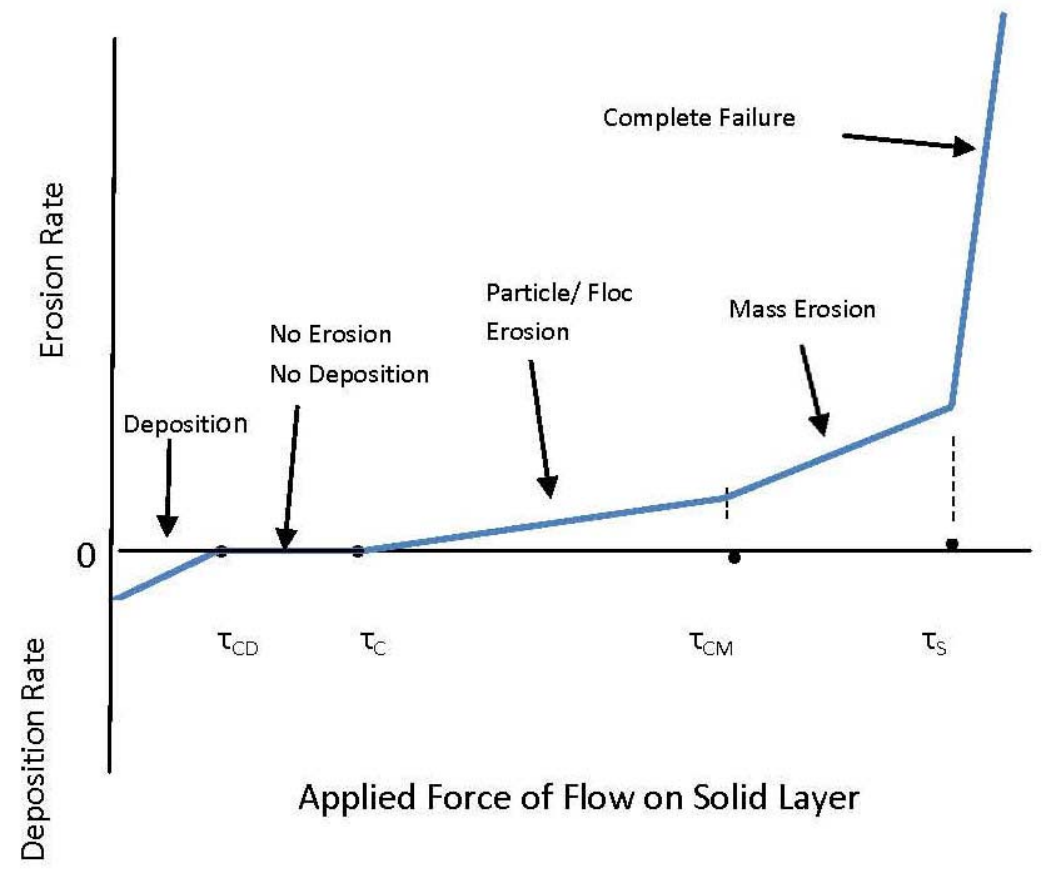

Figure 5.3. Solid Erosion and Deposition Processes

In Figure 5.3, $\tau_{\mathrm{CD}}$ is the critical shear stress for deposition, $\tau_{\mathrm{C}}$ is the critical shear stress for solid erosion by floc (or grain), $\tau_{\mathrm{Cm}}$ is the critical shear stress for solid mass erosion, and $\tau_{\mathrm{S}}$ is the shear strength.

As shown in Figure 5.3,

- For $\tau \leq \tau_{\mathrm{CD}}$, Suspended solids would be deposited.

- For $\tau_{\mathrm{CD}}<\tau<\tau_{\mathrm{C}}, \quad$ No suspended solids would deposit, and no settled solids would be eroded.

- For $\tau_{\mathrm{CR} 1} \leq \tau<\tau_{\mathrm{CM}}$, Settled solids would be eroded floc by floc.

- For $\tau_{\mathrm{CM}} \leq \tau<\tau_{\mathrm{CS}}$, Settled solids would be mass (chunk by chunk)-eroded.

- For $\tau \geq \tau_{\mathrm{S}}, \quad$ Settled solids would be eroded by destroying the structural integrity of the solid layer as a solid. 
In general (Teeter 1988, Onishi et al. 1993),

$$
\tau_{\mathrm{CD}} \ll \tau_{\mathrm{C}} \ll \tau_{\mathrm{S}}
$$

As discussed below, $\tau_{\mathrm{CD}}$ and $\tau_{\mathrm{C}}$ are measured experimentally or at the field. $\tau_{\mathrm{CM}}$ has not been studied much because calculation of the solid erosion rate uses $\tau_{\mathrm{C}}$, not $\tau_{\mathrm{CM}}$.

For a non-cohesive solid, a value of the critical shear stress for deposition, $\tau_{\mathrm{CD}}$, is the same as that of the critical shear stress for erosion, $\tau_{\mathrm{C}}$. But $\tau_{\mathrm{CD}}$ is not used to estimate the deposition of the solid amount because the amount of solid erosion and deposition is not only a function of the liquid and solid properties, but also the flow and suspended solids concentration, as will be discussed later in this section. However, as stated above, the initiation of the non-cohesive solid (i.e., the critical shear stress for erosion, $\left.\tau_{\mathrm{C}}\right)$ is a solid property.

The critical shear stress for erosion is usually expressed through the Shields Diagram, as shown in Figure 5.4 (Vanoni 1975, Onishi 1994, Garcia 2008).

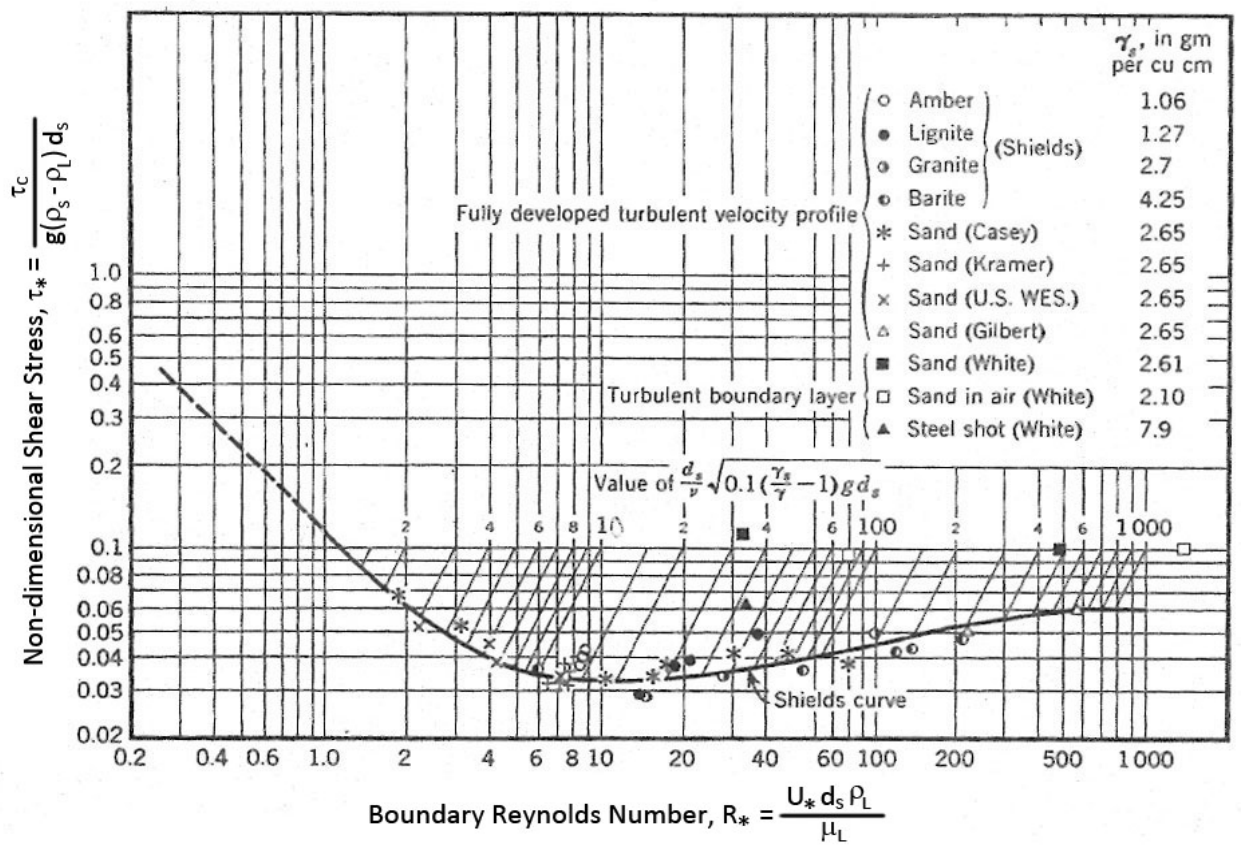

Figure 5.4. Shield Diagram for Critical Shear Stress for Erosion

In this figure, $\tau_{C}$ is the critical shear stress for erosion. $U_{*}\left(=\tau / \rho_{\mathrm{L}}\right)$ is the shear velocity, where $\tau$ is the shear stress (the bed shear stress) of the flow/jet acting on the surface of the solid layer, and $\tau$ is the critical shear stress for erosion, $\tau_{\mathrm{C}}$, when the solid starts to move along the surface of the solid layer as the bed load.

The Shield Diagram applies to a wide range of conditions of various liquids and solids. It provides the specific value of the critical shear stress of erosion for non-cohesive solids. This non-cohesive solid region is shown in the right side of the diagram (the Boundary Reynolds Number, $R^{*} \geq 5$ ). As the Shields Diagram indicates, the larger and/or the heavier the solid, the greater the critical shear stress, and thus it is 
harder to mobilize. For a non-cohesive solid, the critical shear stress for erosion is a solid property and does not depend on the flow condition.

Although the Shields Diagram does not provide the specific value of the critical shear stress for erosion of a cohesive solid, it qualitatively shows that the smaller the solids, the greater the critical shear stress for erosion. It is not quantified because the critical shear stress for erosion of a cohesive solid depends on the cohesiveness of the solid layer, thus affected by not only the sludge physical property and chemistry, but also the sludge conditions (e.g., the overburden weight, a condition under which solids settled to have formed a solid layer, the composition of the solid layer, etc.). Thus, the critical shear stress for erosion of a cohesive solid usually has to be measured.

However, there are some simple formulas to estimate the critical shear stress for erosion (Dunn 1959, Clark and Wynn 2007).

Clark and Wynn (2007) reported that

$$
\tau_{C}=0.16 P I^{0.84}
$$

where PI is the plasticity index (ASTM International 2000), and $\tau_{\mathrm{C}}$ is the critical shear stress for erosion $(\mathrm{Pa})$. The plasticity index (PI) is a measure of the plasticity of a soil. The plasticity index is the size of the range of water contents where the soil exhibits plastic properties. The PI is the difference between the liquid limit and the plastic limit (PI = LL-PL). Soils with a high PI tend to be clay, those with a lower PI tend to be silt, and those with a PI of 0 tend to have little or no silt or clay, as stated in the Wikipedia webpage.

Dunn (1959) proposed a more detailed model as

$$
\tau_{C}=0.02+\frac{\tau_{S}+180}{1000} \tan (30+1.73 P I)
$$

where $\tau_{\mathrm{S}}$ is the shear strength $(\mathrm{Pa})$, and $\tau_{\mathrm{C}}$ is the critical shear stress for erosion $(\mathrm{Pa})$.

Dunn's model was developed with soil data and is most accurate when the PI is between 5 and 16 (Dunn 1959). With the use of Equation 5.3, it might be possible to obtain a rough estimate of the critical shear stress for erosion with the known shear strength and plasticity index of the stored K-Basin sludge with some reservation.

Thus, it may be useful to determine the plasticity index value of the stored K-Basin sludge. The standard method for PI is described in ASTM International (2000). The estimated $\tau_{\mathrm{C}}$ can be compared with measured $\tau_{\mathrm{C}}$ to validate Dunn's formula (Equation 5.3) if the scaled water-jet experimental tests suggested in Section 5.1 are conducted.

Some ECR models use the critical shear stress or its associated critical velocity for erosion. They include Mazurek et al.'s non-dimensional formulas on ECR and the eroded soil volume, V, for a vertically impinging jet (Mazurek et al. 2001). 


$$
\begin{aligned}
\frac{E C R}{h} & =0.19\left(\frac{x-x_{C}}{x_{C}}\right)^{0.74} \\
\frac{\sqrt[3]{V}}{h} & =0.37\left(\frac{x-x_{C}}{x_{C}}\right)^{0.51}
\end{aligned}
$$

Where $\mathrm{x}$ and $\mathrm{x}_{\mathrm{C}}$ are defined as

$$
\begin{aligned}
\tau_{\max }=0.16 \rho U_{j}^{2}\left(\frac{d_{j}}{h}\right)^{2} & =0.16 x \\
\tau_{C}=0.16 \rho U_{j C}^{2}\left(\frac{d_{j}}{h}\right)^{2} & =0.16 x_{C} \\
h & =\text { jet nozzle height above the soil surface } \\
\mathrm{U}_{\mathrm{jc}} & =\text { jet velocity needed to start the solid erosion } \\
\tau_{\max } & =\text { maximum shear stress that the impinging jet is imposing on } \\
& \text { the soil } \\
\tau_{\mathrm{C}} & =\text { critical shear stress or shear strength of the soil. }
\end{aligned}
$$

Kothyan and Jain (2008) developed the following formula based on their experiments to determine the critical shear stress of a mixture of cohesive and non-cohesive sediments:

$$
\frac{\tau_{C C}}{\tau_{C}}=1.88\left(1+P_{C}\right)^{\frac{2}{3}} e^{-\frac{1}{6}}\left(1+0.001 U C S^{*}\right)^{\frac{9}{20}}-1.0
$$

where $\quad \mathrm{P}_{\mathrm{C}}=$ percentage of clay (particle sizes of $0.5 \sim 4 \mu \mathrm{m}$ )

$\mathrm{UCS}^{*}=$ unconfined compressive strength of the mixture of cohesive and non- cohesive sediments

$\tau_{\mathrm{C}}=$ critical shear stress of non-cohesive sediment

$\tau_{\mathrm{CC}}=$ critical shear stress of a mixture of cohesive and non-cohesive sediment having the same median size as that of the non-cohesive sediment alone.

Although Equation 5.6 is for sand, silt, and clay and does not directly apply to the stored K-Basin sludge, it indicates that the ratio of the critical shear stress of a mixture of cohesive/non-cohesive solids to that of noncohesive solid might be estimated by the unconfined compressive strength and the plasticity index of the mixture as well as the critical shear stress for erosion of a noncohesive solid. A pocket penetrometer can measure the unconfined compressive strength while the Shield Diagram provides the critical shear stress for erosion of the non-cohesive solids (Figure 5.4). This approach might be adapted to estimate the critical shear stress of the stored K-Basin sludge.

Thus, it may be useful to obtain the plasticity index of the stored K-Basin sludge besides measuring the unconfined compressive strength. If the scaled water-jet experimental tests suggested in Section 5.1 will be conducted, the $\tau_{\mathrm{C}}$ estimated with Equation 5.6 can be compared with measured $\tau_{\mathrm{C}}$ to validate Kothyan and Jain's formula (Equation 5.6). Thus conducting the scaled water jet testing, Equations 5.3 and 5.6 may be validated or modified to apply to the stored K-Basin sludge condition. These two 
equations could significantly reduce the time and cost to estimate the erosion rate of the stored K-Basin sludge by a water jet.

The shear stress of an impinging jet along the solid surface after the jet perpendicularly hits the solid surface is briefly discussed here. Powell et al. (1995a) derived the following expression for the shear stress acting on the solid surface at the point of impingement based on the jet velocity distribution:

$$
\tau=0.02782 \rho_{S L}\left(\frac{U_{j} d_{j}}{X}\right)^{2}\left[8.5\left\{1-\exp \left(-\frac{1.1284 \frac{X}{d_{j}}+12}{17}\right)\right\}-2\right]
$$

where $\tau$ is the shear stress $\left(\mathrm{N} / \mathrm{m}^{2}\right)$ on the tank wall at some axial (downstream) position, $\mathrm{X}$, and $\mathrm{X}$ is the downstream (axial) distance between the nozzle and the impinged sludge surface (see Figure 2.4).

On the other hand, Beltaos and Rajcratnam (1974) derived the maximum shear stress of an impinging jet acting on the sludge surface to be

$$
\tau_{\max }=0.16 \frac{\rho_{S L} d_{j}{ }^{2} U_{J}}{X^{2}}
$$

Thus, with a known shear stress value generated by an impinging water jet on the solid surface and the critical shear stress of the sludge, it may be possible to determine

- a range of solid properties that would be mobilized by water

- what solids would be suspended by a water jet.

Computational fluid dynamics (CFD) codes capable of simulating erosion, deposition, and transport of cohesive and non-cohesive solids are required to determine the suspended solid concentrations and their uniformity in the STSCs. These codes include the ARIAL (Onishi and Trent 1999) and FLESCOT models (Onishi et al. 1993). They have been applied to many Hanford DSTs (e.g., 241-AZ-101, 241-AZ102, 241-AN-104, 241-AN-105, 241-AY-102) to determine the performance of pump jet mixing (e.g., sludge erosion and settling) and the uniformity of the suspended solid concentrations in these tanks as well as the migration (transport, deposition, and re-suspension) of cohesive-cohensionless sediments and toxic chemicals in the natural environment (e.g., the Buzzard Bay and New Bedford Harbor in Massachusetts).

The combination of the critical shear stress-shear strength measurements and a CFD code would determine

- what solids will be eroded and kept suspended

- what solids will be eroded, but will quickly settle down to the container's bottom

- what solids will not be mobilized

- achievable solid concentrations (e.g., 5 vol\%, 1 vol\%, or less at 70 gpm) 
- Degree of required amounts (volume or weight) of solids dislodged from the container's bottom

- Degree of vertical and horizontal uniformity of suspended solid concentrations

- Amounts and locations of not-mobilized settled solids on the bottom

- the degree of successful/acceptable retrieval.

Thus, the computer simulation would also be suggested as a possible future exploratory work. A CFD code must be able to adequately simulate the solid erosion, suspension, deposition, settling, and transport for sludge consisting of several different particle sizes and densities, besides the slurry flow with varying slurry rheology induced by a water jet.

\subsection{Solid Erosion and Deposition Rates}

This section discusses the erosion rate of the stored K-Basin sludge and the time to erode a satisfactory amount of the sludge in the STSCs. For cohesive solids, the solid erosion and deposition rates (the amounts of solids being eroded or deposited per unit solid bed surface area per time) are usually expressed as (Krone 1965, 1993, Partheniades 1962, 1993, Muzurek et al. 2001, Clark and Wynn 2007).

$$
\begin{aligned}
& S_{R}=k\left(\frac{\tau}{\tau_{C}}-1\right)=K\left(\tau-\tau_{C}\right) \text { when } \tau>\tau_{\mathrm{C}} \\
& S_{D}=V_{S} C\left(1-\frac{\tau}{\tau_{C D}}\right) \text { when } \tau<\tau_{\mathrm{CD}} \\
& S_{R}=S_{D}=0 \quad \text { when } \tau_{\mathrm{CD}}<\tau<\tau_{\mathrm{C}}
\end{aligned}
$$

where $\quad \mathrm{C}=$ solid concentration

$\mathrm{K}, \mathrm{k}=$ erodibility coefficient

$\mathrm{S}_{\mathrm{D}}=$ amount of solid deposited on the bottom per unit bottom surface area per unit time

$\mathrm{S}_{\mathrm{R}}=$ amount of solid eroded from the bottom per unit bottom surface area per unit time

$\mathrm{V}_{\mathrm{S}}=$ solid settling velocity

$\tau=$ flow shear stress.

Some data and erosion formula are available for the solid erosion rate of cohesive sediment when the flow shear stress acting on the surface of the settled solid layer is above the critical shear stress, but below the shear strength (e.g., Krone 1962, Partheniades 1962, Teeter 1988). These studies provide the solid erosion rates of cohesive sediment as the weight of solid eroded per a given area per a given time. Erosion and deposition rate formulas (Equations 5.9 and 5.10) for cohesive sediment were used to determine the solid erosion and deposition with known critical shear stresses and the erodibility coefficient, and have been incorporated into various sediment and contaminant transport codes to predict transport, deposition, and erosion of cohesive sediments (Onishi 1981, Onishi et al. 1993, 2007). This approach would provide the number of hours needed to mobilize the stored K-Basin sludge by a water jet. 
The critical shear stress for erosion, $\tau_{\mathrm{C}}$ and deposition $\tau_{\mathrm{CD}}$, and the erodibility coefficient, $\mathrm{K}$, are usually determined by measurements. However, based on Midwestern U.S. soil, Hanson and Simon (2001) developed the following formula to correlate $\tau_{\mathrm{C}}$ and $\mathrm{K}$ as

$$
K=\frac{0.2}{\sqrt{\tau_{C}}}
$$

Thus, the combined use of Equation 5.3 and 5.12 may determine the values of $\tau_{\mathrm{C}}$ and $\mathrm{K}$ needed to determine the erosion rate and the time to mobilize the required amount of the sludge if the shear strength and the plasticity index of the stored K-Basin sludge are appropriately selected. However, these two equations were developed with soil data, and it is not certain how they apply to the conditions at the K-Basin.

Thus, conducting the scaled water jet experiments would validate or modify Equation 5.12 to apply to the stored K-Basin sludge. This could reduce the time and cost of the feasibility evaluation of the stored K-Basin sludge retrieval by a water jet.

The water jet experiments suggested under Section 5.1 would provide data to evaluate whether Equations 5.3 and 5.12 developed with soil measurements are applicable to the stored K-Basin sludge. If not, these experimental data and their analysis may provide alternative relationships that are more suitable to the K-Basin conditions under many different storage and retrieval scenarios.

The amount of non-cohesive solids eroded from the bottom or deposited to the bottom is usually estimated as (Onishi 1981, 1994, Garcia 2008)

$$
\begin{array}{ll}
S_{R}=\left(Q_{S C}-Q_{S A}\right) / t_{R} & \text { For } Q_{\mathrm{SA}} \leq \mathrm{Q}_{\mathrm{SC}} \\
S_{D}=\left[Q_{S A}-Q_{S C}\right] / t_{D} & \text { For } \mathrm{Q}_{\mathrm{SA}} \geq \mathrm{Q}_{\mathrm{SC}}
\end{array}
$$

where $\mathrm{Q}_{\mathrm{SA}}$ is the actual sediment discharge, $\mathrm{Q}_{\mathrm{SC}}$ is the sediment discharge capacity of a flow to carry sediment, and $t_{D}$ and $t_{R}$ are the durations required to complete deposition and erosion, respectively.

There are many formulas to estimate the non-cohesive sediment discharge capacity, $\mathrm{Q}_{\mathrm{SC}}$ of a given flow (Vanoni 1975, Simon and Senturk 1977, Onishi 1994, Garcia 2008).

Some studies address time versus the solid erosion amount or the ECR (Hamm et al. 1989, Hanson and Robinson 1993, Hanson 2001, Hanson and Simon 2001, Poirier 2004). Hamm et al. (1989) plotted the ECR versus time data and found that the following form fit the data well (Powell et al. 1997):

$$
E C R \propto t^{0.33 \sim 0.5}
$$

Others like Hanson and his associates express the erosion time in a logarithmic form (Hanson 2001). Based on the velocity along the jet centerline expressed in Equation 2.15, Poirier at the Savannah River National Laboratory summarizes various equations for $t$, the time to reach the maximum erosion amount (Poirier 2004), including: 


$$
t=3.2 \frac{D_{\tan k}^{2}}{d_{j} U_{j}}
$$

where $\mathrm{D}_{\text {tank }}$ is the tank diameter ( $\left.\mathrm{ft}\right), \mathrm{t}$ is the time to reach the maximum amount of erosion $(\mathrm{s})$, and $\mathrm{U}_{\mathrm{j}}$ is the jet velocity $(\mathrm{ft} / \mathrm{s})$.

For the pump jet mixing of Tank 241-AZ-101, it took more than a day to erode the 17-in.-deep sludge by two 300-hp pumps, each injecting $60-\mathrm{ft} / \mathrm{s}$ jets through two 6-in. nozzles at a jet discharge of 10,600 gpm (Carlson et al. 2000, 2001).

\subsection{Solid Settling}

Solid settling affects both the deposition and consolidation of solids on the tank bottom and the distribution of the suspended solid concentrations in the STSCs. Heterogeneous simulant development also needs to address solid settling during a simulant making period. The vertical distribution of the suspended solid concentrations is a result of the solid settling counter-balanced by the upward component of the turbulence of the flow (Vanoni 1975). The one-dimensional (vertical) distribution of solid concentration is well characterized by Rouse Number, $\mathrm{z}$ (Vanoni 1975), as shown in Figure 5.5.

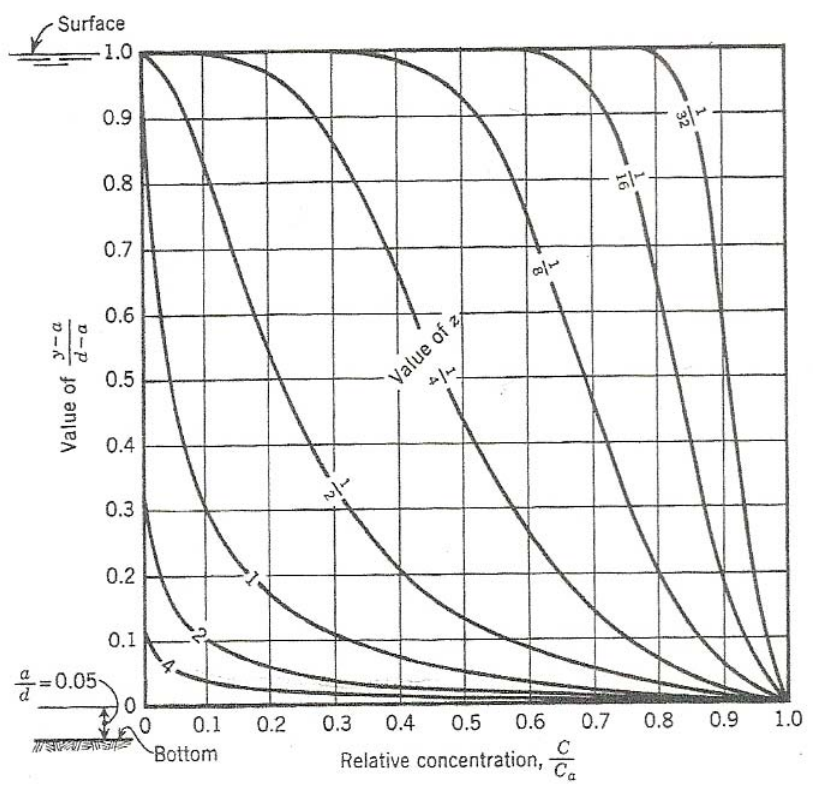

Figure 5.5. One-Dimensional Solid Concentration Distribution

The Rouse Number is defined as

$$
z=\frac{\mathrm{V}_{\mathrm{S}}}{\beta \kappa \mathrm{U}_{*}}=\frac{\mathrm{V}_{\mathrm{S}}}{\beta \kappa \sqrt{\frac{\tau}{\rho_{L}}}} \equiv \text { Rouse Number }
$$


where $\quad \mathrm{Vs}=$ solid settling velocity

$$
\begin{aligned}
\mathrm{U}_{*} & =\text { shear velocity } \\
\beta & =\text { constant }(\approx 1.0) \\
\kappa & =\text { von Kármán constant }(\approx 0.4) \\
\rho_{\mathrm{L}} & =\text { liquid density } \\
\tau & =\text { shear stress acting on the solid surface. }
\end{aligned}
$$

The shear velocity and the shear stress are correlated to the turbulence; thus, the Rouse Number expresses the ratio of the solid settling velocity to the turbulent intensity of the flow.

Therefore, the solid settling has a significant effect on the vertical solid concentration distribution, although a distribution of suspended solid concentrations in an STSC will not be one-dimensional. The solid settling velocity is an important parameter for both solid deposition and accumulation as well as vertical distributions of the solids during the water jet retrieval process.

When solids are suspended, they will settle toward the tank bottom. Some will fall as an individual particle without interacting with other solids. Others will go through the following stages in the sequence:

- Slowly settle while suspended solids are flocculating to form larger agglomerates.

- Settle faster as agglomerates.

- Settle slowly because of hindered solid settling when solid concentrations become high enough, and their falling restricts the flow movement between solids.

- Consolidate settled solids very slowly within the solid layer over a long time.

Three of these four settling stages are clearly identifiable in Figure 5.6, showing the measured solid settling of both actual Hanford waste and chemical simulants in a 30-ft column (MacLean 1999). 


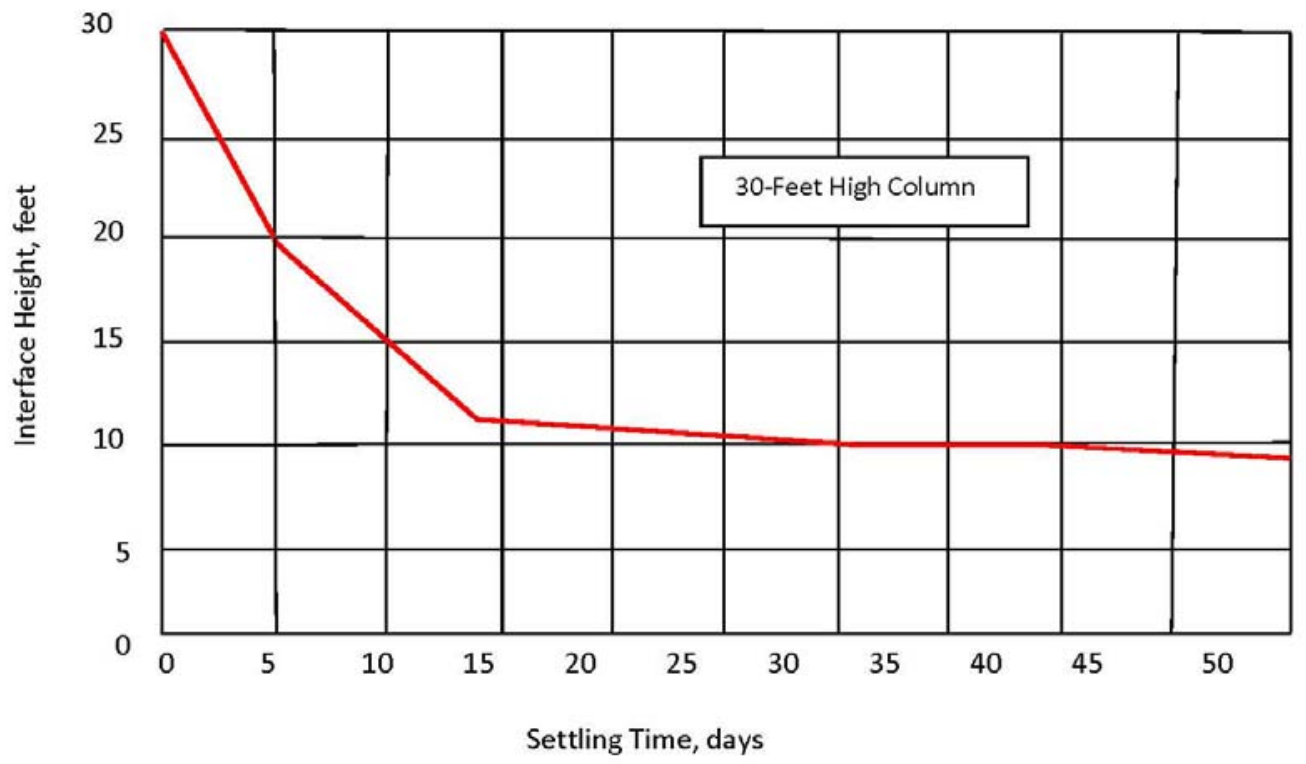

Figure 5.6. Measured Solid Settling of Hanford Waste in a 30-ft Column

The solid settling velocity is generally a function of

- the size, shape, and density of the solid particle

- suspended solid concentration

- density and viscosity of the liquid

- waste chemistry affecting the solid agglomeration.

Individual particle settling:

The fall velocity of an individual spherical particle is described by (Vanoni 1975),

$$
V_{S}^{2}=\frac{4}{3} \frac{g d_{S}}{C_{D}}\left(\frac{\rho_{S}-\rho_{L}}{\rho_{L}}\right)
$$

where $C_{D}=$ drag coefficient

$\mathrm{d}_{\mathrm{S}}=$ spherical particle diameter

$\mathrm{g}=$ gravitational acceleration

$\mathrm{V}_{\mathrm{S}}=$ solid settling velocity

$\rho_{\mathrm{L}} \quad$ liquid density

$\rho_{\mathrm{S}}$ solid density. 


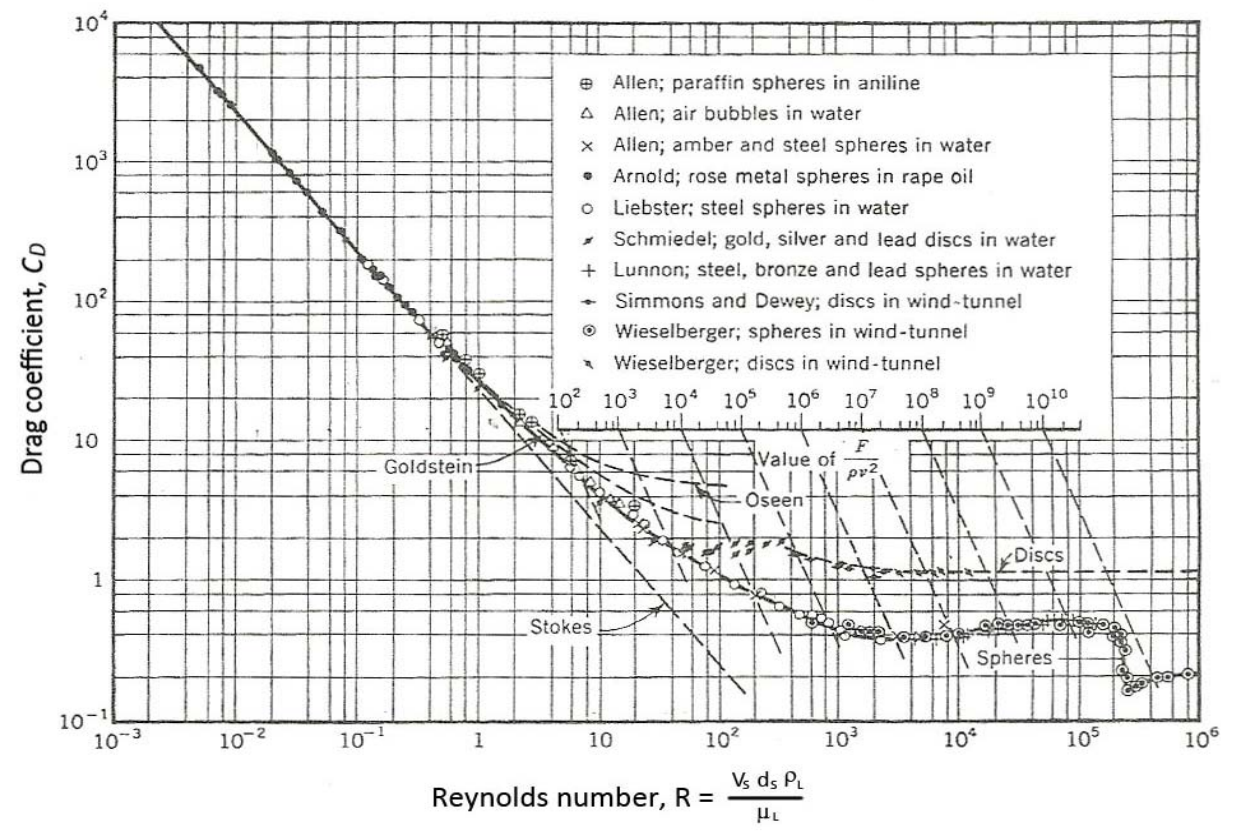

Figure 5.7. Variation of Drag Coefficient with Particle Reynolds Number

Figure 5.7 shows the drag coefficient, $\mathrm{C}_{\mathrm{D}}$, vs. the particle Reynolds Number, $R$, defined by Equation 5.19 .

$$
R=\frac{V_{S} \rho_{L} d_{S}}{\mu_{L}}
$$

The symbol $F$ in Figure 5.7 is defined as

$$
F=\frac{\pi d_{S}^{3} g}{6}\left(\rho_{S}-\rho_{L}\right)
$$

for the third parameter, $F / \rho v^{2}$ (where $\rho$ is $\rho_{\mathrm{L}}$ in this case). The symbol $v$ is the kinematic viscosity $\left(=\mu_{\mathrm{L}} / \rho_{\mathrm{L}}\right)$ of the liquid. With the use of the third parameter, the settling velocity can be calculated without iteration with Figure 5.7.

Equation 5.18 applies to any range of the particle Reynolds number for a spherical particle shown in this figure. If an equivalent spherical particle is used to represent a non-spherical particle with the use of a shape factor, this equation can also apply to a non-spherical particle.

In the Stokes Law range $(R<0.1 \sim 1)$, the drag coefficient, $\mathrm{C}_{\mathrm{D}}$, is

$$
C_{D}=\frac{24}{R}
$$


Substituting Equation 5.21 into Equation 5.18 yields the following well known Stokes settling velocity formula (Wasp et al. 1977):

$$
V_{S}=\frac{g \rho_{L} d_{S}{ }^{2}}{18 \mu_{L}}\left(\frac{\rho_{S}-\rho_{L}}{\rho_{L}}\right)
$$

\section{$\underline{\text { Solid flocculation and agglomerate settling }}$}

When primary (crystal) particles are small, normally less than $20 \mu \mathrm{m}$ for the Hanford waste, primary particles tend to flocculate to each other and form larger agglomerates, although it also depends on waste chemistry (Rector and Bunker 1995, Wells et al. 2007, Hill 2010). The agglomerate density is less than those of primary particles forming an agglomerate, but an agglomerate usually settles faster than its primary particles (MacLean 1999). When the solid concentration exceeds a certain level, say around $0.3 \mathrm{~g} / \mathrm{L}$, the small primary particles start to form agglomerates (Mehta and Partheniades 1973).

A fractal analysis may be used to estimate the density of agglomerate of a given size by (Wells et al. 2007)

$$
\rho=\left(\frac{R}{r}\right)^{D_{F}-3}\left(\rho_{S}-\rho_{L}\right)+\rho_{L}
$$

where $D_{F}$ is the fractal dimension (between 0 and 3), $R$ is the agglomerate size, and $r$ is the primary (crystal) particle size.

Agglomerate density decreases as an agglomerate size increases for a constant value of $\mathrm{D}_{\mathrm{F}}$. The higher solid concentration generally forms larger agglomerates, but not always (Selomnlya et al. 2002).

The value of $\mathrm{D}_{\mathrm{F}}$ is around $1.6 \sim 1.8$ when the driving force for agglomeration is very high (diffusionlimited agglomeration). The value of $\mathrm{D}_{\mathrm{F}}$ is around $1.8 \sim 2.25$ when the driving force is weak (reactionlimited agglomeration). High-packing dense agglomerate may have $D_{F} \geq 2.25$ (Wells et al. 2007). A wide range of primary particles in the Hanford waste may form agglomerates compressed by overlaying solids. Thus, the fractal dimension value may be greater than $2.25 \sim 2.5$ (Bunker et al. 2003, Wells et al. 2007). Selecting an appropriate fractal dimension value and an agglomerate size, one can estimate the density of the agglomerate with Equation 5.23. With known solid size and density, settling velocity equations presented above can determine the settling velocity of agglomerates.

Alternatively, Krone (1962) obtained the following equation by conducting a series of experiments with San Francisco Bay sediments with densities of $2,650 \mathrm{~kg} / \mathrm{m}^{3}$ and solid sizes varying from 1 to $50 \mu \mathrm{m}$. His solid settling equation, Equation 5.24, accounts for flocculation to determine the settling velocity of the resulting agglomerate as a function of the solid concentrations (see Figure 5.8).

$$
V_{S}=A C^{\frac{4}{3}}
$$


where $A$ is the empirical constant, $C$ is the solid concentration in $g / L$, and $V_{S}$ is the solid settling velocity (in $\mathrm{cm} / \mathrm{s}$ in this case).

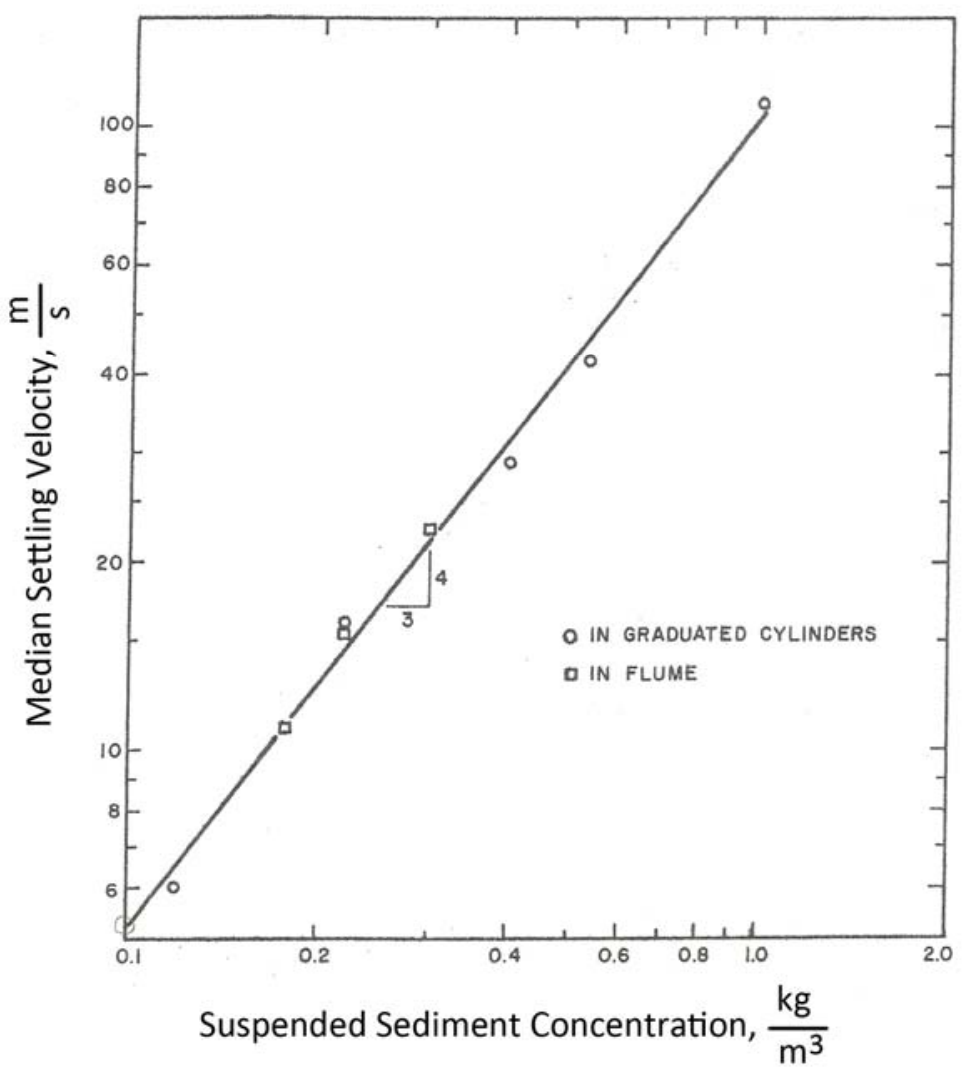

Figure 5.8. Measured Variation of Agglomerate Settling Velocity with Solid Concentrations

Hindered solid settling

When the solid concentration exceeds a certain level, say around $10 \mathrm{~g} / \mathrm{L}$, hindered settling occurs (Krone 1962,1993, Mehta and Partheniades 1973). Perry and Chilton (1973) suggest the following equation for hindered settling:

$$
V_{S}=V_{S 0}\left(1-\frac{C_{V}}{C_{V \max }}\right)^{b}
$$

where $\quad b=$ coefficient $(=4.65$ for the Stokes Law range)

$\mathrm{C}_{\mathrm{V}}=$ solid volume fraction

$\mathrm{C}_{\mathrm{Vmax}}=$ maximum solid volume fraction (the packing factor)

$\mathrm{V}_{\mathrm{s} 0}=$ settling velocity of a single particle.

Equation 5.25 is used in the computational chemical-fluid dynamic code, ARIAL, to assess waste pump jet mixing and retrieval for many DSTs (Onishi and Trent 1999, Onishi et al. 2000, 2003).

MacLean (1999) reported that a form of Equation 5.25 matched reasonably well with settling velocities of 
Hanford wastes (C-106, C-107, S-107, AZ-101/102, BY-104, BY-110, and SX-108 wastes) and simulants.

\section{Unified solid settling approach:}

To illustrate this alternative approach, Equations 5.22, 5.24, and 5.25 were applied to a 241-AZ-101 condition produced by the pump jet mixing testing. Assigning the fully mixed AZ-101 solid concentration to be $31 \mathrm{~g} / \mathrm{L}$ and the spherical particle diameter of the median-size solid $\mathrm{d}_{50}$ to be $3 \mu \mathrm{m}$, these equations yield a settling velocity of $0.029 \mathrm{~cm} / \mathrm{s}$. The AZ-101 test indicates that the majority of the solids settled to within 90 inches above the tank bottom in 6.7 hours, indicating that the solid settling velocity was approximately $0.026 \mathrm{~cm} / \mathrm{s}$. Therefore, the calculated settling velocity of $0.029 \mathrm{~cm} / \mathrm{s}$ is in a good agreement with the measured data. Note that the settling velocity of a single 3- $\mu \mathrm{m}$ particle calculated by Equation 5.22 is $0.00031 \mathrm{~cm} / \mathrm{s}$, which would take 24 days to settle to the same distance.

To illustrate the solid settling behavior, a sample application is shown here. Figure 5.9 shows the settling velocity of two solids of sludge waste by using Equations 5.22, 5.24, and 5.25. The liquid density and viscosity were assumed to be $1,200 \mathrm{~kg} / \mathrm{m}^{3}$ and $2 \mathrm{cP}$. Solid concentrations were assumed to vary from $0.01 \mathrm{~g} / \mathrm{L}(0.0004 \mathrm{vol} \%)$ to $500 \mathrm{~g} / \mathrm{L}(18 \mathrm{vol} \%)$. Two solids selected here for illustration are 6.3 and $14 \mu \mathrm{m}$ with the same solid densities of $2,800 \mathrm{~kg} / \mathrm{m}^{3}$.

As shown in Figure 5.9, the settling velocity is independent of the solid concentration under a very low solid concentration. Above around $0.3-\mathrm{g} / \mathrm{L}$, the fall velocity starts to increase significantly because agglomerate starts forming, resulting in faster solid settling up to two orders of magnitude greater. When the solid concentration becomes very high, then hindered settling occurs, slowing down the solid deposition toward the tank bottom. At $500 \mathrm{~g} / \mathrm{L}$ in this case, the hindering effect becomes large enough that the fall velocity becomes comparable to that of the individual fine particle. These changes in solid settling may need to be accounted for when one evaluates the effectiveness of the stored K-Basin sludge mobilization in the STSCs by water jets. 


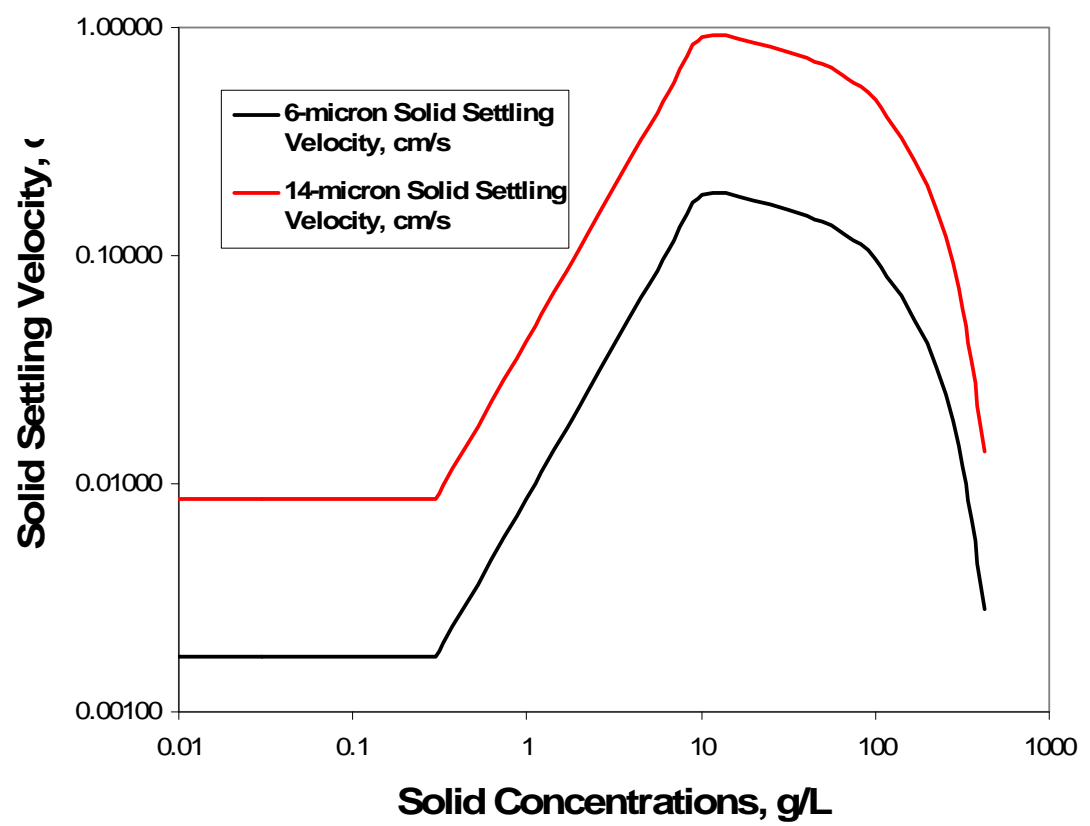

Figure 5.9. Variation of Solid Settling with Solid Concentrations

This solid settling approach provides an example of a simple but a reasonably robust approach to estimate the solid settling, covering individual particle settling, faster settling of agglomerated solids, and hindered settling in a unified way.

However, Equation 5.24 was developed with data of San Francisco mud (silt and clay), and its applicability to the K-Basin sludge is not certain. It may be useful to evaluate the validity of this approach for a potential application to the K-Basin sludge conditions. 


\subsection{Conclusions and Recommendation}

\subsection{Conclusions}

K-Basin sludge will be recovered into the STSCs and will be stored in the T Plant for a number of years while awaiting final sludge treatment/packaging. High uranium content sludge samples stored in hotcells and samples subjected to hydrothermal treatment have been observed to self-cement and form strong sludge (Delegard et al. 2005, Delegard et al. 2007, Wells et al. 2009). The shear strength of the stored K-Basin sludge may range up to $200 \mathrm{kPa}$. This heterogeneous cohesive sludge has both paste and chunks. The paste of some sludge has a shear strength of 3 5 $\mathrm{kPa}$ while chunks have an estimated shear strength of $380 \sim 770 \mathrm{kPa}$ (Wells et al. 2009). The stored K-Basin sludge in the STSC will be mobilized by water jets impinging the sludge. Based on positive experience in the retrieval of sludge simulant from engineered containers using the XAGO HydroLance ${ }^{\mathrm{TM}}$ retrieval system (CHPRC 2009), the STP is considering the XAGO retrieval system as a starting point for designing a system to retrieve sludge from the STSCs after interim storage. The current XAGO system has seven nozzles: two 1-mm, two 3-mm, and three 3.5-mm-diameter nozzles to inject high-speed water jets. It is important to determine whether water jets can mobilize and erode the stored K-Basin sludge from these engineering containers.

The objective of the evaluation was to determine the range of sludge shear strength for which there is high confidence that a water-jet retrieval system can mobilize stored K-Basin sludge from STSCs. Fourteen ECR models were reviewed. These models were all developed with simulants with shear strength of less than $10 \mathrm{kPa}$, and their jet velocities were much smaller than those expected for the stored $\mathrm{K}$-Basin sludge retrieval. The validity of these ECR models was examined by applying them to reproduce the measured ECRs produced by pump jet mixing in SY-101 and AZ-101 DSTs. The validation test identified that the Powell-3 and Crowe-2 ECR models were the most accurate among the ECR models reviewed.

These two ECR models were applied to the stored K-Basin sludge with various shear strength values, assuming that water jet nozzles with 1-, 2-, 3-, and 3.5-mm diameters were located at 1, 5, 10, 17, and 25 inches from the STSC wall. The application results with 200-kPa shear strength follow:

- When a single nozzle located 25 inches from the STSC wall, a jet injected from a 1-mm or probably a 2-mm nozzle is sufficiently strong to mobilize the stored K-Basin sludge up to 25 inches away at 42-gpm discharge. The jet discharge and pressure requirements for 1-mm nozzle would be approximately $16 \mathrm{gpm}$, but the pressure requirement is too large to be practical. Those requirements for the 2-mm nozzle would be approximately $32 \mathrm{gpm}$ and 30,000 psi. The water jet industry has high-pressure pumps that generate 40,000 to 94,000 psi to produce very high velocity. When a single $3-\mathrm{mm}$ or $3.5-\mathrm{mm}$ nozzle is located at 25 inches from the wall, the required jet discharge and pressure for 3-mm nozzles are approximately $48 \mathrm{gpm}$ and 13,000 psi, respectively, to mobilize all sludge up to 25 inches away. Those for a 3.5-mm nozzle are $55 \mathrm{gpm}$ and 9,400 psi.

- If any of these single nozzles are located within 17 inches from the STSC tank wall, stored K-Basin sludge would be eroded to the tank wall at $42 \mathrm{gpm}$. The required jet discharges to mobilize the 200-kPa sludge up to 17 inches away from the nozzles are 11, 22, 32, and 38 gpm for 1-, 2-, 3- and 3.5-mm nozzles, respectively. Pressure requirements for 1-, 2-, 3-, and 3.5-mm nozzles to erode 
200-kPa sludge would be approximately 57,000, 14,000 5,900, and 4,500 psi, respectively. Thus, high-pressure pumps of the water jet industry can provide the required pressure, as stated above.

- If these single nozzles are located 10 inches away from the STSC wall, the required jet discharges for these four nozzles are $6,13,19$, and $22 \mathrm{gpm}$ to erode the sludge up to the tank wall. The required pressure would be approximately $19,000,4,900,2,100$, and 1,500 psi, respectively. The jet velocity and pressure requirements would be further reduced if these nozzles need to erode a shorter distance than 10 inches. This could be achieved if the nozzles can move forward (toward the unmoved portion of the sludge) as they erode the sludge.

- A moving nozzle is known to be more effective in mobilizing the sludge because an impulsive water jet may need about $1 / 3$ or less energy required to break the material than a steady jet.

- For the nozzles located 5 inches from the STSC wall, 1-, 2-, 3-, and 3.5-mm nozzles would need 3.2-, 6.4-, 9.4-, and 11-gpm jet discharges to mobilize the stored K-Basin sludge with 200-kPa shear strength, respectively. The corresponding minimum required pressures are 4,800, 1,200, 510, and 380 psi, respectively.

- For the nozzles located 1 inch from the STSC wall, 1-, 2-, 3-, and 3.5-mm nozzles would need 0.65-, 1.3-, 1.9-, and 2.2-gpm jet discharges to mobilize the stored K-Basin sludge with 200-kPa shear strength, respectively. The corresponding minimum required pressures are 200, 49, 21, and 15 psi, respectively.

- When all seven nozzles of the XAGO system are placed between 5 and 25 inches away from the wall and are used at $42 \mathrm{gpm}$, it is unlikely that these jets would mobilize all of the sludge in the STSCs at 377-psi pressure.

- When these seven nozzles are located at 1 inch from the STSC wall, they would erode the sludge up to the wall at $42 \mathrm{gpm}$. Wall erosion may become an issue if jets continue to hit the same STSC wall location for 2 hours or more.

With the Powell-3 ECR model, parametric studies were also conducted by varying the shear strength of the stored K-Basin sludge, jet nozzle diameters, jet discharge, and the required ECR to erode the sludge up to the STSC tank wall.

The water jets to mobilize the stored K-Basin sludge should not erode more than $10 \%$ of the STSC tank wall. The tank wall erosion amount was estimated with the Papp wall erosion model for 1-, 3-, and 3.5-mm nozzles located at 1, 5, 17, and 25 inches from the STSC wall for 10, 20, 30, and 40-vol\% solids concentrations of the jets and distances between the nozzle and the tank wall. The tank wall erosion rate up to 100 hours was estimated for the 1-, 3-, and 3.5-mm nozzles for four solid concentrations $(10,20,30$, and $40 \mathrm{vol} \%$ ) of the jets. The wall erosion must be evaluated for a water jet retrieval system to confirm that the jet would not erode more than $10 \%$ of the STSC wall thickness. For example, the XAGO system located at 1 inch from the wall may erode the STSC wall at $42 \mathrm{gpm}$ if these jets hit a same spot of the wall for more than two hours. The Papp wall erosion model was derived from experiments with the 1.049-in.diameter nozzle with 12 and $14 \mathrm{~m} / \mathrm{s}$ jet velocities placed at 1.574 inch from a steel surface. These test conditions are not similar to those expected for K-Basin condition. The applicability to the K-Basin conditions and its accuracy are not certain.

These parametric study results with the Powell-3 ECR and the Papp wall erosion models would assist in developing the suitable water jet retrieval system to mobilize the stored K-Basin sludge. A main 
uncertainty of the use of these models for the stored K-Basin sludge analysis is that these models were developed with experiments with much weaker sludge, slower jet velocity, and larger nozzle diameters than those expected for the stored K-Basin sludge.

\subsection{Recommended Exploratory Studies}

As discussed in Section 5, we recommend the following exploratory evaluations as the follow-up for this shear strength threshold of concern evaluation under two phases;

- Small- and large-scale water jet testing to answer the question of

- whether a specific water jet can erode the stored K-Basin sludge

- whether the shear strength of the bulk sludge or the shear strength of the weaker component of the sludge is the controlling sludge property for mobilization

- determining the erosion rate and time that will be required to retrieve a specific amount of sludge by determining the erosion rate, erodibility coefficient, and erosion time

- whether the candidate water jet systems would not erode more than $10 \%$ of the STSC wall thickness.

To answer the first two questions, conduct Phase 1 evaluation in two stages

- Phase 1, Stage 1: Small-scale water jet testing

Use high-strength homogeneous simulants developed by PNNL to evaluate the shear strength range of $3 \mathrm{kPa}$ up to $200 \mathrm{kPa}$.

Use high-strength heterogeneous simulants being developed by PNNL to conduct several sets of heterogeneous simulant testing with 1) weaker weak paste and very hard chunks and 2) stronger weak paste and very hard chunks.

Use a stainless steel simulant container with a simulant and/or a stainless steel plate to confirm that water jets would not erode the steel wall for some selected cases.

- Phase 1, Stage 2: Large-scale water jet testing to repeat selected sets of the small-scale testing conditions with 3- and/or 4- mm nozzles with expected ECR of 10 inches are less. Under these test conditions, the required pressure would be less than 5,000 psi.

Use PNNL homogeneous simulants selected by the small-scale water jet testing.

Use PNNL heterogeneous simulants selected by the small-scale water jet testing.

Water jet testing to estimate the erosion rate and the time needed to erode the required amount of stored K-Basin sludge in the STSCs.

- Phase 2, Stage 1: Small-scale water jet testing

Obtain the critical shear stress for erosion and the erodibility coefficient with high-strength homogeneous and heterogeneous simulants being developed by PNNL under separate tasks of the K-Basin Project. Use the high pressure as required to conduct these tests.

Validate or modify Equations 5.3, 5.6, and 5.12 to estimate the critical shear stress for erosion and the erodibility coefficient of the multi-component stored K-Basin sludge with the known 
unconfined compressive strength and the plasticity index without conducting water jet testing in the future.

- Phase 2, Stage 2: Large-scale water jet testing to repeat selected sets of the small-scale testing conditions with 3-and/or 4- mm nozzles with expected ECR of 10 inches are less. Under these test conditions, the required pressure would be less than 5,000 psi.

- Evaluate the feasibility of estimating the solid settling velocity under the three settling modes of individual solid settling, agglomeration settling, and hindered settling by using the unified solid settling velocity approach (Equations 5.22, 5.24, and 5.25) for the K-Basin sludge.

- Conduct computer simulations of water jet erosion and mixing of the stored K-Basin sludge in the STSCs with a suitable computational fluid dynamics code (e.g., the ARIEL code) to answer the following questions to develop a sludge retrieval operational envelopes:

- Which solids and where would they be eroded and kept suspended?

- How uniform is the suspended solid concentration distributions in the STSC?

- What are the achievable suspended solid concentrations?

- Which suspended solids would be deposited and how fast and where?

- Which solids and which parts of the STSC would not be mobilized?

- What is the degree of successful/acceptable sludge retrieval operation? 


\subsection{References}

ASTM International. 2000. "Standard Test Methods for Liquid Limit, Plastic Limit, and Plasticity index of Solids.” Designation: D 4318-00.

Bathija P. 1982. “Jet Mixing Design and Applications.” Chemical Engineering 89:89-94.

Beltaos S and N Rajcratnam. 1974. "Impinging Circular Turbulent Jets.” Journal of Hydraulics Division, the American Society of Civil Engineers 100(HY10):1313-1329.

Bredt PR, CH Delegard, AJ Schmidt, and KL Silvers. 1999. "Testing and Analysis of Consolidated Sludge from the 105 K East Basin Floor and Canisters.” PNNL-13341, Pacific Northwest National Laboratory, Richland, Washington.

Bunker EC, BW Arey, SK Fiskum, JGH Geeting, ED Jensen, BK McNamara, and AP Peloski. 2003. Identification of Washed Solids from Hanford Tanks 241-AN-102 and 241-AZ-101 with X-ray Diffraction Scanning Electron Microscopy, and Light-Scattering Particle Analysis." PNWD-3300, WTP-RPP-076, Rev. 0, Battelle_-Pacific Northwest Division, Richland Washington.

Carlson AB, JR Bellomy, III, KG Carothers, JM Conner, BK Everrett, JD Guberski, EI Husa, DJ McCain, GW Reddick, Jr., GR Tardiff, AM Templeton, MS Tiffany, SM Merry, PJ Fuller, RE Mendoza, MM Jennings, DM Stenkamp, and DG Douglas. 2000. Preliminary Test Report, 241-AZ-101 Mixer Pump Test. RPP-6548, Rev. 0, CH2MHill Hanford Group, Inc., Richland, Washington.

Carlson AB, PJ Certa, TM Hohl, JR Bellomy, III, TW Crawford, DC Hedengren, AM Templeton, HS Fisher, SJ Greelhood, DG Douglas, and WJ Ulbricht. 2001. Test Report, 241-AZ-101 Mixer Pump test. 5548, Rev. 1, CH2MHill Hanford Group, Inc., Richland, Washington.

CHPRC - CH2M Hill Plateau Remediation Company. 2009. Test Report for Sludge Treatment ProjectEngineered Container Retrieval Campaign Test (XAGO Follow-on. A21C-STP-TR-0012, Revision 0, Richland, Washington.

CHPRC - CH2M Hill Plateau Remediation Company. 2010. Sludge Treatment Project: Concept Design Document. SK-4K-M-011, Rev. C., STSC Test Vessel Assembly Sketch, CH2M Hill Plateau Remediation Company, Richland, Washington.

Clark LA and TM Wynn. 2007. "Methods for Determining Streambank Critical Shear Stress and Soil Erodibility: Implications for Erosion Rate Predictions." Transactions of the American Society of Civil Engineers 50(1):95-106.

Delegard CH, AP Poloski, AJ Schmidt, JW Chenault. 2005. Characterization of Compaction and Dryout Properties of KE Basin Sludge During Long-Term Storage. PNNL-15092, Pacific Northwest National Laboratory, Richland, Washington. 
Delegard CH, AJ Schmidt, and BM Thornton. 2007. Hydrothermal Testing of K Basin Sludge and N Reactor Fuel at Sludge Treatment Project Operating Conditions. PNNL-16496, Pacific Northwest National Laboratory, Richland, Washington.

Dunn IS. 1959. "Tractive Resistance of Cohesive Channels." Journal of Soil Mechanics and Foundations Division, the American Society of Civil Engineers 85(SM3):1-24.

Enderlin CW. 2007. Status of Experimental Results Obtained to Assess Wear on tank S-102 Floor due to Water Jet Flow from Operation of the Viper Ultra-High-Pressure Mixer at Nozzle Elevations Below 12 Inches. PNNL-SA-54104 (070226-PNNL to CH2MHill LetRpt01), Pacific Northwest National Laboratory, Richland, Washington.

Fiskum SK, JM Billing, SJ Bos, CA Burns, CD Carlson, DS Coffey, JV Crum, RC Daniel, CH Delegard, MK Edwards, OT Farmer, LR Greenwood, SA Jones, D Neiner, BM Oliver, KN Pool, AJ Schmidt, RW Shimskey, CZ Soderquist, ML Thomas, CJ Thompson, T Trang-Le, and MW Urie. 2009. Characterization Data Package for Containerized Sludge Samples Collected from Engineered Containers SCS-CON-240, 250, 260, and 220. PNNL-19035, Rev. 0, Pacific Northwest National Laboratory, Richland, Washington.

Garcia MH (Editor). 2008. Sedimentation Engineering: Processes, Measurements, Modeling, and Practice. Manuals and Reports on Engineering Practice, American Society of Civil Engineering, New York, New York.

Gauglitz PA and G Terroners. 2002. Estimated Maximum Gas Retention from Uniformly Dispersed Bubbles in K Basin Sludge Stored in large-Diameter Containers. PNNL-13893, Pacific Northwest National Laboratory, Richland, Washington.

Gauglitz PA, BE Wells, JA Fort, and PA Meyer. 2009. An Approach to Understanding Cohesive Slurry Settling, Mobilization, and Hydrogen Gas Retention in Pulsed Jet Mixed Vessels. PNNL-17707, WTPRPT-177, Pacific Northwest National Laboratory, Richland, Washington.

Gauglitz PA, BE Wells, JA Fort, BE Wells, J Chun, JA Bamberger, and J Jenks. 2010. The Role of Cohesive Particle Interactions on Solids Uniformity and Mobilization During Jet Mixing: Testing Recommendations. PNNL-19245, Pacific Northwest National Laboratory, Richland, Washington.

Hamm BA, WL West, and GB Tatterson. 1989. "Sludge Suspension in Waste Storage Tanks." AIChE Journal 35(8):1391-1394.

Hanson GJ. 2001. "Field and laboratory Jet testing Method for Determining Cohesive Material Erodibility." In: Proceedings of the Seventh Federal Interagency Sedimentation Conference, March 2529, 2001, Reno, Nevada, V-1 V-8.

Hanson GJ and KM Robinson. 1993. "The Influence of Soil Moisture and Compaction of Spillway Erosion." Transaction of the American Society of Civil Engineers 36(5):1349-1352. 
Hanson GJ and A Simon. 2001. "Erodibility of Cohesive Streambeds in the Loess Area of the Midwestern USA." Hydrological Processes 15:23-38.

Hill SR. 2010. Consolidation of K Basin Sludge Data and Experiences on Agglomerate Formation. PRC-STP-00274, Rev. 1, CH2M HILL Plateau Remediation Company, Richland, Washington.

Hollick M. 1976. "Toward a Routine Test for the Assessment of the Critical Tractic Forces of Cohesive Solis.” In: Transactions of the American Society of Civil Engineers, pp. 1076-1081.

Honeyman JO and RJ Rourk. 2009. "Sludge Treatment Project - Project Execution Plan." KBC-30811, Rev 3 (PRC-EDC-09-43288, Rev 3), CH2MHILL Plateau Remediation Company, Richland, Washington.

Hylton TD, RL Cummins, EL Youngblood, and JJ Perona. 1995. Sludge Mobilization with Submerged Nozzles in Horizontal Cylindrical Tanks. ORNL/TM-130346, Oak Ridge National Laboratory, Oak Ridge, Tennessee.

Johnson ME 2010. "Screening Evaluation of Characterization Data for Engineered Container SCSCON-220, -240, -250, and -260.” PRC-STP-00212, Rev 0, CH2MHILL Plateau Remediation Company, Richland, Washington.

Johnson ME and TK Dhaliwal. 2009. Preliminary STP Container and Settler Sludge Process System Description and Material Balance. HNF-41051, Rev. 5, CH2MHILL Plateau Remediation Company, Richland, Washington.

Kothyan UC and RK Jain. 2008. "Influence of Cohesion on the Incipient Motion Condition of Sediment." Water Resources Research 44:W04410.

Krementz D and WL Daugherty. 2007. Testing of TMR Sand Mantis Final Report. WSRC-ST1-200700189, Savannah River National laboratory, Aiken, South Carolina.

Krone RB. 1962. Flume Studies of the Transport of Sediment in Estuarine Shoaling Processes. Hydraulic Engineering Laboratory and Sanitary Engineering Research Laboratory, University of California, Berkeley, California.

Krone RB. 1993. "Sediment Revisited." Nearshore and Estuarine Cohesive Sediment Transport, A.J. Merta, editor, Coastal Estuarine Studies, No. 42, American Geophysical Union, pp. 108-125.

MacLean GT. 1999. The settling and Compaction of Nuclear Waste Studies. HNF-5177, Rev. 0, Fluor Daniel Northwest, Richland, Washington.

Mazurek KA, N Rajaratnam and DC Sego. 2001. "Score of Cohesive Soil by Submerged Circular Turbulent Impinging jets.” Journal of Hydraulic Engineering, ASCE, pp. 598-606.

Mazurek KA and T Hossain. 2009. "Scour of jets in Cohesionless and Cohesive Solids." Canadian Journal of Chemical Engineering 34:744-751. 
Mehta AJ and E Partheniades. 1973. Depositional Behavior of Cohesive Sediments. PB-218-854, Technical Report No. 16, Florida University, Gainesville, Florida.

Meyer PA, JA Bamberger, CW Enderlin, JA Fort, BE Wells, SK Sundaram, PA Scott, MJ Minette, GL Smith, CA Burns, MS Greenwood, GP Morgen, EBK Baer, SF Snyder, M White, GF Piepel, BG Amidan, and A Heredia-Langner. 2009. Pulse Jet Mixing Tests with Noncohesive Solids. PNNL-18098, WTPRPT-182, Rev. 0, Pacific Northwest National Laboratory, Richland Washington.

Moore WL and FD Masch, Jr. 1962. "Experiments on the Score Resistance of Cohesive Sediments." Journal of Geophysical Research 67(4):1437-1446.

Onishi Y. 1981. "Sediment-Contaminant Transport Model." Journal of Hydraulics Division, American Society of Civil Engineers 107(HY9):1089-1107.

Onishi Y, HC Graber, and DS Trent. 1993. "Preliminary Modeling of Wave-Enhanced Sediment and Contaminant Transport in the New Bedford Harbor." In: Book Series 42 of Estuarine and Coastal Water Cohesive Sediment Transport, pp. 541-557, AJ Mehta ed., American Geophysical Union.

Onishi Y. 1994. "Sediment Transport Models and Their Testing." Chapter 10, in: Computer Modeling of Free Surface and Pressurized Flows, pp. 281-312, MH Chaudrey and LW Mays eds., NATO ASI Series E, Applied Sciences- Vol. 274, Klumer Academic Publisher, Dordrecht, The Netherlands.

Onishi Y and KP Recknagle. 1997. Tank 241-AZ-101 Criticality Assessment Resulting from Pump Jet Mixing Sludge Mixing Simulations. PNNL-11486, Pacific Northwest National Laboratory, Richland, Washington.

Onishi Y, DS Trent, TE Michener, JE Van Beek, and CA Rieck. 1999. "Simulation of Radioactive Tank Waste Mixing with Chemical Reaction." FEDSM99-7786: Proceedings of 3rd ASME/JSME Joint Fluids Engineering Conference, San Francisco, California, July 18-23, 1999.

Onishi Y and DS Trent. 1999b. "Mobilization Modeling of Erosion-Resisting Radioactive Tank Waste." In: The Proceedings of the Rheology in the Mineral Industry II, Kahuku, Oahu, Hawaii, March 14-19, 1999, organized by United Engineering Foundation, New York, New York, pp. 45-56.

Onishi Y, KP Recknagle, and BE Wells. 2000. Pump Jet Mixing and Pipeline Transfer Assessment for High-Activity Radioactive Wastes in Hanford Tank 241-AZ-102. PNNL-13275, Pacific Northwest National Laboratory, Richland, Washington.

Onishi Y, ST Yokuda, and CH Majumder. 2002. Optimal Elevation and Configuration of Hanford's Double-Shell Tank Waste Mixer Pumps. PNNL-13913, Pacific Northwest National Laboratory, Richland, Washington.

Onishi Y, DS Trent, and ST Yokuda. 2003. “Optimal Pump Elevation and Configuration for Mixing Erosion-Resisting Radioactive Tank Waste." In: Proceedings of FEDSM'03, $4^{\text {th }}$ ASME/JSME Joint Fluids Engineering Conference, Honolulu, Hawaii, USA, July 6-11, 2003, FEDSM2003-45502. 
Onishi Y, SL Kivva, MJ Zheleznyak, and OV Voitsekhovich. 2007. "Aquatic Assessment of the Chernobyl Nuclear Accident and Its Remediation." Journal of Environmental Engineering, American Society of Civil Engineers, 133(11):1015-1023.

Papp IG. 2008. EFRT Issue M2 Closure Report. 24590-WTP-RPT-PET-08-008, Rev 0. DOE Contract DE-AC27-01RV14136.

Papp IG and GM Duncan. 2009. "Investigation of Erosion from High-Level Waste Slurries at the Hanford Waste Treatment and Immobilization Plant.” December 2009 Bechtel Technology Journal, Vol. 2, No. 1, Bechtel Corporation.

Partheniades E. 1962. "A Study of Erosion and Deposition of Cohesive Solids in Salt Water." Ph.D. Thesis, Civil Engineering Department, University of California, Berkeley, California.

Partheniades E. 1993. "Turbulence, Flocculation, and Cohesive Sediment Dynamics." In: Nearshore and Estuarine Cohesive Sediment Transport, AJ Merta, editor, Coastal Estuarine Studies, No. 42, American Geophysical Union, pp. 40-59.

Plys MG, and AJ Schmidt. 2009. Supporting Basis for Spent Nuclear Fuel Project Sludge Technical Databook. SNF-7765, Rev. 3D, CH2M Hill Plateau Remediation Company.

Poloski AP, PR Bredt, AJ Schmidt, RG Swoboda, JW Chenault, and SR Gano. 2002. Thermal Conductivity and Shear Strength of K Basin Sludge. PNNL-13911, Pacific Northwest National Laboratory, Richland, Washington.

Peloski AP, JM Tingey, BE Wells, LA Mahoney, MH Hall, GL Smith, SL Thomson, ME Johnson, MA Knight, JE Meacham, MJ Thien, JJ Davis, and Y Onishi. 2007. Estimate of Hanford Waste Rheology and Settling Behavior. PNNL-16857, WTP-RPT-154, Rev. 0, Pacific Northwest National Laboratory, Richland, Washington.

Perry RH and CH Chilton. 1973. Perry’s Chemical Engineering Handbook. McGraw Hill, New York, New York.

Poirier MR. 2004. Mixing in SRS Closure Business Unit Applications. WSRC-TR-2004-00153, Savannah River Laboratory, Aiken, South Carolina.

Powell MP, GR Golcar, CR Hymas, and RL McKay. 1995a. Fiscal 1993 1/25-Scale Sludge Mobilization Testing. PNL-10464, Pacific Northwest National Laboratory, Richland, Washington.

Powell MP, CM Gates, CR Hymas, MA Sprecher, and NJ Morter. 1995b. Fiscal 1994 1/25-Scale Sludge Mobilization Testing. PNL-10582, Pacific Northwest National Laboratory, Richland, Washington.

Powell MP, Y Onishi, and R Shekarris. 1997. Research on Jet Mixing of Settled Sludges in Nuclear Waste Tanks at Hanford and Other DOE Sites: A Historical Perspective. PNNL-11686, Pacific Northwest National Laboratory, Richland, Washington. 
Rector DR and BC Bunker. 1995. Effects of Colloidal Aggregation on the Sedimentation and Rheological Properties of Tank Waste. PNL-10761, Pacific Northwest National Laboratory, Richland, Washington.

Reshman R, M Daas, R Srivastava, and B Tansel. 2007. "Resuspension of Non-Newtonian Slurries by Submerged Jet-Nozzles.” Science Direct, Experimental Thermal and Fluid Science 31:771-778.

Schmidt AJ. 2010. "Spent Nuclear Fuel Project Technical Databook, Vol. 2, Sludge." HNF-SD-SNFTI-015, Rev 14B, Volume 2, Fluor Hanford, Richland, Washington.

Selomnlya C, G Bushell, R Amal, and TD Waste. 2002. "Agglomeration Mechanisms of Latex of Different Particle Sizes in a Controlled Shear Environment.” Langmuir 18:1974-1984.

Simons DB and F Senturk. 1977. Sediment Transport Technology. Water Resources Publications, Fort Collins, Colorado.

Summers DA. 1995. Waterjetting Technology. E\&FN SPON, London, United Kingdom.

Tedeschi AR. 2000. Derived Requirements for Double-shell Tank High-Level Waste Auxiliary Solids mobilization. RPP-5664, CH2M Hill Hanford Group, Inc., Richland, Washington.

Teeter AM. 1988. New Bedford Harbor Project—Acushnet River Estuary Engineering Feasibility Study of Dredging Material Disposal Alternatives-Report 2, Sediment and Contaminant Hydraulic Transport Investigations. U.S. Army Corps of Engineers, Waterway Experiment Station, Vicksburg, Mississippi.

Terrones G and PA Gauglitz. 2002. Vessel-Spanning Bubble Formation in K-Basin Sludge Stored in Large-Diameter Containers. PNNL-13805, Pacific Northwest National Laboratory, Richland, Washington.

Tolhurst TJ, KS Black, SA Shayler, S Mather, I Black, K Baker, and DM Paterson. 1999. "Measuring the in situ Erosion Shear Stress of Intertidal Sediments with the Cohesive Strength Meter (CSM)." Estuarine, Coastal and Shelf Science 49:281-294.

Vanoni AA (editor). 1975. "Sedimentation Engineering." The ASCE Task Committee for the Preparation of the Manual on Sedimentation of the Sedimentation Committee of the Hydraulic Division, the American Society of Civil Engineers, New York, New York.

Wasp EJ, JP Kenny, and RL Gandhi. 1977. Solid-Liquid Flow: Slurry Pipeline Transportation, Vol. 1, No. 4, Series on Bulk Materials Handling, Trans Tech Publications, Glausthal, Germany.

Westcott JL, BJ Makenas, TL Welsh, JA Pottmeyer, and AJ Schmidt. 2009. Data Quality Objectives for Sampling and Analysis of K Basin Sludge. HNF-36985, Rev. 3, CH2M Hill Plateau Remediation, Company, Richland, Washington.

Weigel RL. 1964. Oceanographical Engineering. Prentice-Hall, Inc., Englewood Cliff, New Jersey. 
Wells BE, MA Knight, EC Buck, SK Cooley, RC Daniel, LA Mahoney, PA Meyer, AP Poloski, JM Tingey, WS Callaway III, GA Cooke, ME Johnson, MG Thien, DJ Washenfender, JJ Davis, MN Hall, GL Smith, SL Thomson, and Y Onishi. 2007. Estimate of Hanford Waste Insoluble Solid Particle Size and Density Distribution. PNWD-3824, WTP-RPT-153, Battelle-Pacific Northwest Division, Richland, Washington.

Wells BE, CW Enderlin, PA Gauglitz, and RA Peterson. 2009. Assessment of Jet Erosion for Potential Post-Retrieval K-Basin Settled Sludge. PNNL-18831, Pacific Northwest National Laboratory, Richland, Washington. 

PNNL-19946

53451-RPT12

\section{Distribution}

No. of

\section{Copies}

1 U.S. Department of Energy/Richland Operations

6 CH2M Hill Plateau Remediation Company

R. B. Baker

D.W. Hamilton

J.O. Honeyman

M.E. Johnson

R.E. Raymond

J.P. Sloughter
A3-06

A3-06

A3-06

A $0-26$

A $0-26$

A3-06
No. of

Copies

23 Pacific Northwest National Laboratory

E.B. Baer

P7-15

C.A. Burns

$\mathrm{P} 7-25$

C.D. Carlson

P7-25

J. Chun

K6-24

R.C. Daniel

$\mathrm{P} 7-25$

C.H. Delegard (electronic)

$\mathrm{P} 7-25$

C.W. Enderlin

K7-15

P.A. Gauglitz

K7-15

D.E. Kurath

$\mathrm{K} 7-15$

T.E. Michener

$\mathrm{K} 7-15$

K7-15

Y. Onishi (10)

K6-24

P8-60

A.J. Schmidt

K7-15

B.E. Wells

S.T. Yokuda

K7-15

Information Release (pdf)

Distr. 1 


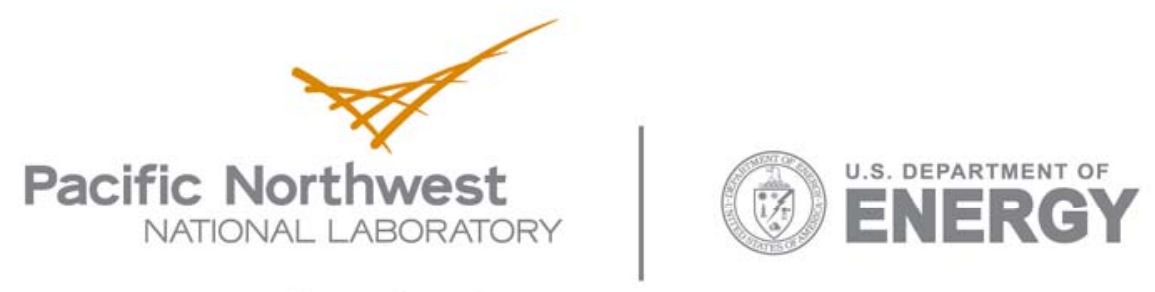

902 Battelle Boulevard

P.O. Box 999

Richland, WA 99352

1-888-375-PNNL (7665)

www.pnl.gov 